\title{
2011 ACCF/AHA guideline for the diagnosis and treatment of hypertrophic cardiomyopathy: Executive summary
}

A report of the American College of Cardiology Foundation/American Heart Association Task Force on Practice Guidelines

Developed in Collaboration With the American Association for Thoracic Surgery, American Society of Echocardiography, American Society of Nuclear Cardiology, Heart Failure Society of America, Heart Rhythm Society, Society for Cardiovascular Angiography and Interventions, and Society of Thoracic Surgeons

Writing Bernard J. Gersh, MB, ChB, DPhil, FACC, FAHA, Co-Chair ${ }^{*}{ }^{\dagger}$ Barry J. Maron, MD, FACC, Committee Co-Chair, ${ }^{*}, \dagger$ Robert O. Bonow, MD, MACC, FAHA, ${ }^{\ddagger}$ Joseph A. Dearani, MD, FACC, ${ }^{\S, \|}$

Members:* Michael A. Fifer, MD, FACC, FAHA, ${ }^{*}, \dagger$ Mark S. Link, MD, FACC, FHRS, $*, \boldsymbol{q}^{\dagger}$

Srihari S. Naidu, MD, FACC, FSCAI, ${ }^{*},{ }^{*}$ Rick A. Nishimura, MD, FACC, FAHA, ${ }^{\dagger}$

Steve R. Ommen, MD, FACC, FAHA, ${ }^{\dagger}$ Harry Rakowski, MD, FACC, FASE ${ }^{\dagger, *, *}$

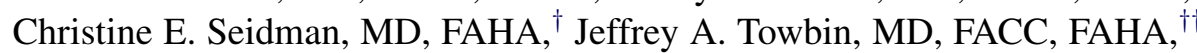

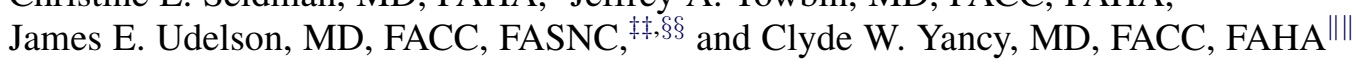

ACCF/AHA Alice K. Jacobs, MD, FACC, FAHA, Chair, 2009-2011, Sidney C. Smith, Jr, MD, FACC, FAHA, Task Force Immediate Past Chair, 2006-2008, " Jeffrey L. Anderson, MD, FACC, FAHA, Chair-Elect,

Members: $\quad$ Nancy M. Albert, PhD, CCNS, CCRN, FAHA, Christopher E. Buller, MD, FACC, ๆ

Mark A. Creager, MD, FACC, FAHA, Steven M. Ettinger, MD, FACC, Robert A. Guyton, MD, FACC, Jonathan L. Halperin, MD, FACC, FAHA, Judith S. Hochman, MD, FACC, FAHA, Harlan M. Krumholz, MD, FACC, FAHA, ${ }^{\text {ฯथ }}$ Frederick G. Kushner, MD, FACC, FAHA, Rick A. Nishimura, MD, FACC, FAHA, ${ }^{\uparrow \uparrow}$ E. Magnus Ohman, MD, FACC, Richard L. Page, MD, FACC, FAHA, "ब William G. Stevenson, MD, FACC, FAHA, Lynn G. Tarkington, RN, ${ }^{\text {ฯा }}$ and Clyde W. Yancy, MD, FACC, FAHA

\section{Supplemental material is available online.}

\footnotetext{
"Writing committee members are required to recuse themselves from voting on sections to which their specific relationships with industry and other entities may apply; see Appendix 1 for detailed information. ${ }^{\dagger} \mathrm{ACCF} / \mathrm{AHA}$ Representative. ${ }^{\ddagger}$ ACCF/AHA Task Force on Performance Measures Liaison. ${ }^{\circledR}$ Society of Thoracic Surgeons Representative. "American Association for Thoracic Surgery Representative. "Heart Rhythm Society Representative. "Society for Cardiovascular Angiography and Interventions Representative. ${ }^{* *}$ American Society of Echocardiography Representative. ${ }^{\dagger \dagger}$ Pediatric Content Expert. ${ }^{\ddagger \dagger}$ Heart Failure Society of America Representative. ${ }^{\S \S}$ American Society of Nuclear Cardiology Representative. ${ }^{\|\|}$ACCF/AHA Task Force on Practice Guidelines Liaison. ${ }^{\mathbb{\top}}$ Former Task Force member during this writing effort.

This document was approved by the American College of Cardiology Foundation Board of Trustees and the American Heart Association Science Advisory and Coordinating Committee in April 2011. The American Association for Thoracic Surgery, American Society of Echocardiography, American Society of Nuclear Cardiology, Heart Failure Society of America, Heart Rhythm Society, Society for Cardiovascular Angiography and Interventions, and Society of Thoracic Surgeons approved the document in June 2011.

The American Association for Thoracic Surgery requests that this document be cited as follows: Gersh BJ, Maron BJ, Bonow RO, Dearani JA, Fifer MA, Link MS, Naidu SS, Nishimura RA, Ommen SR, Rakowski H, Seidman CE, Towbin JA,
}

Udelson JE, Yancy CW. 2011 ACCF/AHA guideline for the diagnosis and treatment of hypertrophic cardiomyopathy: executive summary: a report of the American College of Cardiology Foundation/American Heart Association Task Force on Practice Guidelines. J Thorac Cardiovasc Surg. 2011;142:1303-38.

This article is copublished in the Journal of the American College of Cardiology and Circulation

Copies: This document is available on the World Wide Web sites of the American College of Cardiology (www.cardiosource.org) and the American Heart Association (my.americanheart.org). For copies of this document, please contact Elsevier Inc. Reprint Department, fax (212) 633-3820; E-mail, reprints@elsevier.com.

Expert peer review of AHA Scientific Statements is conducted at the AHA National Center. For more on AHA statements and guidelines development, visit http://my americanheart.org/statements and select the "Policies and Development" link.

Permissions: Multiple copies, modification, alteration, enhancement, and/or distribution of this document are not permitted without the express permission of The American Association for Thoracic Surgery. Please contact Elsevier's permission department at healthpermissions@elsevier.com. $0022-5223 / \$ 36.00$

Copyright (C) 2011 by The American Association for Thoracic Surgery doi:10.1016/j.jtcvs.2011.10.019 


\section{TABLE OF CONTENTS}

Preamble . . . . . . . . . . . . . . . . . . . . . . . . . . . . . . 1304

1. Introduction . . . . . . . . . . . . . . . . . . . . 1307

1.1. Methodology and Evidence Review . . . . . . . . 1307

1.2. Organization of the Writing Committee. . . . . . . . 1307

1.3. Document Review and Approval . . . . . . . . . . . 1307

1.4. Scope of the Guideline . . . . . . . . . . . . . . . 1307

2. Recommendations for HCM. . . . . . . . . . . . . 1308

2.1. Genetic Testing Strategies/Family Screening-

Recommendations. . . . . . . . . . . . . . . . . . . 1308

2.1.1. Genotype-Positive/Phenotype-Negative

Patients-Recommendation . . . . . . . . 1308

2.2. Electrocardiography-Recommendations . . . . . . 1308

2.3. Echocardiography-Recommendations . . . . . . 1308

2.4. Stress Testing-Recommendations . . . . . . . . 1309

2.5. Cardiac Magnetic Resonance-Recommendations . 1309

2.6. Detection of Concomitant Coronary Disease-

Recommendations. . . . . . . . . . . . . . . . . . . 1309

2.7. Asymptomatic Patients-Recommendations. . . . . . 1309

2.8. Pharmacologic Management-Recommendations . . 1310

2.9. Invasive Therapies-Recommendations . . . . . . 1310

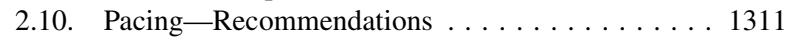

2.11. Patients With LV Systolic Dysfunction-

Recommendations. . . . . . . . . . . . . . 1311

2.12. Selection of Patients for Heart Transplantation-

Recommendations. . . . . . . . . . . 1311

2.13. SCD Risk Stratification-Recommendations . . . . 1311

2.14. Selection of Patients for ICDs-

Recommendations. . . . . . . . . . . . 1312

2.15. Selection of ICD Device Type-

Recommendations. . . . . . . . . . . . . 1313

2.16. Participation in Competitive or Recreational Sports and Physical Activity-Recommendations . . . . 1313

2.17. Management of AF-Recommendations . . . . . . 1313

2.18. Pregnancy/Delivery-Recommendations . . . . . 1314

3. Prevalence/Nomenclature/Differential Diagnosis . . . . 1314

3.1. Prevalence . . . . . . . . . . . . . . . . . . . 1314

3.1.1. Clinical Definition and Differential

Diagnosis . . . . . . . . . . . . . 1314

3.1.2. Impact of Genetics . . . . . . . . . . . . . . . . . . . . . . . . . . . . . . .

3.1.3. HCM Centers. . . . . . . . . . . . . 1315

4. Clinical Course and Natural History, Including

Absence of Complications . . . . . . . . . . . . . . . 1315

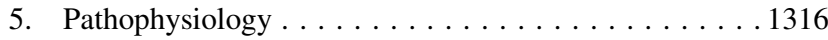

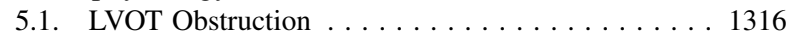

6. Diagnosis. . . . . . . . . . . . . . . . . 1316

6.1. Cardiovascular Magnetic Resonance . . . . . . . . 1317

7. Concomitant Coronary Disease. . . . . . . . . . . 1318

8. Choice of Imaging Modality . . . . . . . . . . . . 1318

8.1. Invasive Coronary Arteriography . . . . . . . . . 1318

8.2. Noninvasive CTA . . . . . . . . . . . . . . . . . . 1318

8.3. Single Photon Emission Computed Tomography

Myocardial Perfusion Imaging . . . . . . . . . . 1318

8.4. Positron Emission Tomography . . . . . . . . . . 1318

8.5. Stress Echocardiography . . . . . . . . . . . . . . . . . . . 1318

9. Management of HCM . . . . . . . . . . . . . . 1318

9.1. Asymptomatic Patients . . . . . . . . . . . . . 1318

9.2. Symptomatic Patients . . . . . . . . . . . . . . 1319

9.3. Invasive Therapies . . . . . . . . . . . . . . . 1320

9.3.1. Selection of Patients . . . . . . . . . . . 1320
9.3.2. Results of Invasive Therapy for the Relief

of LVOT Obstruction . . . . . . . . . 1320

9.3.3. Operator Experience . . . . . . . . . . . . . . . . . . . . . . . . . . . . . .

9.3.4. Surgical Therapy . . . . . . . . . . . . . . 1321

9.3.4.1. Outcomes . . . . . . . . . . . . . . . . 1321

9.3.4.2. Complications . . . . . . . . . . . . . 1321

9.3.4.3. Mitral Valve Abnormalities and Other

Anatomic Issues . . . . . . . . . . . . . . 1322

9.3.5. Alcohol Septal Ablation . . . . . . . . . . 1322

9.3.5.1. Selection of Patients. . . . . . . . . . . 1322

9.3.5.2. Results . . . . . . . . . . . . . . . . . 1322

9.3.5.3. Complications . . . . . . . . . . . 1323

9.3.6. DDD Pacing . . . . . . . . . . . . . . . . . . . . . . . . . . . .

9.3.7. LV Systolic Dysfunction . . . . . . . . . . . 1323

9.4. Prevention of SCD . . . . . . . . . . . . . 1323

9.4.1. Established Risk Markers . . . . . . . . . 1323

9.4.1.1. Prior Personal History of Ventricular

Fibrillation, SCD, or Sustained VT . . 1323

9.4.1.2. Family History of SCD. . . . . . . . . . . 1323

9.4.1.3. Syncope . . . . . . . . . . . . . . . . 1324

9.4.1.4. Nonsustained Ventricular Tachycardia . 1324

9.4.1.5. Maximum LV Wall Thickness. . . . . . 1324

9.4.1.6. Abnormal Blood Pressure Response

During Exercise. . . . . . . . . . . . 1324

9.4.2. Other Potential SCD Risk Modifiers. . . . 1324

9.4.2.1. LVOT Obstruction . . . . . . . . . . . . 1324

9.4.2.2. LGE on CMR Imaging. . . . . . . . . . . . . . . . . . . 1324

9.4.2.3. LV Apical Aneurysm . . . . . . . . . . . . 1324

9.4.2.4. Genetic Mutations . . . . . . . . . . . . . 1324

9.4.3. Utility of SCD Risk Markers in Clinical

Practice. . . . . . . . . . . . . 1324

9.5. ICD Therapy in HCM. . . . . . . . . . . . . . . 1325

9.5.1. Complications of ICD Therapy

in $\mathrm{HCM} \ldots \ldots \ldots . \ldots . \ldots . \ldots 1325$

9.6. Participation in Competitive or Recreational Sports

and Physical Activity . . . . . . . . . . . . . . . . . . 1325

9.7. Atrial Fibrillation . . . . . . . . . . . . . . . . . . 1326

10. Occupational Considerations. . . . . . . . . . . . 1327

Staff . . . . . . . . . . . . . . . . . . . 1327

References . . . . . . . . . . . . . . . . . . . . . . . . 1327

Appendix 1 Author relationships with industry and other entities (relevant)—2011 ACCF/AHA guideline for the diagnosis and treatment of hypertrophic cardiomyopathy . . . . . . 1335

Appendix 2 Reviewer relationships with industry and other entities (relevant)—2011 ACCF/AHA guideline for the diagnosis and treatment of hypertrophic cardiomyopathy .1337

\section{PREAMBLE}

It is essential that the medical profession play a central role in critically evaluating the evidence related to drugs, devices, and procedures for the detection, management, or 
prevention of disease. Properly applied, rigorous, expert analysis of the available data documenting absolute and relative benefits and risks of these therapies and procedures can improve the effectiveness of care, optimize patient outcomes, and favorably affect the cost of care by focusing resources on the most effective strategies. One important use of such data is the production of clinical practice guidelines that, in turn, can provide a foundation for a variety of other applications such as performance measures, appropriateness use criteria, clinical decision support tools, and quality improvement tools.

The American College of Cardiology Foundation (ACCF) and the American Heart Association (AHA) have jointly engaged in the production of guidelines in the area of cardiovascular disease since 1980. The ACCF/AHA Task Force on Practice Guidelines (Task Force) is charged with developing, updating, and revising practice guidelines for cardiovascular diseases and procedures, and the Task Force directs and oversees this effort. Writing committees are charged with assessing the evidence as an independent group of authors to develop, update, or revise recommendations for clinical practice.

Experts in the subject under consideration have been selected from both organizations to examine subject-specific data and write guidelines in partnership with representatives from other medical practitioner and specialty groups. Writing committees are specifically charged to perform a formal literature review, weigh the strength of evidence for or against particular tests, treatments, or procedures, and include estimates of expected health outcomes where data exist. Patient-specific modifiers, comorbidities, and issues of patient preference that may influence the choice of tests or therapies are considered. When available, information from studies on cost is considered, but data on efficacy and clinical outcomes constitute the primary basis for recommendations in these guidelines.

In analyzing the data and developing the recommendations and supporting text, the writing committee used evidence-based methodologies developed by the Task Force, which are described elsewhere. ${ }^{1}$ The committee reviewed and ranked evidence supporting current recommendations with the weight of evidence ranked as Level A if the data were derived from multiple randomized clinical trials (RCTs) or meta-analyses. The committee ranked available evidence as Level B when data were derived from a single RCT or nonrandomized studies. Evidence was ranked as Level $\mathrm{C}$ when the primary source of the recommendation was consensus opinion, case studies, or standard of care. In the narrative portions of these guidelines, evidence is generally presented in chronological order of development. Studies are identified as observational, retrospective, prospective, or randomized when appropriate. For certain conditions for which inadequate data are available, recommendations are based on expert consensus and clinical experience and ranked as Level C. An example is the use of penicillin for pneumococcal pneumonia, for which there are no RCTs and treatment is based on clinical experience. When recommendations at Level $\mathrm{C}$ are supported by historical clinical data, appropriate references (including clinical reviews) are cited if available. For issues where sparse data are available, a survey of current practice among the clinicians on the writing committee was the basis for Level $\mathrm{C}$ recommendations and no references are cited. The schema for Classification of Recommendations and Level of Evidence is summarized in Table 1, which also illustrates how the grading system provides an estimate of the size and the certainty of the treatment effect. A new addition to the ACCF/AHA methodology is separation of the Class III recommendations to delineate whether the recommendation is determined to be of "no benefit" or associated with "harm" to the patient. In addition, in view of the increasing number of comparative effectiveness studies, comparator verbs and suggested phrases for writing recommendations for the comparative effectiveness of one treatment/strategy with respect to another for Class of Recommendation I and IIa, Level of Evidence A or B only have been added.

The Task Force makes every effort to avoid actual, potential, or perceived conflicts of interest that may arise as a result of relationships with industry and other entities (RWI) among the writing committee. Specifically, all members of the writing committee, as well as peer reviewers of the document, are required to disclose all relevant relationships and those 12 months prior to initiation of the writing effort. The policies and procedures for RWI for this guideline were those in effect at the initial meeting of this committee (March 28, 2009), which included 50\% of the writing committee with no relevant RWI. All guideline recommendations require a confidential vote by the writing committee and must be approved by a consensus of the members voting. Members who were recused from voting are indicated on the title page of this document with detailed information included in Appendix 1. Members must recuse themselves from voting on any recommendations where their RWI apply. If a writing committee member develops a new RWI during his/her tenure, he/she is required to notify guideline staff in writing. These statements are reviewed by the Task Force and all members during each conference call and/or meeting of the writing committee and are updated as changes occur. For detailed information regarding guideline policies and procedures, please refer to the ACCF/AHA methodology and policies manual. ${ }^{1}$ RWI pertinent to this guideline for authors and peer reviewers are disclosed in Appendixes 1 and 2, respectively. Comprehensive disclosure information for the Task Force is also available online at http://www. cardiosource.org/ACC/About-ACC/Leadership/Guidelines- 
TABLE 1. Applying classification of recommendation and level of evidence

SIZE OF TREATMENT EFFECT

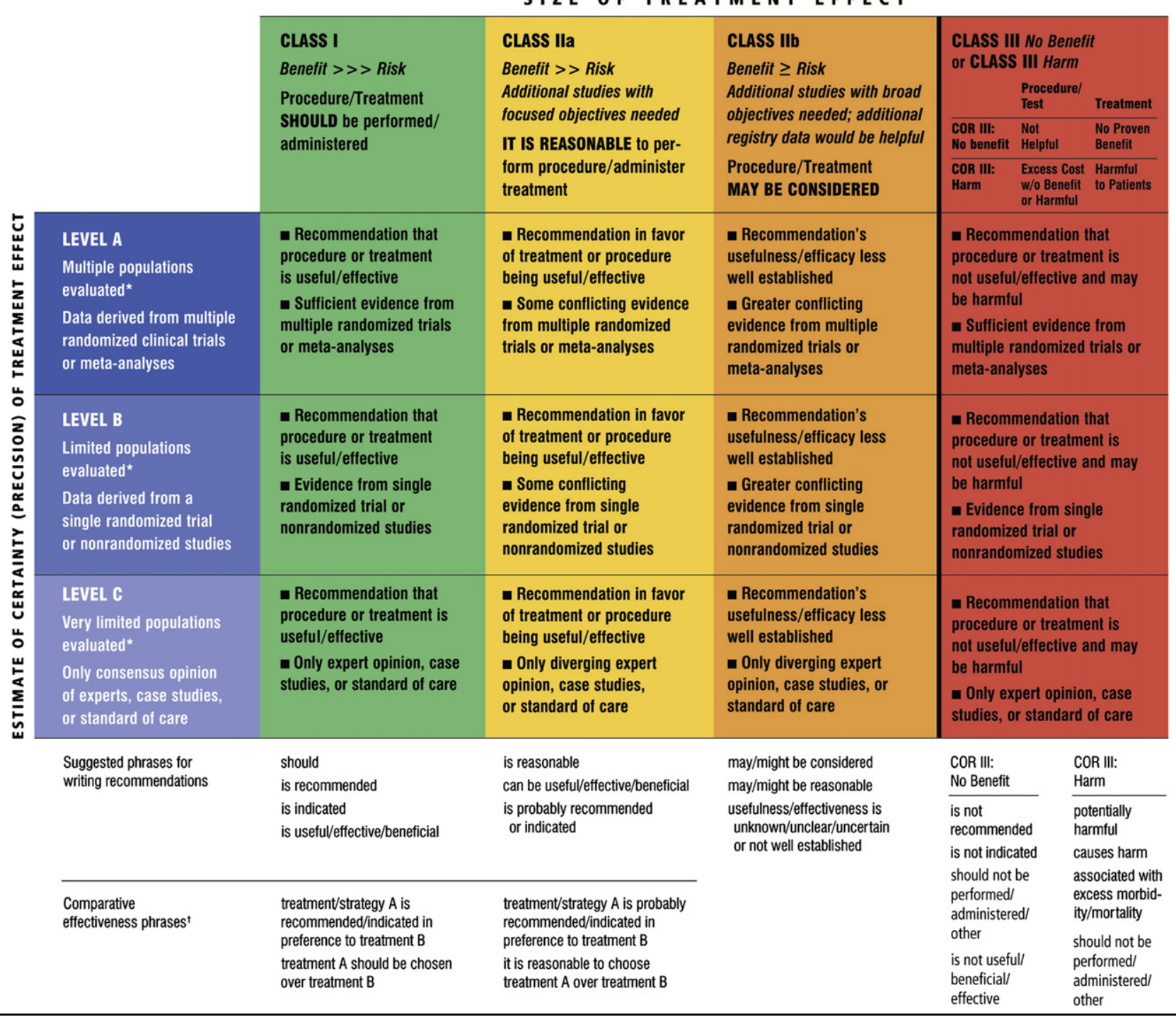

A recommendation with Level of Evidence B or C does not imply that the recommendation is weak. Many important clinical questions addressed in the guidelines do not lend themselves to clinical trials. Although randomized trials are unavailable, there may be a very clear clinical consensus that a particular test or therapy is useful or effective. *Data available from clinical trials or registries about the usefulness/efficacy in different subpopulations, such as sex, age, history of diabetes, history of prior myocardial infarction, history of heart failure, and prior aspirin use. †FFr comparative effectiveness recommendations (Class I and IIa; Level of Evidence A and B only), studies that support the use of comparator verbs should involve direct comparisons of the treatments or strategies being evaluated.

and-Documents-Task-Forces.aspx. The work of the writing committee was supported exclusively by the ACCF and AHA without commercial support. Writing committee members volunteered their time for this effort.

The ACCF/AHA practice guidelines address patient populations (and healthcare providers) residing in North America. As such, drugs that are currently unavailable in North America are discussed in the text without a specific class of recommendation. For studies performed in large numbers of subjects outside of North America, each writing group reviews the potential impact of different practice patterns and patient populations on the treatment effect and on the relevance to the ACCF/AHA target population to determine whether the findings should inform a specific recommendation.

The ACCF/AHA practice guidelines are intended to assist healthcare providers in clinical decision making by describing a range of generally acceptable approaches for the diagnosis, management, and prevention of specific diseases or conditions. These practice guidelines represent a consensus of expert opinion after a thorough review of the available current scientific evidence and are intended to improve patient care. The guidelines attempt to define practices that meet the needs of most patients in most circumstances. The 
ultimate judgment regarding care of a particular patient must be made by the healthcare provider and patient in light of all the circumstances presented by that patient. Thus, there are situations in which deviations from these guidelines may be appropriate. Clinical decision making should consider the quality and availability of expertise in the area where care is provided. When these guidelines are used as the basis for regulatory or payer decisions, the goal should be improvement in quality of care. The Task Force recognizes that situations arise for which additional data are needed to better inform patient care; these areas will be identified within each respective guideline when appropriate.

Prescribed courses of treatment in accordance with these recommendations are effective only if they are followed. Because lack of patient understanding and adherence may adversely affect outcomes, physicians and other healthcare providers should make every effort to engage the patient's active participation in prescribed medical regimens and lifestyles.

The guideline will be reviewed annually by the Task Force and considered current unless it is updated, revised, or withdrawn from distribution. The full-text version ${ }^{1 \mathrm{a}}$ of the guideline is e-published in the Journal of the American College of Cardiology and Circulation and is posted on the ACC (www. cardiosource.org) and AHA (my.americanheart.org) World Wide Web sites. Guidelines are official policy of both the $\mathrm{ACCF}$ and AHA.

Alice K. Jacobs, MD, FACC, FAHA

Chair, ACCF/AHA Task Force on Practice Guidelines

\section{INTRODUCTION}

\subsection{Methodology and Evidence Review}

The recommendations listed in this document are, whenever possible, evidence based. An extensive evidence review was conducted through January 2011. Searches were limited to studies, reviews, and other evidence conducted in human subjects and published in English. Key search words included, but were not limited to, hypertrophic cardiomyopathy (HCM), surgical myectomy, ablation, exercise, sudden cardiac death (SCD), athletes, dual-chamber pacing, left ventricular outflow tract (LVOT) obstruction, alcohol septal ablation, automobile driving and implantable cardioverterdefibrillators (ICDs), catheter ablation, defibrillators, genetics, genotype, medical management, magnetic resonance imaging, pacing, permanent pacing, phenotype, pregnancy, risk stratification, sudden death in athletes, surgical septal myectomy, and septal reduction. References selected and published in this document are representative and not all-inclusive.

\subsection{Organization of the Writing Committee}

The committee was composed of physicians and cardiac surgeons with expertise in HCM, invasive cardiology, noninvasive testing and imaging, pediatric cardiology, electrophysiology, and genetics. The committee included representatives from the American Association for Thoracic Surgery, American Society of Echocardiography, American Society of Nuclear Cardiology, Heart Failure Society of America, Heart Rhythm Society, Society for Cardiovascular Angiography and Interventions, and the Society of Thoracic Surgeons.

\subsection{Document Review and Approval}

This document was reviewed by 2 outside reviewers nominated by both the ACCF and AHA, as well as 2 reviewers each from the American Association for Thoracic Surgery, American Society of Echocardiography, American Society of Nuclear Cardiology, Heart Failure Society of America, Heart Rhythm Society, Society for Cardiovascular Angiography and Interventions, and the Society of Thoracic Surgeons. Other content reviewers included members from the ACCF Adult Congenital and Pediatric Cardiology Council, ACCF Surgeons' Scientific Council, and ACCF Interventional Scientific Council. All information on reviewers' RWI was distributed to the writing committee and is published in this document (Appendix 2).

This document was approved for publication by the governing bodies of the ACCF and the AHA and endorsed by the American Association for Thoracic Surgery, American Society of Echocardiography, American Society of Nuclear Cardiology, Heart Failure Society of America, Heart Rhythm Society, Society for Cardiovascular Angiography and Interventions, and Society of Thoracic Surgeons.

\subsection{Scope of the Guideline}

Although there are reports of this disease dating back to the $1800 \mathrm{~s}$, the first modern pathologic description was provided over 50 years ago by Teare ${ }^{2}$ and the most important early clinical report by Braunwald et al in $1964 .^{3}$

The impetus for the guidelines is based on an appreciation of the frequency of this clinical entity and a realization that many aspects of clinical management, including the use of diagnostic modalities and genetic testing, lack consensus. Moreover, the emergence of 2 different approaches to septal reduction therapy (septal myectomy and alcohol septal ablation) in addition to the ICD has created considerable controversy. The discussion and recommendations about the various diagnostic modalities apply to patients with established HCM and to a variable extent to patients with a high index of suspicion of the disease.

Although the Task Force was aware of the lack of high levels of evidence regarding HCM provided by clinical trials, it was believed that a guideline document based on expert consensus that outlines the most important diagnostic and management strategies would be helpful.

To facilitate ease of use, it was decided that recommendations in the pediatric and adolescent age groups would not 
appear as a separate section but instead would be integrated into the overall content of the guideline where relevant.

\section{RECOMMENDATIONS FOR HCM}

\subsection{Genetic Testing Strategies/Family Screening- Recommendations}

\section{Class I}

1. Evaluation of familial inheritance and genetic counseling is recommended as part of the assessment of patients with $\mathrm{HCM}^{4-9}$ (Level of Evidence: $\mathrm{B}$ )

2. Patients who undergo genetic testing should also undergo counseling by someone knowledgeable in the genetics of cardiovascular disease so that results and their clinical significance can be appropriately reviewed with the patient. ${ }^{10-14}$ (Level of Evidence: B)

3. Screening (clinical, with or without genetic testing) is recommended in first-degree relatives of patients with HCM. ${ }^{4-7,9,15,16}$ (Level of Evidence: $B$ )

4. Genetic testing for HCM and other genetic causes of unexplained cardiac hypertrophy is recommended in patients with an atypical clinical presentation of HCM or when another genetic condition is suspected to be the cause. ${ }^{17-19}$ (Level of Evidence: $B$ )

\section{Class IIa}

1. Genetic testing is reasonable in the index patient to facilitate the identification of first-degree family members at risk for developing HCM. ${ }^{5,8,15}$ (Level of Evidence: B)

\section{Class IIb}

1. The usefulness of genetic testing in the assessment of risk of SCD in HCM is uncertain. ${ }^{20,21}$ (Level of Evidence: $B$ )

\section{Class III: No Benefit}

1. Genetic testing is not indicated in relatives when the index patient does not have a definitive pathogenic mutation..$^{4-9,22}$ (Level of Evidence: $B$ )

2. Ongoing clinical screening is not indicated in genotype-negative relatives in families with $\mathrm{HCM}^{22-25}$ (Level of Evidence: B)

See Online Data Supplement 1 for additional data regarding genetic testing strategies/family screening.

\subsubsection{Genotype-Positive/Phenotype-Negative Patients- Recommendation}

\section{Class I}

1. In individuals with pathogenic mutations who do not express the HCM phenotype, it is recommended to perform serial electrocardiogram (ECG), transthoracic echocardiogram (TTE), and clinical assessment at periodic intervals (12 to 18 months in children and adolescents and about every 5 years in adults), based on the patient's age and change in clinical status. ${ }^{26-29}$ (Level of Evidence: $B$ )

\subsection{Electrocardiography-Recommendations}

\section{Class I}

1. A 12-lead ECG is recommended in the initial evaluation of patients with HCM. (Level of Evidence: C)

2. Twenty-four-hour ambulatory (Holter) electrocardiographic monitoring is recommended in the initial evaluation of patients with
HCM to detect ventricular tachycardia (VT) and identify patients who may be candidates for ICD therapy. ${ }^{30-33}$ (Level of Evidence: B)

3. Twenty-four-hour ambulatory (Holter) electrocardiographic monitoring or event recording is recommended in patients with HCM who develop palpitations or lightheadedness. ${ }^{30-32}$ (Level of Evidence: $B$ )

4. A repeat ECG is recommended for patients with $\mathrm{HCM}$ when there is worsening of symptoms. (Level of Evidence: C)

5. A 12-lead ECG is recommended every 12 to 18 months as a component of the screening algorithm for adolescent first-degree relatives of patients with HCM who have no evidence of hypertrophy on echocardiography. (Level of Evidence: $C$ )

6. A 12-lead ECG is recommended as a component of the screening algorithm for first-degree relatives of patients with HCM. (Level of Evidence: C)

\section{Class IIa}

1. Twenty-four-hour ambulatory (Holter) electrocardiographic monitoring, repeated every 1 to 2 years, is reasonable in patients with HCM who have no previous evidence of VT to identify patients who may be candidates for ICD therapy. ${ }^{33}$ (Level of Evidence: $C$ )

2. Annual 12-lead ECGs are reasonable in patients with known HCM who are clinically stable to evaluate for asymptomatic changes in conduction or rhythm (ie, atrial fibrillation $[\mathrm{AF}]$ ). (Level of Evidence: C)

\section{Class IIb}

1. Twenty-four-hour ambulatory (Holter) electrocardiographic monitoring might be considered in adults with HCM to assess for asymptomatic paroxysmal AF/atrial flutter. (Level of Evidence: C)

\subsection{Echocardiography—Recommendations}

\section{Class I}

1. A TTE is recommended in the initial evaluation of all patients with suspected HCM. ${ }^{34-41}$ (Level of Evidence: B)

2. A TTE is recommended as a component of the screening algorithm for family members of patients with HCM unless the family member is genotype negative in a family with known definitive mutations. $^{42-45}$ (Level of Evidence: $\left.B\right)$

3. Periodic (12 to 18 months) TTE screening is recommended for children of patients with HCM, starting by age 12 years or earlier if a growth spurt or signs of puberty are evident and/or when there are plans for engaging in intense competitive sports or there is a family history of SCD. ${ }^{45,46}$ (Level of Evidence: $C$ )

4. Repeat TTE is recommended for the evaluation of patients with HCM with a change in clinical status or new cardiovascular event. ${ }^{47-53}$ (Level of Evidence: $B$ )

5. A transesophageal echocardiogram (TEE) is recommended for the intraoperative guidance of surgical myectomy. ${ }^{54-56}$ (Level of Evidence: $B$ )

6. TTE or TEE with intracoronary contrast injection of the candidate's septal perforator(s) is recommended for the intraprocedural guidance of alcohol septal ablation. ${ }^{57-60}$ (Level of Evidence: $B$ )

7. TTE should be used to evaluate the effects of surgical myectomy or alcohol septal ablation for obstructive HCM. ${ }^{60-66}$ (Level of Evidence: $\mathrm{C}$ )

\section{Class IIa}

1. TTE studies performed every 1 to 2 years can be useful in the serial evaluation of symptomatically stable patients with HCM to assess 
the degree of myocardial hypertrophy, dynamic obstruction, and myocardial function. ${ }^{35,37,41}$ (Level of Evidence: C)

2. Exercise TTE can be useful in the detection and quantification of dynamic LVOT obstruction in the absence of resting outflow tract obstruction in patients with HCM. ${ }^{48,51,53,67,68}$ (Level of Evidence: $B$ )

3. TEE can be useful if TTE is inconclusive for clinical decision making about medical therapy and in situations such as planning for myectomy, exclusion of subaortic membrane or mitral regurgitation secondary to structural abnormalities of the mitral valve apparatus, or in assessment for the feasibility of alcohol septal ablation. ${ }^{54-56}$ (Level of Evidence: $C$ )

4. TTE combined with the injection of an intravenous contrast agent is reasonable if the diagnosis of apical HCM or apical infarction or severity of hypertrophy is in doubt, particularly when other imaging modalities such as cardiovascular magnetic resonance (CMR) are not readily available, not diagnostic, or are contraindicated. (Level of Evidence: $C$ )

5. Serial TTE studies are reasonable for clinically unaffected patients who have a first-degree relative with HCM when genetic status is unknown. Such follow-up may be considered every 12 to 18 months for children or adolescents from high-risk families and every 5 years for adult family members. ${ }^{43-46}$ (Level of Evidence: $C$ )

\section{Class III: No Benefit}

1. TTE studies should not be performed more frequently than every 12 months in patients with HCM when it is unlikely that any changes have occurred that would have an impact on clinical decision making. (Level of Evidence: C)

2. Routine TEE and/or contrast echocardiography is not recommended when TTE images are diagnostic of $\mathrm{HCM}$ and/or there is no suspicion of fixed obstruction or intrinsic mitral valve pathology. (Level of Evidence: $C$ )

\subsection{Stress Testing-Recommendations}

\section{Class IIa}

1. Treadmill exercise testing is reasonable to determine functional capacity and response to therapy in patients with HCM. (Level of Evidence: $C$ )

2. Treadmill testing with monitoring of an ECG and blood pressure is reasonable for SCD risk stratification in patients with HCM. ${ }^{69-71}$ (Level of Evidence: $B$ )

3. In patients with $\mathrm{HCM}$ who do not have a resting peak instantaneous gradient of greater than or equal to $50 \mathrm{~mm} \mathrm{Hg}$, exercise echocardiography is reasonable for the detection and quantification of exerciseinduced dynamic LVOT obstruction. ${ }^{67,70-72}$ (Level of Evidence: B)

\subsection{Cardiac Magnetic Resonance- \\ Recommendations}

\section{Class I}

1. CMR imaging is indicated in patients with suspected HCM when echocardiography is inconclusive for diagnosis. ${ }^{73,74}$ (Level of Evidence: $B$ )

2. CMR imaging is indicated in patients with known HCM when additional information that may have an impact on management or decision making regarding invasive management, such as magnitude and distribution of hypertrophy or anatomy of the mitral valve apparatus or papillary muscles, is not adequately defined with echocardiography. ${ }^{73-77}$ (Level of Evidence: B)

\section{Class IIa}

1. CMR imaging is reasonable in patients with HCM to define apical hypertrophy and/or aneurysm if echocardiography is inconclusive. $^{73,75}$ (Level of Evidence: $B$ )

\section{Class IIb}

1. In selected patients with known HCM, when SCD risk stratification is inconclusive after documentation of the conventional risk factors (Section 2.13), CMR imaging with assessment of late gadolinium enhancement (LGE) may be considered in resolving clinical decision making. ${ }^{78-82}$ (Level of Evidence: $C$ )

2. CMR imaging may be considered in patients with $L V$ hypertrophy and the suspicion of alternative diagnoses to HCM, including cardiac amyloidosis, Fabry disease, and genetic phenocopies such as LAMP2 cardiomyopathy. ${ }^{83-85}$ (Level of Evidence: C)

\subsection{Detection of Concomitant Coronary Disease- Recommendations}

\section{Class I}

1. Coronary arteriography (invasive or computed tomographic imaging) is indicated in patients with HCM with chest discomfort who have an intermediate to high likelihood of coronary artery disease (CAD) when the identification of concomitant CAD will change management strategies. (Level of Evidence: $C$ )

\section{Class IIa}

1. Assessment of coronary anatomy with computed tomographic angiography (CTA) is reasonable for patients with HCM with chest discomfort and a low likelihood of CAD to assess for possible concomitant CAD. (Level of Evidence: $C$ )

2. Assessment of ischemia or perfusion abnormalities suggestive of CAD with single photon emission computed tomography (SPECT) or positron emission tomography (PET) myocardial perfusion imaging (MPI; because of excellent negative predictive value) is reasonable in patients with HCM with chest discomfort and a low likelihood of CAD to rule out possible concomitant CAD. (Level of Evidence: $\mathrm{C}$ )

\section{Class III: No Benefit}

1. Routine SPECT MPI or stress echocardiography is not indicated for detection of "silent" CAD-related ischemia in patients with HCM who are asymptomatic. (Level of Evidence: $C$ )

2. Assessment for the presence of blunted flow reserve (microvascular ischemia) using quantitative myocardial blood flow measurements by PET is not indicated for the assessment of prognosis in patients with HCM. (Level of Evidence: C)

\subsection{Asymptomatic Patients-Recommendations}

\section{Class I}

1. For patients with HCM, it is recommended that comorbidities that may contribute to cardiovascular disease (eg, hypertension, diabetes, hyperlipidemia, obesity) be treated in compliance with relevant existing guidelines. ${ }^{86}$ (Level of Evidence: $C$ )

\section{Class IIa}

1. Low-intensity aerobic exercise is reasonable as part of a healthy lifestyle for patients with HCM. ${ }^{32,87}$ (Level of Evidence: C) 


\section{Class IIb}

1. The usefulness of beta blockade and calcium channel blockers to alter clinical outcome is not well established for the management of asymptomatic patients with $\mathrm{HCM}$ with or without obstruction. ${ }^{32}$ (Level of Evidence: $C$ )

\section{Class III: Harm}

1. Septal reduction therapy should not be performed for asymptomatic adult and pediatric patients with $\mathrm{HCM}$ with normal effort tolerance regardless of the severity of obstruction. ${ }^{32,38}$ (Level of Evidence: C)

2. In patients with HCM with resting or provocable outflow tract obstruction, regardless of symptom status, pure vasodilators and highdose diuretics are potentially harmful. ${ }^{3,38}$ (Level of Evidence: C)

\subsection{Pharmacologic Management- \\ Recommendations}

\section{Class I}

1. Beta-blocking drugs are recommended for the treatment of symptoms (angina or dyspnea) in adult patients with obstructive or nonobstructive HCM but should be used with caution in patients with sinus bradycardia or severe conduction disease. ${ }^{3,32,36,38,88-96}$ (Level of Evidence: $B$ )

2. If low doses of beta-blocking drugs are ineffective for controlling symptoms (angina or dyspnea) in patients with HCM, it is useful to titrate the dose to a resting heart rate of less than 60 to $65 \mathrm{bpm}$ (up to generally accepted and recommended maximum doses of

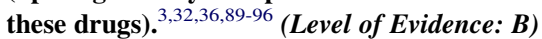

3. Verapamil therapy (starting in low doses and titrating up to 480 $\mathrm{mg} / \mathrm{d}$ ) is recommended for the treatment of symptoms (angina or dyspnea) in patients with obstructive or nonobstructive HCM who do not respond to beta-blocking drugs or who have side effects or contraindications to beta-blocking drugs. However, verapamil should be used with caution in patients with high gradients, advanced heart failure, or sinus bradycardia. ${ }^{32,36,88,97-101}$ (Level of Evidence: $\mathrm{B})$

4. Intravenous phenylephrine (or another pure vasoconstricting agent) is recommended for the treatment of acute hypotension in patients with obstructive HCM who do not respond to fluid administration. ${ }^{36,102-104}$ (Level of Evidence: B)

\section{Class IIa}

1. It is reasonable to combine disopyramide with a beta-blocking drug or verapamil in the treatment of symptoms (angina or dyspnea) in patients with obstructive HCM who do not respond to beta-blocking drugs or verapamil alone. ${ }^{32,36,88,105-108}$ (Level of Evidence: $\mathrm{B})$

2. It is reasonable to add oral diuretics in patients with nonobstructive HCM when dyspnea persists despite the use of beta blockers or verapamil or their combination. ${ }^{41,88}$ (Level of Evidence: C)

\section{Class IIb}

1. Beta-blocking drugs might be useful in the treatment of symptoms (angina or dyspnea) in children or adolescents with HCM, but patients treated with these drugs should be monitored for side effects, including depression, fatigue, or impaired scholastic performance. (Level of Evidence: C)

2. It may be reasonable to add oral diuretics with caution to patients with obstructive HCM when congestive symptoms persist despite the use of beta blockers or verapamil or their combination. ${ }^{32,36,88}$ (Level of Evidence: $C$ )

3. The usefulness of angiotensin-converting enzyme inhibitors or angiotensin receptor blockers in the treatment of symptoms (angina or dyspnea) in patients with HCM with preserved systolic function is not well established, and these drugs should be used cautiously (if at all) in patients with resting or provocable LVOT obstruction. (Level of Evidence: $C$ )

4. In patients with HCM who do not tolerate verapamil or in whom verapamil is contraindicated, diltiazem may be considered. (Level of Evidence: $\mathrm{C}$ )

\section{Class III: Harm}

1. Nifedipine or other dihydropyridine calcium channel-blocking drugs are potentially harmful for treatment of symptoms (angina or dyspnea) in patients with $\mathrm{HCM}$ who have resting or provocable LVOT obstruction. (Level of Evidence: $C$ )

2. Verapamil is potentially harmful in patients with obstructive HCM in the setting of systemic hypotension or severe dyspnea at rest. (Level of Evidence: C)

3. Digitalis is potentially harmful in the treatment of dyspnea in patients with $\mathrm{HCM}$ and in the absence of $\mathrm{AF}^{3,32,36,109-111}$ (Level of Evidence: $B$ )

4. The use of disopyramide alone without beta blockers or verapamil is potentially harmful in the treatment of symptoms (angina or dyspnea) in patients with HCM with AF because disopyramide may enhance atrioventricular conduction and increase the ventricular rate during episodes of $\mathbf{A F} .^{32,40,88,112-117}$ (Level of Evidence: $B$ )

5. Dopamine, dobutamine, norepinephrine, and other intravenous positive inotropic drugs are potentially harmful for the treatment of acute hypotension in patients with obstructive HCM. ${ }^{3,102-104,118-121}$ (Level of Evidence: $B$ )

\subsection{Invasive Therapies-Recommendations}

\section{Class I}

1. Septal reduction therapy should be performed only by experienced operators* in the context of a comprehensive HCM clinical program and only for the treatment of eligible patients with severe drug-refractory symptoms and LVOT obstruction. ${ }^{\dagger 12}$ (Level of Evidence: $C$ )

\section{Class IIa}

1. Consultation with centers experienced in performing both surgical septal myectomy and alcohol septal ablation is reasonable when discussing treatment options for eligible patients with HCM with severe drug-refractory symptoms and LVOT obstruction. (Level of Evidence: $C$ )

2. Surgical septal myectomy, when performed in experienced centers, can be beneficial and is the first consideration for the majority of eligible patients with HCM with severe drug-refractory symptoms and LVOT obstruction. ${ }^{60,64,65,123-125}$ (Level of Evidence: B)

\footnotetext{
* Experienced operators are defined as an individual operator with a cumulative case volume of at least 20 procedures or an individual operator who is working in a dedicated HCM program with a cumulative total of at least 50 procedures (Section 9.3.3).

${ }^{\dagger}$ Eligible patients are defined by all of the following:

a. Clinical: Severe dyspnea or chest pain (usually New York Heart Association [NYHA] functional classes III or IV) or occasionally other exertional symptoms (such as syncope or near syncope) that interfere with everyday activity or quality of life despite optimal medical therapy.

b. Hemodynamic: Dynamic LVOT gradient at rest or with physiologic provocation $\geq 50 \mathrm{~mm} \mathrm{Hg}$ associated with septal hypertrophy and systolic anterior motion (SAM) of the mitral valve.

c. Anatomic: Targeted anterior septal thickness sufficient to perform the procedure safely and effectively in the judgment of the individual operator.
} 
3. Surgical septal myectomy, when performed at experienced centers, can be beneficial in symptomatic children with HCM and severe resting obstruction $(>50 \mathrm{~mm} \mathrm{Hg}$ ) for whom standard medical therapy has failed. ${ }^{126}$ (Level of Evidence: $\mathrm{C}$ )

4. When surgery is contraindicated or the risk is considered unacceptable because of serious comorbidities or advanced age, alcohol septal ablation, when performed in experienced centers, can be beneficial in eligible adult patients with HCM with LVOT obstruction and severe drug-refractory symptoms (usually NYHA functional classes III or IV). ${ }^{60,62,127-131}$ (Level of Evidence: B)

\section{Class IIb}

1. Alcohol septal ablation, when performed in experienced centers, may be considered as an alternative to surgical myectomy for eligible adult patients with HCM with severe drug-refractory symptoms and LVOT obstruction when, after a balanced and thorough discussion, the patient expresses a preference for septal ablation. ${ }^{62,123,128,130,131}$ (Level of Evidence: $B$ )

2. The effectiveness of alcohol septal ablation is uncertain in patients with HCM with marked (ie, $>30 \mathrm{~mm}$ ) septal hypertrophy, and therefore the procedure is generally discouraged in such patients. (Level of Evidence: $C$ )

\section{Class III: Harm}

1. Septal reduction therapy should not be done for adult patients with HCM who are asymptomatic with normal exercise tolerance or whose symptoms are controlled or minimized on optimal medical therapy. (Level of Evidence: $C$ )

2. Septal reduction therapy should not be done unless performed as part of a program dedicated to the longitudinal and multidisciplinary care of patients with HCM. (Level of Evidence: C)

3. Mitral valve replacement for relief of LVOT obstruction should not be performed in patients with HCM in whom septal reduction therapy is an option. (Level of Evidence: $C$ )

4. Alcohol septal ablation should not be done in patients with HCM with concomitant disease that independently warrants surgical correction (eg, coronary artery bypass grafting for $\mathrm{CAD}$, mitral valve repair for ruptured chordae) in whom surgical myectomy can be performed as part of the operation. (Level of Evidence: $C$ )

5. Alcohol septal ablation should not be done in patients with $\mathrm{HCM}$ who are less than 21 years of age and is discouraged in adults less than 40 years of age if myectomy is a viable option. (Level of Evidence: $C$ )

See Online Data Supplement 2 for additional data regarding invasive therapies.

\subsection{Pacing-Recommendations}

\section{Class IIa}

1. In patients with HCM who have had a dual-chamber device implanted for non-HCM indications, it is reasonable to consider a trial of dual-chamber atrial-ventricular pacing (from the right ventricular apex) for the relief of symptoms attributable to LVOT obstruction. $^{132-135}$ (Level of Evidence: B)

\section{Class IIb}

1. Permanent pacing may be considered in medically refractory symptomatic patients with obstructive HCM who are suboptimal candidates for septal reduction therapy. ${ }^{132-136}$ (Level of Evidence: B)

\section{Class III: No Benefit}

1. Permanent pacemaker implantation for the purpose of reducing gradient should not be performed in patients with HCM who are asymptomatic or whose symptoms are medically controlled. ${ }^{136-138}$ (Level of Evidence: $C$ )

2. Permanent pacemaker implantation should not be performed as a first-line therapy to relieve symptoms in medically refractory symptomatic patients with HCM and LVOT obstruction who are candidates for septal reduction. ${ }^{136-138}$ (Level of Evidence: B)

See Online Data Supplement 3 for additional data regarding pacing.

\subsection{Patients With LV Systolic Dysfunction- Recommendations}

\section{Class I}

1. Patients with nonobstructive HCM who develop systolic dysfunction with an ejection fraction (EF) less than or equal to $50 \%$ should be treated according to evidence-based medical therapy for adults with other forms of heart failure with reduced EF, including angiotensin-converting enzyme inhibitors, angiotensin receptor blockers, beta blockers, and other indicated drugs. ${ }^{49,139}$ (Level of Evidence: $B$ )

2. Other concomitant causes of systolic dysfunction (such as CAD) should be considered as potential contributors to systolic dysfunction in patients with HCM. (Level of Evidence: $C$ )

\section{Class IIb}

1. ICD therapy may be considered in adult patients with advanced (as defined by NYHA functional class III or IV heart failure) nonobstructive HCM, on maximal medical therapy, and EF less than or equal to $50 \%$, who do not otherwise have an indication for an ICD. ${ }^{49}$ (Level of Evidence: C)

2. For patients with HCM who develop systolic dysfunction, it may be reasonable to reassess the use of negative inotropic agents previously indicated, for example, verapamil, diltiazem, or disopyramide, and to consider discontinuing those therapies. (Level of Evidence: $C$ )

\subsection{Selection of Patients for Heart} Transplantation-Recommendations

\section{Class I}

1. Patients with advanced heart failure (end-stage*) and nonobstructive HCM not otherwise amenable to other treatment interventions, with EF less than $50 \%$ (or occasionally with preserved EF), should be considered for heart transplantation. ${ }^{49,140}$ (Level of Evidence: B)

2. Symptomatic children with HCM with restrictive physiology who are not responsive to or appropriate candidates for other therapeutic interventions should be considered for heart transplantation. ${ }^{141,142}$ (Level of Evidence: $C$ )

\section{Class III: Harm}

1. Heart transplantation should not be performed in mildly symptomatic patients of any age with HCM. (Level of Evidence: $C$ )

\subsection{SCD Risk Stratification-Recommendations}

\section{Class I}

\footnotetext{
$\bar{*}$ Characterized by systolic dysfunction ( $\mathrm{EF} \leq 50 \%)$, often associated with LV remod eling, including cavity enlargement and wall thinning, and because of diffuse myocardial scarring.
} 
1. All patients with HCM should undergo comprehensive SCD risk stratification at initial evaluation to determine the presence of the following: ${ }^{30,31,143-152}$ (Level of Evidence: B)

a. A personal history for ventricular fibrillation, sustained VT, or SCD events, including appropriate ICD therapy for ventricular tachyarrhythmias. ${ }^{\dagger}$

b. A family history for SCD events, including appropriate ICD therapy for ventricular tachyarrhythmias. ${ }^{\dagger}$

c. Unexplained syncope.

d. Documented nonsustained ventricular tachycardia (NSVT) defined as 3 or more beats at greater than or equal to $120 \mathrm{bpm}$ on ambulatory (Holter) ECG.

e. Maximal LV wall thickness greater than or equal to $30 \mathrm{~mm}$.

\section{Class IIa}

1. It is reasonable to assess blood pressure response during exercise as part of SCD risk stratification in patients with HCM. ${ }^{30,71,149}$ (Level of Evidence: $B$ )

2. SCD risk stratification is reasonable on a periodic basis (every 12 to 24 months) for patients with HCM who have not undergone ICD implantation but would otherwise be eligible in the event that risk factors are identified (12 to 24 months). (Level of Evidence: C)

\section{Class IIb}

1. The usefulness of the following potential SCD risk modifiers is unclear but might be considered in selected patients with HCM for whom risk remains borderline after documentation of conventional risk factors:
a. CMR imaging with LGE. ${ }^{78,82}$ (Level of Evidence: $\boldsymbol{C}$ )
b. Double and compound mutations (ie, >1). (Level of Evi- dence: $\mathrm{C}$ )
c. Marked LVOT obstruction. ${ }^{30,48,51,149}$ (Level of Evidence: B)

\section{Class III: Harm}

1. Invasive electrophysiologic testing as routine SCD risk stratification for patients with HCM should not be performed. (Level of Evidence: C)

See Online Data Supplement 4 for additional data regarding SCD risk stratification.

\subsection{Selection of Patients for ICDs—Recommendations}

\section{Class I}

1. The decision to place an ICD in patients with HCM should include application of individual clinical judgment, as well as a thorough discussion of the strength of evidence, benefits, and risks to allow the informed patient's active participation in decision making (Figure 1). ${ }^{144,150,153,154}$ (Level of Evidence: C)

2. ICD placement is recommended for patients with HCM with prior documented cardiac arrest, ventricular fibrillation, or hemodynamically significant VT. ${ }^{145,146,148,150}$ (Level of Evidence: B)

\section{Class IIa}

1. It is reasonable to recommend an ICD for patients with HCM with:

\footnotetext{
${ }^{\dagger}$ Appropriate ICD discharge is defined as ICD therapy triggered by VT or ventricular fibrillation, documented by stored intracardiac electrogram or cycle-length data, in conjunction with the patient's symptoms immediately before and after device discharge.
}

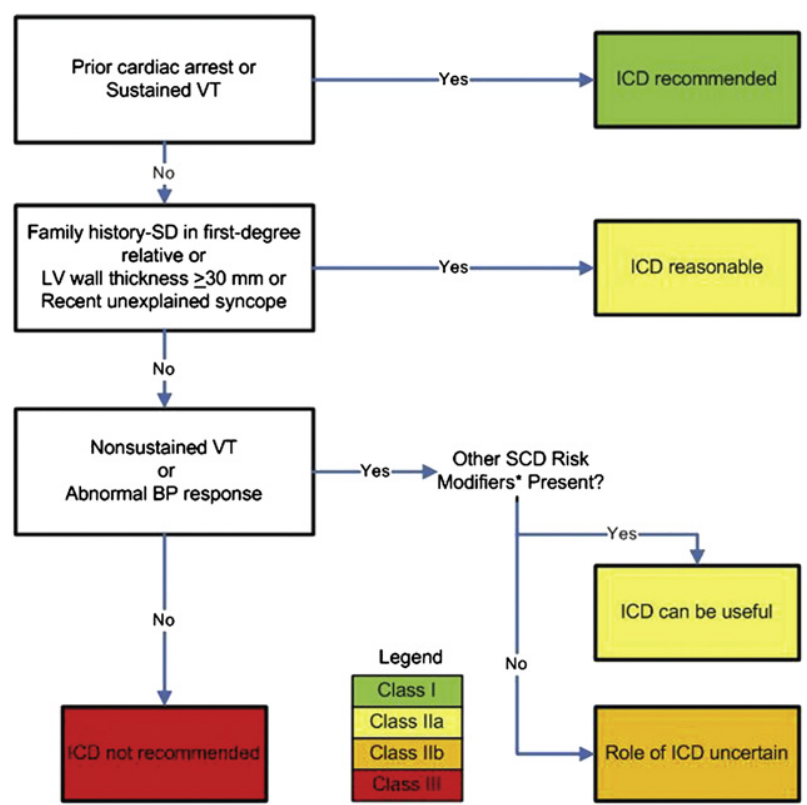

Regardless of the level of recommendation put forth in these guidelines, the decision for placement of an ICD must involve prudent application of individual clinical judgment, thorough discussions of the strength of evidence, the benefits, and the risks (including but not limited to inappropriate discharges, lead and procedural complications) to allow active participation of the fully informed patient in ultimate decision making.

FIGURE 1. Indications for ICDs in HCM. *SCD risk modifiers include established risk factors and emerging risk modifiers (Section 9.4.2). BP, Blood pressure; $I C D$, implantable cardioverter-defibrillator; $L V$, left ventricular; $S C D$, sudden cardiac death; $S D$, sudden death; $V T$, ventricular tachycardia.

a. Sudden death presumably caused by HCM in 1 or more firstdegree relatives. ${ }^{155}$ (Level of Evidence: $C$ )

b. A maximum $\mathrm{LV}$ wall thickness greater than or equal to 30 mm. ${ }^{147,156-158}$ (Level of Evidence: C)

c. One or more recent, unexplained syncopal episodes. ${ }^{152}$ (Level of Evidence: $C$ )

2. An ICD can be useful in select patients with NSVT (particularly those $<\mathbf{3 0}$ years of age) in the presence of other SCD risk factors or modifiers. ${ }^{\ddagger 33,144}$ (Level of Evidence: $C$ )

3. An ICD can be useful in select patients with HCM with an abnormal blood pressure response with exercise in the presence of other SCD risk factors or modifiers. ${ }^{\ddagger 70,71,149}$ (Level of Evidence: C)

4. It is reasonable to recommend an ICD for high-risk children with HCM, based on unexplained syncope, massive LV hypertrophy, or family history of SCD, after taking into account the relatively high complication rate of long-term ICD implantation. (Level of Evidence: $C$ )

\section{Class IIb}

1. The usefulness of an ICD is uncertain in patients with HCM with isolated bursts of NSVT when in the absence of any other SCD risk factors or modifiers. ${ }^{\ddagger 114}$ (Level of Evidence: $C$ )

2. The usefulness of an ICD is uncertain in patients with HCM with an abnormal blood pressure response with exercise when in the absence of any other SCD risk factors or modifiers, ${ }^{\ddagger}$ particularly in the presence of significant outflow obstruction. ${ }^{70,71,149}$ (Level of Evidence: C)

\footnotetext{
${ }^{\ddagger}$ SCD risk modifiers are discussed in Section 9.4.2.
} 


\section{Class III: Harm}

1. ICD placement as a routine strategy in patients with HCM without an indication of increased risk is potentially harmful. (Level of Evidence: $C$ )

2. ICD placement as a strategy to permit patients with HCM to participate in competitive athletics is potentially harmful. (Level of Evidence: $C$ )

3. ICD placement in patients who have an identified HCM genotype in the absence of clinical manifestations of HCM is potentially harmful. (Level of Evidence: $C$ )

\subsection{Selection of ICD Device Type- Recommendations}

\section{Class IIa}

1. In patients with HCM who meet indications for ICD implantation, single-chamber devices are reasonable in younger patients without a need for atrial or ventricular pacing. ${ }^{159-162}$ (Level of Evidence: $B$ )

2. In patients with HCM who meet indications for ICD implantation, dual-chamber ICDs are reasonable for patients with sinus bradycardia and/or paroxysmal AF. ${ }^{159}$ (Level of Evidence: C)

3. In patients with HCM who meet indications for ICD implantation, dual-chamber ICDs are reasonable for patients with elevated resting outflow gradients greater than $50 \mathrm{~mm} \mathrm{Hg}$ and significant heart failure symptoms who may benefit from right ventricular pacing (most commonly, but not limited to, patients $>65$ years of age). ${ }^{136-138,159}$ (Level of Evidence: B)

\subsection{Participation in Competitive or Recreational Sports and Physical Activity-Recommendations}

\section{Class IIa}

1. It is reasonable for patients with HCM to participate in lowintensity competitive sports (eg, golf and bowling). ${ }^{163,164}$ (Level of Evidence: $C$ )

2. It is reasonable for patients with HCM to participate in a range of recreational sporting activities as outlined in Table $2 .^{87}$ (Level of Evidence: $\mathrm{C}$ )

\section{Class III: Harm}

1. Patients with HCM should not participate in intense competitive sports regardless of age, sex, race, presence or absence of LVOT obstruction, prior septal reduction therapy, or implantation of a cardioverter-defibrillator for high-risk status. ${ }^{163-169}$ (Level of Evidence: C)

\subsection{Management of AF-Recommendations}

\section{Class I}

1. Anticoagulation with vitamin $K$ antagonists (ie, warfarin, to an international normalized ratio of 2.0 to 3.0 ) is indicated in patients with paroxysmal, persistent, or chronic AF and HCM. ${ }^{170-172}$ (Anticoagulation with direct thrombin inhibitors [ie, dabigatran ${ }^{\S}$ ] may represent another option to reduce the risk of thromboembolic events, but data for patients with HCM are not available. ${ }^{173}$ ) (Level of Evidence: C)

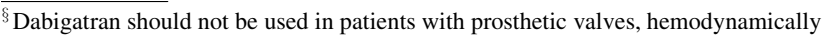
significant valve disease, advanced liver failure, or severe renal failure (creatinine clearance $<15 \mathrm{~mL} / \mathrm{min}) .{ }^{173}$
}

TABLE 2. Recommendations for the acceptability of recreational (noncompetitive) sports activities and exercise in patients with $\mathrm{HCM}^{*}$

\begin{tabular}{|c|c|}
\hline Intensity level & Eligibility scale for $\mathrm{HCM} \dagger$ \\
\hline \multicolumn{2}{|l|}{ High } \\
\hline Basketball (full court) & 0 \\
\hline Basketball (half court) & 0 \\
\hline Body building $\ddagger$ & 1 \\
\hline Gymnastics & 2 \\
\hline Ice hockey $\ddagger$ & 0 \\
\hline Racquetball/squash & 0 \\
\hline Rock climbing $\ddagger$ & 1 \\
\hline Running (sprinting) & 0 \\
\hline Skiing (downhill) $\ddagger$ & 2 \\
\hline Skiing (cross-country) & 2 \\
\hline Soccer & 0 \\
\hline Tennis (singles) & 0 \\
\hline Touch (flag) football & 1 \\
\hline Windsurfing $\oint$ & 1 \\
\hline \multicolumn{2}{|l|}{ Moderate } \\
\hline Baseball/softball & 2 \\
\hline Biking & 4 \\
\hline Hiking & 3 \\
\hline Modest hiking & 4 \\
\hline Motorcycling $\ddagger$ & 3 \\
\hline Jogging & 3 \\
\hline Sailing $\oint$ & 3 \\
\hline Surfing $\S$ & 2 \\
\hline Swimming (laps) $\S$ & 5 \\
\hline Tennis (doubles) & 4 \\
\hline Treadmill/stationary bicycle & 5 \\
\hline Weightlifting (free weights) $\ddagger, \|$ & 1 \\
\hline \multicolumn{2}{|l|}{ Low } \\
\hline Bowling & 5 \\
\hline Brisk walking & 5 \\
\hline Golf & 5 \\
\hline Horseback riding $\ddagger$ & 3 \\
\hline Scuba diving $\oint$ & 0 \\
\hline Skating $₫$ & 5 \\
\hline Snorkeling $\S$ & 5 \\
\hline Weights (nonfree weights) & 4 \\
\hline
\end{tabular}

*Recreational sports are categorized according to high, moderate, and low levels of exercise and graded on a relative scale (from 0 to 5 ) for eligibility, with 0 to 1 indicating generally not advised or strongly discouraged; 4 to 5 , probably permitted; and 2 to 3 , intermediate and to be assessed clinically on an individual basis. The designations of high, moderate, and low levels of exercise are equivalent to an estimated $>6,4$ to 6 , and $<4$ metabolic equivalents, respectively. $\dagger$ Assumes absence of laboratory DNA genotyping data; therefore, limited to clinical diagnosis. $¥$ These sports involve the potential for traumatic injury, which should be taken into consideration for individuals with a risk for impaired consciousness. §The possibility of impaired consciousness occurring during water-related activities should be taken into account with respect to the individual patient's clinical profile. \|Recommendations generally differ from those for weighttraining machines (nonfree weights), based largely on the potential risks of traumatic injury associated with episodes of impaired consciousness during bench-press maneuvers; otherwise, the physiologic effects of all weight-training activities are regarded as similar with respect to the present recommendations. $\lceil$ Individual sporting activity not associated with the team sport of ice hockey. Adapted with permission from Maron et al. ${ }^{87}$

2. Ventricular rate control in patients with $\mathrm{HCM}$ with $\mathrm{AF}$ is indicated for rapid ventricular rates and can require high doses of beta antagonists and nondihydropyridine calcium channel blockers. ${ }^{170,172}$ (Level of Evidence: $C$ ) 


\section{Class IIa}

1. Disopyramide (with ventricular rate-controlling agents) and amiodarone are reasonable antiarrhythmic agents for $\mathrm{AF}$ in patients with HCM. ${ }^{170,174}$ (Level of Evidence: B)

2. Radiofrequency ablation for AF can be beneficial in patients with HCM who have refractory symptoms or who are unable to take antiarrhythmic drugs. ${ }^{175-179}$ (Level of Evidence: B)

3. Maze procedure with closure of left atrial appendage is reasonable in patients with HCM with a history of AF, either during septal myectomy or as an isolated procedure in selected patients. (Level of Evidence: $C$ )

\section{Class IIb}

1. Sotalol, dofetilide, and dronedarone might be considered alternative antiarrhythmic agents in patients with HCM, especially in those with an ICD, but clinical experience is limited. (Level of Evidence: $C$ )

\subsection{Pregnancy/Delivery—Recommendations}

\section{Class I}

1. In women with HCM who are asymptomatic or whose symptoms are controlled with beta-blocking drugs, the drugs should be continued during pregnancy, but increased surveillance for fetal bradycardia or other complications is warranted. ${ }^{43,44,181}$ (Level of Evidence: $C$ )

2. For patients (mother or father) with HCM, genetic counseling is indicated before planned conception. (Level of Evidence: $C$ )

3. In women with HCM and resting or provocable LVOT obstruction greater than or equal to $50 \mathrm{~mm} \mathrm{Hg}$ and/or cardiac symptoms not controlled by medical therapy alone, pregnancy is associated with increased risk, and these patients should be referred to a highrisk obstetrician. (Level of Evidence: $C$ )

4. The diagnosis of HCM among asymptomatic women is not considered a contraindication for pregnancy, but patients should be carefully evaluated in regard to the risk of pregnancy. (Level of Evidence: $C$ )

\section{Class IIa}

1. For women with HCM whose symptoms are controlled (mild to moderate), pregnancy is reasonable, but expert maternal/fetal medical specialist care, including cardiovascular and prenatal monitoring, is advised. (Level of Evidence: $C$ )

\section{Class III: Harm}

1. For women with advanced heart failure symptoms and HCM, pregnancy is associated with excess morbidity/mortality. (Level of Evidence: $C$ )

\section{PREVALENCE/NOMENCLATURE/ DIFFERENTIAL DIAGNOSIS}

\subsection{Prevalence}

$\mathrm{HCM}$ is a common genetic cardiovascular disease. In addition, HCM is a global disease, ${ }^{182}$ with epidemiological studies from several parts of the world ${ }^{183}$ reporting a similar prevalence of LV hypertrophy, the quintessential phenotype of $\mathrm{HCM}$, to be about $0.2 \%$ (ie, 1:500) in the general population, which is equivalent to at least 600,000 people affected in the United States. ${ }^{184}$

\subsubsection{Clinical Definition and Differential Diagnosis}

HCM is the preferred nomenclature to describe this disease, ${ }^{185}$ although confusion over the names used to characterize this entity has arisen over the years in part because one third of patients have no obstruction either at rest or with physiologic provocation. ${ }^{67}$ The generally accepted definition of HCM is a disease state characterized by unexplained LV hypertrophy associated with nondilated ventricular chambers in the absence of another cardiac or systemic disease that itself would be capable of producing the magnitude of hypertrophy evident in a given patient, ${ }^{32,38,184-187}$ with the caveat that patients who are genotype positive may be phenotypically negative without overt hypertrophy. ${ }^{188,189}$ Clinically, HCM is usually recognized by a maximal $\mathrm{LV}$ wall thickness $\geq 15 \mathrm{~mm}$. In the case of children, increased LV wall thickness is defined as wall thickness $\geq 2$ standard deviations above the mean ( $\mathrm{z}$ score $\geq 2$ ) for age, sex, or body size. However, it should be underscored that in principle, any degree of wall thickness is compatible with the presence of the HCM genetic substrate. Furthermore, although a myriad of patterns and distribution of LV hypertrophy (including diffuse and marked) have been reported in $\mathrm{HCM},{ }^{37,76,190}$ about one third of patients have largely segmental wall thickening involving only a small portion of the left ventricle, and indeed, such patients with HCM usually have normal calculated LV mass. ${ }^{76}$

Differential diagnosis of HCM and other cardiac conditions (with LV hypertrophy) may arise, most commonly with hypertensive heart disease and the physiologic remodeling associated with athletic training ("athlete's heart"), ${ }^{191-195}$ usually when maximum wall thickness is in the modest range of 13 to $15 \mathrm{~mm}$.

These important distinctions are often resolved by noninvasive markers, including sarcomeric mutations or family history of HCM, LV cavity dimension, diastolic function, pattern of LV hypertrophy, or short deconditioning periods. ${ }^{191-195}$

It is evident that metabolic or infiltrative storage disorders with LV hypertrophy in babies, older children, and young adults can mimic clinically diagnosed HCM (attributable to sarcomeric protein mutations), for example, conditions such as mitochondrial disease, ${ }^{196,197}$ Fabry disease, ${ }^{198}$ or storage diseases caused by mutations in the genes encoding the $\gamma$-2-regulatory subunit of the adenosine monophosphate (AMP)-activated protein kinase (PRKAG2) or the X-linked lysosome-associated membrane protein gene (LAMP2; Danon disease). ${ }^{4,199-201}$ Use of the term HCM is not appropriate to describe these and other patients with LV hypertrophy that occurs in the context of a multisystem disorder $^{202-206}$ (Figure 2). In addition, differential diagnosis 


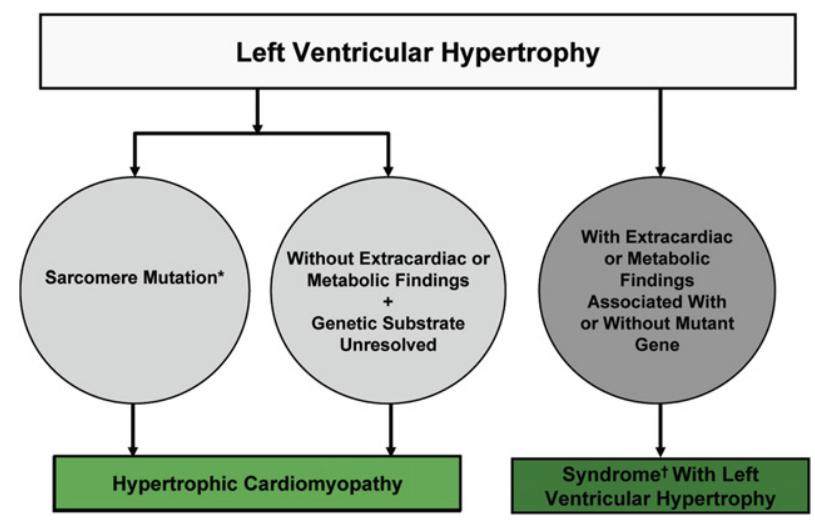

FIGURE 2. Summary of the nomenclature that distinguishes HCM from other genetic diseases associated with LV hypertrophy. *At this time the overwhelming evidence links the clinical diagnosis of HCM with a variety of genes encoding protein components of the cardiac sarcomere. However, it is possible that in the future other nonsarcomeric (but also nonmetabolic) genes may prove to cause HCM. †An example is Noonan syndrome with cardiomyopathy. Modified with permission from Maron et al. ${ }^{187}$

of HCM may require distinction from dilated cardiomyopathy when HCM presents in the end stage. ${ }^{49}$

\subsubsection{Impact of Genetics}

On the basis of the genotype-phenotype data available at this time, HCM is regarded here as a disease entity caused by autosomal dominant mutations in genes encoding protein components of the sarcomere and its constituent myofilament elements. ${ }^{43,199,207,208}$ Intergenetic diversity is compounded by considerable intragene heterogeneity, with $>1400$ mutations identified among at least 8 genes. The current weight of evidence supports the view that the vast majority of genes and mutations responsible for clinically diagnosed HCM encode proteins within and associated with the sarcomere, accounting in large measure for those patients described in the voluminous amount of HCM literature published over 50 years. $^{43,199,207,208}$

\subsubsection{HCM Centers}

The writing committee considers it important to emphasize that HCM is a complex disease entity with a broad (and increasing) clinical and genetic spectrum. ${ }^{38}$ Although HCM is one of the most common forms of genetic heart disease and relatively common in the general population, ${ }^{184}$ this disease entity is infrequent in general clinical practice, with most cardiologists responsible for the care of only a few patients with $\mathrm{HCM} .{ }^{209}$ This principle has led to an impetus for establishing clinical programs of excellenceusually within established centers-in which cardiovascular care is focused on the management of HCM (ie, "HCM centers"). ${ }^{209,210}$

\section{CLINICAL COURSE AND NATURAL HISTORY, INCLUDING ABSENCE OF COMPLICATIONS}

HCM is a heterogeneous cardiac disease with a diverse clinical presentation and course, presenting in all age groups from infancy to the very elderly. ${ }^{32,38,49,51}$ Most affected individuals probably achieve a normal life expectancy without disability or the necessity for major therapeutic interventions. ${ }^{21-214}$ On the other hand, in some patients, HCM is associated with disease complications that may be profound, with the potential to result in disease progression or premature death. $^{32,38,49,51,147,156}$ When the disease does result in significant complications, there are 3 relatively discrete but not mutually exclusive pathways of clinical progression (Figure 3):

1. SCD due to unpredictable ventricular tachyarrhythmias, most commonly in asymptomatic patients $<35$ years of age $^{50,144,147,150,153,154,156,166,168,215}$ (including competitive athletes). ${ }^{166,168}$

2. Heart failure characterized by exertional dyspnea (with or without chest pain) that may be progressive. ${ }^{49}$

3. AF, also associated with various degrees of heart failure $^{172}$ and an increased risk of systemic thromboembolism and stroke.

The natural history of HCM can be altered by a number of therapeutic interventions: ICDs for secondary or primary prevention of sudden death in patients with risk factors ${ }^{150,153,154}$; drugs appropriate to control heart failure symptoms (principally those of exertional dyspnea and chest discomfort), ${ }^{32,38}$ surgical septal myectomy ${ }^{64}$ or alcohol septal ablation ${ }^{60}$ for progressive and drugrefractory heart failure caused by LVOT obstruction; heart transplantation for systolic (or less frequently, intractable diastolic) dysfunction associated with severe unrelenting symptoms ${ }^{49}$; and drug therapy or possibly radiofrequency ablation or surgical maze procedure for AF. ${ }^{175,178,179}$

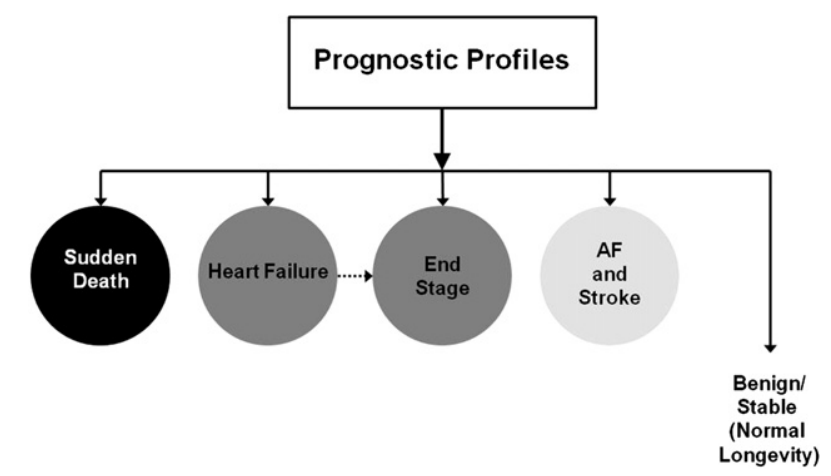

FIGURE 3. Prognosis profiles for HCM and targets for therapy. AF, Atrial fibrillation. Modified with permission from Maron et al. ${ }^{32}$ 


\section{PATHOPHYSIOLOGY}

The pathophysiology of HCM is complex and consists of multiple interrelated abnormalities, including LVOT obstruction, diastolic dysfunction, mitral regurgitation, myocardial ischemia, and arrhythmias. ${ }^{38,40,41}$ It is clinically important to distinguish between the obstructive and nonobstructive forms of HCM because management strategies are largely dependent on the presence or absence of symptoms caused by obstruction.

\subsection{LVOT Obstruction}

The original observations by Brock ${ }^{216}$ and Braunwald et $\mathrm{al}^{3}$ emphasized the functional subvalvular LVOT gradient, which was highly influenced by alterations in the load and contractility of the left ventricle. The clinical significance of the outflow tract gradient has periodically been controversial, ${ }^{217-220}$ but careful studies have shown definitively that true mechanical obstruction to outflow does occur. ${ }^{40,41}$ For HCM, it is the peak instantaneous LV outflow gradient rather than the mean gradient that influences treatment decisions (Table 3 ).

Outflow obstruction usually occurs in HCM by virtue of mitral valve SAM and mitral-septal contact. Muscular obstruction can also be present in the midcavitary region, occasionally because of hypertrophied papillary muscles abutting the septum ${ }^{223}$ or anomalous papillary muscle insertion into the anterior mitral leaflet. ${ }^{224}$

Obstruction to LV outflow is dynamic, varying with loading conditions and contractility of the ventricle. ${ }^{3}$ Increased myocardial contractility, decreased ventricular volume, or decreased afterload increases the degree of subaortic obstruction. Patients may have little or no obstruction of the LVOT at rest but can generate large LVOT gradients under conditions such as exercise, the strain phase of the Valsalva maneuver, or during pharmacologic provocation. ${ }^{40,41}$ There is often large spontaneous variation in the severity of the gradient during day-to-day activities or even with food or alcohol intake 225 ; exacerbation of symptoms during the postprandial period is

TABLE 3. Definitions of dynamic left ventricular outflow tract obstruction

\begin{tabular}{llc}
\hline $\begin{array}{c}\text { Hemodynamic } \\
\text { State }\end{array}$ & \multicolumn{1}{c}{ Conditions } & Outflow gradient* \\
\hline Basal obstruction & Rest & $\geq 30 \mathrm{~mm} \mathrm{Hg} \dagger$ \\
Nonobstructive & Rest & $<30 \mathrm{~mm} \mathrm{Hg}$ \\
& Physiologically provoked & $<30 \mathrm{~mm} \mathrm{Hg}$ \\
Labile obstruction & Rest & $<30 \mathrm{~mm} \mathrm{Hg} \dagger$ \\
& Physiologically provoked & $\geq 30 \mathrm{~mm} \mathrm{Hg} \dagger$ \\
\hline
\end{tabular}

*Either the peak instantaneous continuous wave Doppler gradient or the peak-topeak cardiac catheterization gradient, which are equivalent in hypertrophic cardiomyopathy. ${ }^{221,222} \dagger$ Gradients $\geq 50 \mathrm{~mm} \mathrm{Hg}$ either at rest or with provocation are considered the threshold for septal reduction therapy in severely symptomatic patients. common. Importantly, it has been well established that LVOT obstruction contributes to the debilitating heart failure-related symptoms that may occur in $\mathrm{HCM}^{40,41}$ and is also a major determinant of outcome. ${ }^{51}$

The presence and magnitude of outflow obstruction are usually assessed with 2-dimensional echocardiography and continuous wave Doppler. Combining exercise testing with Doppler echocardiography is useful in identifying the presence of physiologically provocable LVOT obstruction and is particularly helpful in patients with symptoms during routine physical activities who do not manifest outflow obstruction at rest. ${ }^{67}$ Provocation with dobutamine infusion during Doppler echocardiography is no longer recommended as a strategy to induce outflow gradients in HCM.

\section{DIAGNOSIS}

The clinical diagnosis of HCM is conventionally made with cardiac imaging, at present most commonly with 2dimensional echocardiography and increasingly with CMR. Morphologic diagnosis is based on the presence of a hypertrophied and nondilated left ventricle in the absence of another cardiac or systemic disease capable of producing the magnitude of hypertrophy evident in a patient (usually $\geq 15 \mathrm{~mm}$ in an adult or the equivalent relative to body surface area in children). Genetic testing, which is now commercially available, is a powerful strategy for definitive diagnosis of affected genetic status and is currently used most effectively in the identification of affected relatives in families known to have HCM.

$\mathrm{HCM}$ is caused by an autosomal dominant mutation in genes that encode sarcomere proteins or sarcomereassociated proteins. The most vigorous evidence indicates that 8 genes are known to definitively cause HCM: beta myosin heavy chain, myosin binding protein $\mathrm{C}$, troponin $\mathrm{T}$, troponin $\mathrm{I}$, alpha tropomyosin, actin, regulatory light chain, and essential light chain. ${ }^{43,186,187,199,207,208}$ In addition, actinin and myozenin are associated with less definitive evidence for causing HCM. At this time there is inconclusive evidence to support other genes causing $\mathrm{HCM}^{7,9,226,227}$ but research is ongoing. ${ }^{6,228}$ A single mutation in 1 of the 2 alleles (or copies) of a gene is sufficient to cause HCM; however, $5 \%$ of patients with HCM have $\geq 2$ mutations in the same or different genes. $^{23,229}$

Genetic and/or clinical screening of all first-degree family members of patients with HCM is important to identify those with unrecognized disease. On the basis of family history, clinical screening, and pedigree analyses, the pattern of inheritance is ascertained to identify and counsel relatives at risk. ${ }^{14}$ Because familial HCM is a dominant disorder, the risk that an affected patient will transmit disease to each offspring is $50 \%$. When a pathogenic mutation is 
identified in an index patient, the genetic status of each family member can be readily ascertained.

Because unrelated patients with HCM will have different mutations, a comprehensive sequence-based analysis of all HCM genes is necessary to define the pathogenic (eg, disease causing) mutation in an index patient. Experienced clinical laboratories identify the pathogenic HCM mutation in approximately $60 \%$ to $70 \%$ of patients with a positive family history and approximately $10 \%$ to $50 \%$ of patients without a family history. ${ }^{6,15}$ Genetic testing may identify a pathogenic mutation (eg, analysis defines a sequence variant known to cause $\mathrm{HCM}$ ) or a "likely pathogenic" mutation, a DNA variant that was previously unknown as a cause of HCM but has molecular characteristics that are similar to recognized HCM mutations. Genetic testing may also identify "variants of uncertain significance." Studies suggest that the presence of $>1 \mathrm{HCM}$-associated sarcomere mutation is associated with greater severity of disease. ${ }^{23,24,230,231}$

When genetic testing reveals a mutation in the index patient, ascertainment of genetic status in first-degree relatives can be predictive of risk for developing HCM. ${ }^{18}$ Genetic counseling should precede genetic testing of family members. ${ }^{14}$ Relatives with overt HCM will have the same pathogenic HCM mutation as the index patient. Pathogenic mutations may also be identified in other relatives with unknown clinical status. These mutation carriers should be evaluated by physical examination, electrocardiography, and 2-dimensional echocardiography, and if HCM is identified, these individuals should undergo risk stratification (Section 2.13). Mutation carriers without evidence of HCM (genotype positive/phenotype negative) are at considerable risk for future development of HCM, and guidelines to evaluate these individuals are discussed below. ${ }^{188,189}$ Mutation-negative family members and their descendents have no risk for developing HCM and do not need further evaluation. Information from genotyping may help define clinical manifestations and outcomes in specific families with HCM (Table 4). ${ }^{7-9,18,20-22,232}$

\subsection{Cardiovascular Magnetic Resonance}

CMR provides superior spatial resolution with sharp contrast between blood and myocardium, as well as tomographic imaging of the entire LV myocardium and therefore the opportunity to more accurately characterize the presence and distribution of LV hypertrophy in HCM.

Two-dimensional echocardiography has demonstrated the heterogeneity of the hypertrophic phenotype in patients with HCM, particularly with regard to distribution of LV hypertrophy and mechanisms of outflow obstruction. ${ }^{32,38,67,76,190,220,234}$ However, there remain patients in whom the diagnosis of HCM is suspected but the echocardiogram is inconclusive, mostly because of suboptimal imaging from poor acoustic windows or when
TABLE 4. Proposed clinical screening strategies with echocardiography (and 12-lead ECG) for detection of hypertrophic cardiomyopathy with left ventricular hypertrophy in families*

Age $<12$ y

Optional unless

Malignant family history of premature death from HCM or other adverse complications

Patient is a competitive athlete in an intense training program

Onset of symptoms

Other clinical suspicion of early LV hypertrophy

Age 12 to $18-21$ y

Every $12-18$ mo

Age $>18-21$ y

At onset of symptoms or at least every $5 \mathrm{y}$. More frequent intervals are appropriate in families with a malignant clinical course or late-onset HCM

$E C G$, Electrocardiogram; $H C M$, hypertrophic cardiomyopathy; $L V$, left ventricular *When pathologic mutations are not identified or genetic testing is either ambiguous or not performed. $\dagger$ Age range takes into consideration individual variability in achieving physical maturity and in some patients may justify screening at an earlier age. Initial evaluation should occur no later than early pubescence. ${ }^{233}$

hypertrophy is localized to regions of the LV myocardium not well visualized by echocardiography. ${ }^{76}$ In 1 study, $6 \%$ of patients with suspected HCM were identified with increased LV wall thickness (predominantly in the anterolateral wall) by CMR but not by echocardiography. ${ }^{74,76,77}$ In addition, hypertrophy confined to the apex (ie, apical HCM) may be difficult to visualize with echocardiography but is evident with $\mathrm{CMR}^{73,75}$ Furthermore, CMR can more readily detect the presence of apical aneurysms (particularly when small). The latter has potential implications for management with ICDs and/or anticoagulation. The magnitude of LV wall thickening may be underestimated by echocardiography compared with CMR, particularly when this region involves the anterolateral free wall, ${ }^{76,77}$ and therefore CMR may identify high-risk status on the basis of massive hypertrophy. Accurate characterization of the HCM phenotype by CMR may also be useful in management decisions for invasive therapies (septal myectomy or alcohol septal ablation) by more precisely defining the location and magnitude of hypertrophy, as well as characterizing the mitral and submitral apparatus and papillary muscles. ${ }^{235,236}$

The opportunity for contrast-enhanced CMR with LGE to identify areas of myocardial fibrosis in patients with HCM has been the subject of a growing literature. ${ }^{79-81,237,238}$ Although patients with the end-stage phenotype almost universally demonstrate such findings, ${ }^{49}$ patients with HCM with preserved systolic function may also have areas of LGE. ${ }^{79-81}$ Importantly, patients with HCM with evidence of LGE on CMR imaging tend to have more markers of risk of SCD, such as NSVT on Holter monitoring, than patients without LGE. ${ }^{78,80}$ 
It is plausible that areas of LGE (ie, probably largely replacement myocardial fibrosis) could represent a substrate for the generation of malignant ventricular tachyarrhythmias in HCM. Several studies have addressed this issue and have reported either trends in such a direction or significant associations between the presence of LGE (not extent) and cardiac outcome events. ${ }^{81,239}$ However, there is insufficient evidence at this time to support a significant association between the extent of LGE and outcome. Nonetheless, the present data would support a potential role of LGE as an arbitrator in decision making for primary prevention ICDs in patients in whom risk status remains uncertain after assessment of conventional risk markers. ${ }^{79,80}$

\section{CONCOMITANT CORONARY DISEASE}

Chest discomfort is a common symptom in patients with HCM. A key management issue revolves around whether the discomfort may be caused by concomitant epicardial obstructive CAD with inducible ischemia or a consequence of microvascular dysfunction. ${ }^{38}$ Concomitant presence of CAD in patients with HCM identifies a higher risk for adverse outcomes and potential candidates for revascularization. ${ }^{240,241}$

Myocardial bridging of the left anterior descending coronary artery is a frequent component of phenotypically expressed HCM and more common than in other diseases with or without LV hypertrophy. Although it has been suggested that ischemia secondary to bridging could be a potential mechanism for sudden death in $\mathrm{HCM},{ }^{242}$ there is no consistent evidence to support this hypothesis in either adults or children. $^{243,244}$

\section{CHOICE OF IMAGING MODALITY}

\subsection{Invasive Coronary Arteriography}

Invasive coronary arteriography is indicated in patients with HCM when knowledge of these features will importantly influence management strategies. Coronary arteriography should be undertaken before alcohol septal ablation in order to define the anatomy of the septal perforators and exclude obstructive coronary stenoses.

\subsection{Noninvasive CTA}

Although there are no published data specifically assessing the performance characteristics of CTA for documenting the presence or absence of epicardial CAD in HCM, there is no reason to believe that performance of the test should differ in patients with HCM. A high negative predictive value to exclude CAD is particularly consistent in the literature.

\subsection{Single Photon Emission Computed Tomography Myocardial Perfusion Imaging}

Stress SPECT MPI in patients with HCM will often demonstrate reversible or fixed perfusion defects consistent with ischemia or infarction, respectively, even in the absence of epicardial CAD. ${ }^{245,246}$ Several lines of evidence support that these defects, even in the absence of symptoms, represent true flow abnormalities and possibly "silent" ischemia. ${ }^{247}$

Fixed defects may also be seen with SPECT MPI, a finding consistent with infarction. These patients will often have the "end-stage" clinical phenotype with reduced $\mathrm{EF}^{245}$ and likely correspond to patients who demonstrate LGE in CMR studies. ${ }^{49}$

\subsection{Positron Emission Tomography}

PET imaging has been used in patients with HCM to study myocardial blood flow, as well as myocardial metabolism. In patients with HCM with normal coronary arteries, myocardial perfusion PET studies have shown that although resting myocardial blood flow may be similar to normal control subjects, the augmentation of blood flow with vasodilation, for example, dipyridamole, may be significantly blunted. ${ }^{248-251}$ However, the quantitative PET techniques used in these studies are not part of routine clinical practice, and the management implications of identifying abnormalities in flow reserve are unresolved.

\subsection{Stress Echocardiography}

There are no published studies addressing the performance characteristics of stress echocardiography to detect or exclude CAD in patients with HCM. Patients with HCM have heterogeneous wall-thickness patterns, and wall motion at rest may appear abnormal in regions of hypertrophied myocardium. Therefore, stress echocardiography to detect or rule out CAD may be unreliable in HCM but may be useful to document the presence or magnitude of outflow tract obstruction generated by exercise ${ }^{67}$ (Section 5.1).

\section{MANAGEMENT OF HCM}

Treatment of patients with HCM requires a thorough understanding of the complex, diverse pathophysiology and natural history and must be individualized to the patient, but the general approach of the writing committee is outlined in Figure 4.

\subsection{Asymptomatic Patients}

A large proportion of patients presenting with $\mathrm{HCM}$ are asymptomatic, and most will achieve a normal life expectancy. ${ }^{213,252,253}$ It is essential to educate these patients and their families about the disease process, including 


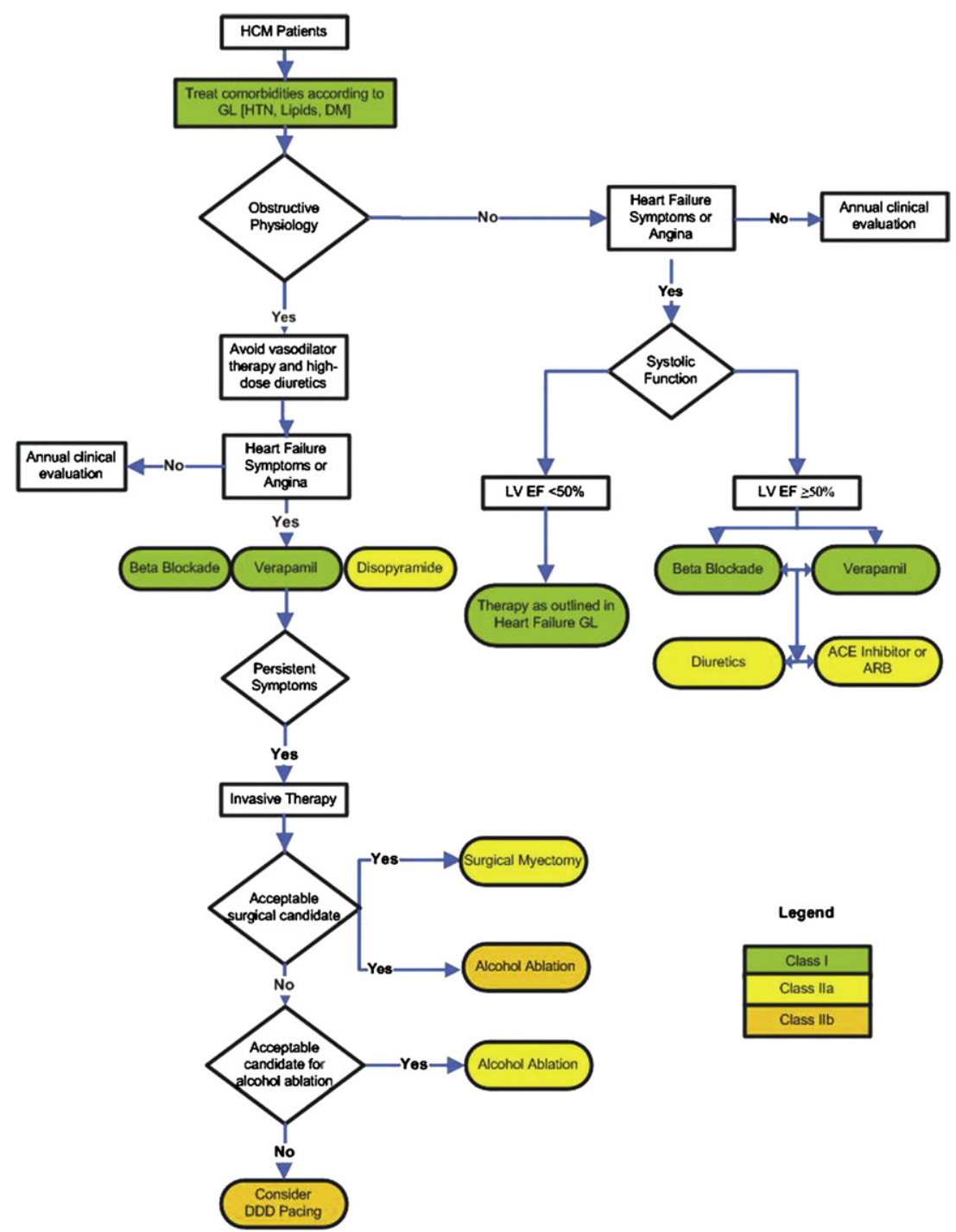

FIGURE 4. Treatment algorithm. $A C E$, Angiotensin-converting enzyme; $A R B$, angiotensin receptor blocker; $D M$, diabetes mellitus; $E F$, ejection fraction; $G L$, guidelines; $H C M$, hypertrophic cardiomyopathy; $H T N$, hypertension; $L V$, left ventricular.

screening of first-degree relatives and avoiding particularly strenuous activity or competitive athletics. ${ }^{88}$ Risk stratification for SCD should also be performed in all patients, irrespective of whether symptoms are present. ${ }^{32,38}$

Because concomitant CAD has a significant impact on survival in patients with $\mathrm{HCM},{ }^{240}$ it is recommended that other risk factors that may contribute to atherosclerotic disease be aggressively treated in concordance with existing guidelines (Figure 4). ${ }^{32,86}$

Hydration and avoidance of environmental situations where vasodilatation may occur are important in the asymptomatic patient with resting or provocable LVOT obstruction. High-dose diuretics and vasodilators (for treatment of other diseases such as hypertension) should be avoided, because these may exacerbate the degree of obstruction. ${ }^{3,38}$
Finally, the indication for septal reduction therapy is to improve symptoms that are not relieved by medical therapy and that impair the patient's quality of life, usually consistent with NYHA functional classes III or IV. ${ }^{32,38}$ Thus, septal reduction therapy with either septal myectomy or alcohol septal ablation should not be performed in the asymptomatic patient, regardless of the severity of obstruction. ${ }^{32,38}$

\subsection{Symptomatic Patients}

The major goal of pharmacologic therapy in symptomatic patients with HCM is to alleviate symptoms of exertional dyspnea, palpitations, and chest discomfort, which may reflect pathophysiologic mechanisms such as LVOT obstruction, reduced supply of myocardial oxygen, mitral 
regurgitation, and impaired $\mathrm{LV}$ diastolic relaxation and compliance. $^{32,38,88}$

Beta blockers are the mainstay of pharmacologic therapy and the first-line agents because of their negative inotropic effects $^{260}$ and their ability to attenuate adrenergic-induced tachycardia (Figure 4). The reduction in heart rate also prolongs the diastolic filling period, which may allow for more efficient inactivation of myocardial contractile proteins, thereby improving diastolic filling. ${ }^{255,256}$

In those patients unable to tolerate beta blockers or those with symptoms unresponsive to beta blockers, calcium channel blockers may provide effective symptomatic relief. Verapamil has been the most intensively studied such agent (Figure 4). ${ }^{99,257}$ Possible mechanisms for symptomatic improvement include negative inotropic and rate-lowering effects similar to those of beta blockers. However, the effect of verapamil on diastolic dysfunction is controversial. $^{258-262}$ Diltiazem has also been shown to improve measures of diastolic performance ${ }^{263}$ and to prevent or diminish myocardial ischemia. ${ }^{264}$ Both verapamil and diltiazem should be used cautiously in patients with severe outflow tract obstruction, elevated pulmonary artery wedge pressure, and low systemic blood pressure, because a decrease in blood pressure with treatment may trigger an increase in outflow obstruction and precipitate pulmonary edema. Administration of beta-blocking drugs with either verapamil or diltiazem should also be used with caution because of the potential for high-grade atrioventricular block. Dihydropyridine class calcium channel blockers (eg, nifedipine) should not be used in patients with obstructive physiology because their vasodilatory effects may aggravate outflow obstruction.

In patients with obstructive HCM who remain symptomatic despite the use of beta blockers and calcium channel blockers, alone or in combination, disopyramide may be effective in ameliorating symptoms (Figure 4). ${ }^{6,265}$ Diuretics may be effective for symptomatic relief in patients with pulmonary congestion but should be used judiciously in those with outflow tract obstruction at rest or with provocation.

\subsection{Invasive Therapies}

For severe refractory symptoms that are attributable to LVOT obstruction, invasive therapies can be used to improve quality of life (Figure 4). Surgical approaches have been used for 5 decades ${ }^{52,220}$ so that relief of outflow tract obstruction and symptoms can be achieved with minimal perioperative morbidity or mortality in experienced centers. $^{64,65}$ However, some patients are not optimal surgical candidates (eg, because of comorbidities or advanced age) or have such a strong desire to avoid surgery that alternative therapeutic interventions have been implemented. Alcohol septal ablation, which has been used for the past 17 years, has become the leading strategy in these circumstances. ${ }^{266}$

\subsubsection{Selection of Patients}

It is well recognized that the appropriate selection of patients for individual procedures is an important predictor of outcome. Because the majority of patients with HCM can achieve control of their symptoms with optimal pharmacologic therapy, and in light of the complications inherent with invasive therapies, a core set of clinical, anatomic, and hemodynamic criteria are required before patients are considered candidates for invasive therapies. Specifically, patients must have symptoms attributable to LVOT obstruction that are refractory to optimal pharmacologic therapy. Similarly, it must be demonstrated that the obstruction is caused by apposition of the mitral valve with the hypertrophied septum. ${ }^{52,220}$ Maximal instantaneous gradients of at least $50 \mathrm{~mm} \mathrm{Hg}$ at rest or with physiologic provocation are necessary to produce symptoms amenable to invasive therapies. $^{32}$

Given the duration of experience, documented long-term results, and safety data, surgical septal myectomy is considered the preferred treatment for most patients who meet these criteria (Figure 4). Considerations that favor surgical intervention include younger age, greater septal thickness, and concomitant cardiac disease independently requiring surgical correction (eg, intrinsic mitral valve disease or coronary artery bypass grafting). Additionally, specific abnormalities of the mitral valve and its support apparatus can contribute significantly to the generation of outflow tract obstruction, suggesting the potential value of additional surgical approaches (eg, plication, valvuloplasty, and papillary muscle relocation) and making myectomy more appropriate than alcohol septal ablation in some patients. ${ }^{26,224,267-272}$ Among patients who meet the core selection criteria, factors that influence a decision to proceed with alcohol septal ablation include older or advanced age, significant comorbidity that selectively increases surgical risk, (eg, significant concerns about lung or airway management), and the patient's strong desire to avoid open heart surgery after a thorough discussion of both options.

\subsubsection{Results of Invasive Therapy for the Relief of LVOT Obstruction}

More detailed discussions specific to each type of procedure follow in subsequent sections of this document. Overall, reports suggest that technical success, variably defined, is achieved in $90 \%$ to $95 \%$ of patients who undergo surgical myectomy, ${ }^{273}$ less in septal ablation, and only in the minority of patients studied in trials of pacemaker therapy. ${ }^{132,134,135,274}$ Patients undergoing septal ablation may have hemodynamic and symptomatic improvement comparable to septal myectomy if the area of the SAMseptal contact can be accessed by the first septal perforator and ablated. However, compared with septal myectomy in which the hypertrophied muscle is directly visualized and resected, successful septal ablation is dependent on the 
variable septal artery anatomy, which may not supply the targeted area of the septum in up to $20 \%$ to $25 \%$ of patients. ${ }^{60,275}$

In a nonrandomized retrospective evaluation of patients with $\mathrm{HCM}<65$ years of age, survival free from recurrent symptoms favored myectomy over ablation ( $89 \%$ versus $71 \%, P=.01) .{ }^{60}$ Procedural success is associated with very low mortality $\left(<1 \%\right.$ for myectomy, ${ }^{64,65,276}$ ranging from $0 \%$ to $4 \%$ for ablation), ${ }^{277-279}$ and low nonfatal complication rates (2\% to $3 \%$ in experienced centers). The exception is high-grade atrioventricular block requiring permanent pacemakers following septal ablation (in 10\% to $20 \%$ of patients), an inherent aspect of the septal infarction. ${ }^{279 a-c}$

\subsubsection{Operator Experience}

Operator and institutional experience, including procedural volume, is a key determinant of successful outcomes and lower complication rates for any procedure. For HCM, a disease of substantial heterogeneity and relatively uncommon in general cardiology practice, this is an important issue. As a consensus opinion, the writing committee recommends an operator volume of at least 20 procedures or that the operator work within the context of an HCM program with a cumulative procedural volume of at least 50 procedures. In addition, given the data available from experienced centers, operators and institutions should aim to achieve mortality rates of $<1 \%$ and major complication rates of $<3 \%$, with documented success in both hemodynamic and symptom benefit for their patients. This is best achieved in the context of a systematic program dedicated to the multidisciplinary and longitudinal care of patients with HCM.

\subsubsection{Surgical Therapy}

Transaortic septal myectomy is currently considered the most appropriate treatment for the majority of patients with obstructive HCM and severe symptoms unresponsive to medical therapy (Figure 4). ${ }^{126,273,280-288}$ Surgical results, although vastly improved in recent years, are nevertheless limited to relatively few centers with extensive experience and particular interest in the management of HCM. ${ }^{270,289}$ Both the traditional myectomy (Morrow procedure) with about a $3-\mathrm{cm}$ long resection ${ }^{284}$ or extended myectomy (a resection of about $7 \mathrm{~cm}$ ) are currently used. ${ }^{270,289}$

The transaortic approach remains the primary method of exposure. Virtual abolition of the LV outflow gradient and mitral regurgitation is usually accomplished by muscular resection resulting in physical enlargement of the outflow tract and by interruption of the mitral valve SAM, which is usually responsible for the outflow gradient. ${ }^{297}$

In selected circumstances, some surgeons have also used concomitant mitral valve repair, particularly when the anterior leaflet is elongated. Finally, enlarged or malpositioned papillary muscles can also contribute to residual obstruction. This can be effectively treated by shaving the hypertrophied papillary muscles, incising papillary muscles off the ventricular free wall, and in selected circumstances repositioning one papillary muscle by suture approximation to the adjacent papillary muscle.

\subsubsection{Outcomes}

Early Results. Based on the experience and data assembled from multiple centers worldwide over the last 4 decades, ${ }^{126,273,280,282,283,285,286}$ septal myectomy is established as the most effective and proven approach for reversing the consequences of heart failure by providing amelioration of obstruction (and relief of mitral regurgitation) at rest, with restoration of functional capacity and acceptable quality of life at any age, exceeding that achievable with long-term administration of cardioactive drugs. ${ }^{32,290}$

LV outflow gradient reduction with myectomy results from basal septal thinning with resultant enlargement of the LVOT area (and redirection of forward flow with loss of the drag and Venturi effects on the mitral valve) ${ }^{291}$ and consequently abolition of SAM and mitral-septal contact. ${ }^{289,292,293}$ Mitral regurgitation is also usually eliminated without the need for additional mitral valve surgery. ${ }^{56}$ With myectomy, left atrial size (and possibly long-term risk for $\mathrm{AF}$ ) is reduced ${ }^{65}$ and $\mathrm{LV}$ pressures (and wall stress) are normalized. ${ }^{32,56,64,291,294}$ Thus, obstructive HCM is a surgically and mechanically reversible form of heart failure. In experienced centers, operative risk is now particularly low, in the range of $<1 \%{ }^{290}$

Late Results. Relief of outflow obstruction by septal myectomy may also extend the longevity of patients with HCM. $^{64}$ Although RCTs involving myectomy surgery have not been performed, in a nonrandomized study, myectomy resulted in excellent long-term survival similar to that in the general population. After septal myectomy, long-term actuarial survival was $99 \%, 98 \%$, and $95 \%$ at 1,5 , and 10 years, respectively (when considering HCM-related mortality). This survival rate did not differ from that expected in a matched general US population and was superior to that achieved by patients with obstructed HCM who did not undergo surgical myectomy. ${ }^{64}$ Similarly the rate of SCD or appropriate ICD discharge after myectomy is very low $(<0.9 \%) .{ }^{64,295,296}$ Nonetheless, surgical myectomy does not eliminate the need to assess each patient's risk for SCD and to consider placement of an ICD in those with a significant risk burden.

\subsubsection{Complications}

Complications following myectomy are rare when performed in experienced centers. ${ }^{297}$ The risk of complete heart block is approximately $2 \%$ with myectomy (higher in myectomy patients with preexisting right bundlebranch block), but in myectomy patients who have had previous alcohol septal ablation, risk is much higher (50\% to 
$85 \%){ }^{298}$ Iatrogenic ventricular septal defect occurs in $<1 \%$ of patients.

\subsubsection{Mitral Valve Abnormalities and Other Anatomic Issues}

Abnormalities of the mitral valve and subvalvar apparatus (including anomalous direct anterolateral papillary muscle insertion into anterior mitral leaflet and elongated mitral leaflets) ${ }^{224,299}$ can be identified preoperatively with TTE or intraoperative TEE and can be corrected with modified mitral valve repair or extended myectomy techniques without the need for mitral valve replacement.

\subsubsection{Alcohol Septal Ablation}

First reported in 1995, ${ }^{266}$ alcohol septal ablation uses transcoronary administration of absolute ethanol via a percutaneous approach to induce a localized infarction of the basal septum at the point of contact of the anterior mitral valve leaflet, thereby reducing outflow tract gradient and associated mitral regurgitation and simulating the results of surgical myectomy. Developed as an alternative to surgical septal myectomy, the technique is particularly useful when surgery is contraindicated and in patients who are considered poor surgical candidates. ${ }^{129}$ Since its development, alcohol septal ablation has been performed successfully in a large number of patients. ${ }^{62}$

Contrast angiography of the septal perforator through the balloon central lumen with simultaneous echocardiographic guidance $^{300,301}$ confirms delivery to only the target myocardium. About 1 to $3 \mathrm{~mL}$ of alcohol is infused in controlled fashion. ${ }^{59,302-304}$ It is important that the balloon be inflated and that a contrast injection also show that there is no extravasation of dye into the distal left anterior descending coronary artery. Contrast enhancement of other regions (papillary muscles, free wall) indicates collateral circulation from the septal perforator artery, and alcohol should not be infused. A decrease in resting and provocable gradients usually occurs immediately after the procedure (because of stunning), and remodeling can result in continued or variable gradient reduction over the first 3 months after the procedure.

\subsubsection{Selection of Patients}

Alcohol septal ablation has the potential for greater patient satisfaction because of the absence of a surgical incision and general anesthesia, less overall discomfort, and a much shorter recovery time. The benefit of alcohol septal ablation in patients of advanced age is similar to that in other patients. ${ }^{127,305}$ Because the postoperative risks and complications of cardiac surgery increase with age, ablation may offer a selective advantage in older patients, in whom operative risk may be increased because of comorbidities. Alcohol septal ablation is not indicated in children.
On the other hand, longer-term follow-up data are available for septal myectomy than for septal ablation, a consideration relevant to the selection of patients for either septal reduction therapy. The likelihood of implantation of a permanent pacemaker is 4- to 5-fold higher after septal ablation than after septal myectomy. Furthermore, patients with massive septal thickness approaching or exceeding $30 \mathrm{~mm}$ may experience little or no benefit from septal ablation. The surgeon can tailor the myectomy under direct visualization to address specific anatomic abnormalities of the LVOT or mitral valve apparatus, whereas alcohol septal ablation indirectly (and is restricted to) targets the distribution of the septal perforator artery.

Septal myectomy is the preferred treatment option for most severely symptomatic patients with obstructive HCM, especially in younger, healthy adults, whereas septal ablation is preferred in patients for whom surgery is contraindicated or considered high risk (particularly the elderly) (Figure 4). Data comparing alcohol septal ablation with septal myectomy are inadequate to fully inform clinical decision making in certain cases. For such patients, the principle of patient autonomy dictates that it is appropriate for the informed patient to choose between the 2 procedures.

\subsubsection{Results}

Necrosis of the basal ventricular septum ${ }^{306}$ produces an immediate fall in gradient from decreased septal contraction in $>90 \%$ of patients. ${ }^{66,279,307-309}$ This effect is followed by LV remodeling over 6 to 12 months, a process that includes scar retraction and resultant widening of the outflow tract, associated with further reduction in gradient and degree of mitral regurgitation, regression of hypertrophy, and improvement in diastolic function. ${ }^{63,279,310-312}$ The beneficial results of alcohol septal ablation have been reported to almost 5 years after the procedure with improved functional and angina classes, exercise capacity, and quality of life. ${ }^{62,279,313-316}$ However, hemodynamic and symptomatic success is dependent on the ability to cannulate and ablate a septal perforator artery that supplies the area of the SAM-septal contact.

Although RCTs comparing surgical myectomy with alcohol septal ablation have not been conducted and are highly unlikely in the future, meta-analyses have noted similar hemodynamic and functional improvement over 3 to 5 years when examining the cumulative average of outcomes. $^{317-319}$ What the meta-analyses do not report are a subset of patients in whom alcohol septal ablation is unreliable because of the inability to ablate the area of the SAM-septal contact. ${ }^{320}$ Older patients, especially those considered to be at high surgical risk, may be well served by alcohol septal ablation, whereas younger patients may benefit most from surgical myectomy. ${ }^{60,129}$ Despite age 
differences in treatment allocation, with septal ablation patients on average approximately 10 years older in clinical practice, ${ }^{317,318}$ the 4 -year survival rate is similar for the 2 procedures. ${ }^{60,128}$ Most studies that have compared surgical myectomy and alcohol septal ablation have involved a large single-center experience in which treatment assignment was not randomized.

\subsubsection{Complications}

In approximately half of patients undergoing alcohol septal ablation, temporary complete atrioventricular block occurs during the procedure. ${ }^{321-323}$ Persistent complete heart block prompting implantation of a permanent pacemaker occurs in $10 \%$ to $20 \%$ of patients based on the available data. $^{36}$ Approximately 5\% of patients have sustained ventricular tachyarrhythmias during hospitalization. The inhospital mortality rate is up to $2 \% .^{60,62,129,318}$ Because of the potential for creating a ventricular septal defect, septal ablation should not be performed if the target septal thickness is $\leq 15 \mathrm{~mm}$.

Alcohol septal ablation is a therapeutic alternative to surgical myectomy for selected patients and produces a transmural infarction of ventricular septum occupying on average $10 \%$ of the overall LV wall. ${ }^{144,275,324}$ There has been concern that the potential ventricular arrhythmogenicity of the scar created by septal ablation might augment risk in the HCM population. Several studies have documented the occurrence of sustained ventricular arrhythmias ${ }^{301,314,325-331}$ and SCD following septal ablation $^{296}$ in about $3 \%$ to $10 \%$ of patients both with or without risk factors for SCD. Patients with HCM considered to carry sufficient risk to warrant ICD placement have an annual incidence of appropriate interventions for VT/ventricular fibrillation of $3 \%$ to $10 \% .^{150,328,332}$ It is uncertain how common such events are attributable to the procedure or alternatively to the underlying disease, but the incidence of sustained ventricular arrhythmias after myectomy is extremely low $(0.2 \%$ to $0.9 \%$ per year). ${ }^{64,295,296}$

Meta-analyses have indicated no difference between septal ablation and myectomy in the medium-term incidence of SCD or all-cause mortality. ${ }^{317,333}$ Although no definitive evidence is available that the ablation scar as such increases (or does not increase) long-term risk for SCD in absolute terms in this patient population, resolution will require greatly extended follow-up studies in larger patient cohorts. $^{144,325}$

\subsubsection{DDD Pacing}

Implantation of a dual-chamber pacemaker was proposed as an alternative treatment for patients with severe symptomatic obstructive HCM. ${ }^{335-337}$ However, there have been 3 randomized crossover trials showing that although symptomatic improvement was reported by the majority of patients following continuous DDD pacing, a similar frequency of improvement was reported by patients during the AAI mode (control mode without pacing). These findings suggest a placebo effect responsible for the perceived improvement in symptoms. ${ }^{136,137,338}$ However, there is some evidence that patients $>65$ years of age may be a subgroup who achieve the greatest benefit. ${ }^{136}$ There are no data that dual-chamber pacing either reduces the risk of SCD in patients with HCM, alters the underlying progression of disease, or is of benefit to patients with nonobstructive HCM. $^{136,335,339}$ A trial of dual-chamber pacing may be considered for symptomatic patients with obstruction in whom an ICD has already been implanted for high-risk status.

\subsubsection{Systolic Dysfunction}

Standard heart failure therapies should be implemented in patients with $\mathrm{HCM}$ when $\mathrm{EF}$ is $\leq 50 \%$. Patients with HCM were not included in the primary prevention ICD trials for patients with heart failure due to CAD or dilated cardiomyopathy (and reduced EF). Prophylactic ICD implantation is nevertheless the generally accepted clinical practice for HCM patients with systolic dysfunction.

\subsection{Prevention of SCD}

A minority of clinically recognized patients with HCM are judged to be at increased risk for SCD, with a rate of about $1 \%$ per year. ${ }^{143-146,148,150}$ ICDs offer the only effective means of preventing SCD and prolonging life in patients with HCM. ${ }^{150}$ Selection of patients who are appropriate for implantation for primary as opposed to secondary prevention can be a difficult clinical decision owing to the individuality of each patient and family, variable definitions for risk markers, sparse clinical data, the relative infrequency of both HCM and SCD in most clinical practices, and the cumulative morbidity of living with an ICD.

\subsubsection{Established Risk Markers}

\subsubsection{Prior Personal History of Ventricular Fibrillation, $S C D$, or Sustained VT}

As expected, patients with HCM who have experienced SCD or sustained VT represent the highest risk for subsequent arrhythmogenic events. The annualized rate of subsequent events is approximately $10 \%$ per year, although it has been shown that individuals may have no recurrent events or may have decades-long arrhythmia-free intervals between episodes. ${ }^{145,146,148,150,340}$

\subsubsection{Family History of $S C D$}

It has been recognized that SCD events can cluster in families. Notably, some studies have not demonstrated an independent link between family history of SCD and risk for individual patients on multivariate analysis, ${ }^{147,149,155}$ whereas others have suggested that family history is an independent predictor. ${ }^{155}$ These differences may be 
explained in part by the relative infrequency of events but also likely reflect variability in the definition of a family history of SCD.

\subsubsection{Syncope}

Syncope represents a complex symptom with a multifactorial etiology that requires a careful clinical history before it can be considered a potential marker for SCD. ${ }^{147,152}$ In one analysis, syncope that was unexplained or thought to be consistent with arrhythmia (ie, not neurally mediated) showed a significant independent association with SCD only when the events occurred in the recent past $(<6$ months). ${ }^{152}$

\subsubsection{Nonsustained Ventricular Tachycardia}

Although sustained ventricular arrhythmia is clearly associated with SCD, the data for NSVT are less robust. However, 1 contemporary study showed that NSVT is independently associated with SCD on multivariate analysis ${ }^{30}$ and is more important in younger patients $(<30$ years of age). ${ }^{33}$ Furthermore, exercise-induced NSVT has been found to have independent association with SCD. ${ }^{341}$ NSVT probably should not be considered in a simply binary manner (ie, as either positive or negative), and there may be some value in long-term ambulatory monitoring when NSVT is discovered on the screening 24-hour assessment.

\subsubsection{Maximum LV Wall Thickness}

The relationship between severity of LV hypertrophy and SCD has been investigated in several studies predicated on the concept that the more severe the disease expression, the more likely the individual patient is to experience adverse events. Most, but not all, ${ }^{156,342}$ studies have shown at least a univariate association between maximum wall thickness and SCD, ${ }^{148,342,343}$ whereas other large studies have shown that when magnitude of hypertrophy is $\geq 30$ $\mathrm{mm}$, there is an independent association with SCD. ${ }^{147,152,158}$

\subsubsection{Abnormal Blood Pressure Response During Exer- cise}

For up to a third of patients with HCM, there is an inappropriate systemic systolic blood pressure response during exercise testing (defined as either a failure to increase by at least $20 \mathrm{~mm} \mathrm{Hg}$ or a drop of at least $20 \mathrm{~mm} \mathrm{Hg}$ during effort). ${ }^{70,71}$ Two studies have shown a univariate association between this finding and subsequent SCD. ${ }^{30,71,147,149}$

\subsubsection{Other Potential SCD Risk Modifiers}

\subsubsection{LVOT Obstruction}

Although some studies have not found a significant association between LVOT obstruction and SCD,${ }^{51,158,212}$ other studies have found higher rates of SCD among patients with resting gradients $\geq 30 \mathrm{~mm} \mathrm{Hg} \mathrm{Hg}^{30,149}$ and that the risk is positively correlated with severity of LVOT obstruction. ${ }^{30}$ Conversely, relief of outflow tract obstruction through surgical myectomy is associated with very low rates of $\mathrm{SCD}^{64,307}$ A limitation to using LVOT obstruction as an independent risk marker is that the obstruction in HCM is dynamic and highly variable. ${ }^{225,344}$

\subsubsection{LGE on CMR Imaging}

There has been considerable interest in promoting LGE on CMR imaging as a potential SCD risk marker in HCM. Because LGE is believed to represent myocardial fibrosis or scarring, it has been hypothesized that LGE may represent myocardium prone to ventricular tachyarrhythmia. ${ }^{82}$ Indeed, LGE has been associated with NSVT and ventricular ectopy but has not been associated with clinical SCD events or ICD discharge in published studies. ${ }^{78,79,82}$ More recent studies have shown a relationship between LGE and SCD and heart failure, but with low positive predictive accuracy. ${ }^{80,81}$

\subsubsection{LV Apical Aneurysm}

A subset of patients with HCM (prevalence about 2\%) develop a thin-walled LV apical aneurysm associated with regional scarring ${ }^{75}$ and more adverse clinical events during follow-up, including progressive heart failure and evolution into the end-stage phase, as well as SCD. Although data on LV aneurysms in HCM are limited, this abnormality may warrant consideration in SCD riskassessment strategies.

\subsubsection{Genetic Mutations}

SCD may cluster in certain families with HCM, and the possibility that specific sarcomere mutations may confer SCD risk has been hypothesized. Indeed, several early studies of HCM pedigrees implicated certain mutations as "malignant." 20,227,345,346 However, subsequent studies of less selected consecutive patients with HCM found that it was problematic to infer likelihood of SCD events on the basis of the proposed mutations, because in some instances the rate of adverse events (and prevalence of associated SCD risk markers) was lower in patients with "malignant" mutations than it was in those with mutations believed to be "benign., ",347-349 The data from unselected consecutive outpatients suggest that most mutations are "novel" and limited to particular families ("private" mutations). Therefore, routine mutational screening would appear to be of little prognostic value in HCM.

\subsubsection{Utility of SCD Risk Markers in Clinical Practice}

Other than cardiac arrest, each of the HCM risk factors has low positive predictive value (approximately $10 \%$ to $20 \%)$ and modestly high negative predictive value $(85 \%$ 
to $95 \%$ ). Multiple risk markers in individual patients would intuitively suggest greater risk for $\mathrm{SCD}$; however, the vast majority of patients with $\geq 1$ risk marker will not experience SCD, and simple arithmetic summing of risk markers is not precise because of the uncertainty implicit in assigning a relative weight to any individual risk factor. ${ }^{147,156,350}$ Notably, in the international HCM-ICD registry, ${ }^{150}$ the number of risk factors did not correlate with the rate of subsequent appropriate ICD discharges among presumably high-risk patients selected for ICD placement. These data suggest that the presence of a single risk marker may be sufficient to warrant ICD placement in many patients, but these decisions need to be individualized with respect to age, the strength of the risk factor, and the risk-benefit of lifelong ICD therapy. ${ }^{150,351}$

\subsection{ICD Therapy in HCM}

Although the overall rate of SCD in HCM is approximately $1 \%$ per year, clearly there are individuals at higher risk for whom prophylactic therapy may be indicated. Pharmacologic therapy has not been demonstrated to provide protection from SCD. Conversely, the ICD has proved to be effective in terminating life-threatening ventricular tachyarrhythmia in HCM, altering the natural course of the disease and prolonging life.

The decision for placement of primary prevention ICD in $\mathrm{HCM}$ often involves a large measure of individual clinical judgment, particularly when the evidence for risk is ambiguous. The potential for SCD needs to be discussed with each fully informed HCM patient and family member in the context of their concerns and anxieties and should be balanced against the risks and benefits of proposed prophylactic ICD strategy. Consideration of the patient's age is warranted, particularly because device complications are more likely in children and young adults over the long period of follow-up. ${ }^{150,351}$

There have been 2 reports from an international, multicenter registry of patients with HCM who have undergone ICD placement on the basis of the clinical perception of SCD sufficient to justify device therapy. ${ }^{150,153}$ Among patients who received a device as a result of a prior personal history of cardiac arrest or sustained ventricular arrhythmia (secondary prevention ICD), the annualized rate of subsequent appropriate ICD discharge was $10 \%$ per year. Patients with primary prevention ICDs placed on the basis of 1 or more of the conventional risk markers experienced appropriate ICD therapy at a rate of $4 \%$ per year. ${ }^{150,153}$ The number of risk markers present did not predict subsequent device discharge. ${ }^{150,351}$

\subsubsection{Complications of ICD Therapy in HCM}

It is important to recognize and discuss with patients potential ICD-related complications (both procedural and long term) that occur at a rate of $4 \%$ per year in patients with HCM. ${ }^{351}$ Potential early problems may include pneumothorax, pericardial effusion, pocket hematoma, acute pocket infection, and/or lead dislodgment. Late complications include upper extremity deep venous thrombosis, lead dislodgment, infection, high defibrillation threshold necessitating lead revision, and inappropriate shocks, that is, shocks triggered by supraventricular arrhythmias, sinus tachycardia, lead fractures or dislodgment, oversensing, double counting, and programming malfunctions.

Reported rates of complications include approximately $25 \%$ of patients with HCM who experienced inappropriate ICD discharge; $6 \%$ to $13 \%$ who experienced lead complications (fracture, dislodgment, oversensing); $4 \%$ to $5 \%$ who developed a device-related infection; and approximately $2 \%$ to $3 \%$ who experienced bleeding or thrombosis complications. ${ }^{150,351}$ The rate of inappropriate shocks and lead fractures appears to be higher in children than in adults, largely because their activity level and body growth places continual strain on the leads, which are the weakest link in the system. ${ }^{143}$ ICD leads fail at a rate of $0.5 \%$ to $1 \%$ per year, although there are data showing that failure rates are increased in younger populations. ${ }^{160}$ This issue is of particular concern, given the long periods that young patients will have prophylactically implanted devices.

Industry-related ICD problems have affected patients with HCM. Prominent recalls have included defective generators leading to several deaths ${ }^{352}$ and small-diameter high-voltage leads prone to fracture. ${ }^{160,353}$ The implant procedure has been largely free of significant risk, without reported deaths, although selected patients with extreme hypertrophy or who have received amiodarone may require high-energy output generators or epicardial lead systems. ${ }^{354}$

In patients with LVOT obstruction in whom ICDs are indicated, dual-chamber pacing may have the potential to reduce gradient and symptoms (Section 2.10). In general, the younger the patient, the more appropriate it is for singlechamber devices to be used to decrease the amount of hardware in the venous system.

\subsection{Participation in Competitive or Recreational Sports and Physical Activity}

A number of large cohort studies from the United States indicate that HCM is the most common cardiovascular cause of SCD in young athletes, accounting for about one third of these events. ${ }^{166-168,355}$ The American College of Cardiology Bethesda Conference No. 36, ${ }^{163,339}$ as well as the European Society of Cardiology guidelines ${ }^{164,356}$ indicate that risk for SCD is increased during intense competitive sports and also suggest that the removal of these individuals from the athletic arena can diminish 
their risk. This principle is the basis for disqualification of athletes with HCM from sanctioned high school and college sports. ${ }^{163,356}$ It should be underscored that these consensus recommendations for competitive athletes are independent of those for noncompetitive, informal recreational sporting activities. ${ }^{87}$

General recommendations for recreational exercise in patients with HCM should be tailored to the individual's desires and abilities; however, certain guidelines prevail. For example, aerobic exercise as opposed to isometric exercise is preferable. Patients with HCM should avoid recreational sports in which participation is intense and simulates competitive organized athletics. Also, burst exertion, in which an abrupt increase in heart rate is triggered (eg, sprinting in half-court basketball), is less desirable than swimming laps or cycling. Finally, it is prudent for such patients to avoid physical activity in extreme environmental conditions of heat, cold, or high humidity, with attention paid to maintaining volume status. Detailed recommendations for individual sports appear in Table 2.

\subsection{Atrial Fibrillation}

$\mathrm{AF}$ is an important cause of symptoms, morbidity, and even mortality in patients with HCM. ${ }^{50,172}$ Patients with $\mathrm{HCM}$ are at increased risk of AF compared with agematched cohorts, but AF is seldom seen in patients with $\mathrm{HCM}$ who are $<30$ years of age and becomes more prevalent with age. AF occurring in HCM may not be associated with symptoms or hemodynamic compromise in one third of patients but is poorly tolerated in many others. There is evidence that $\mathrm{AF}$ is an indicator of unfavorable prognosis, including increased risk of HCM-related heart failure, death, and stroke. ${ }^{172,357}$

Therapy for AF includes prevention of thromboembolic stroke and controlling symptoms (Figure 5). The risk of systemic embolization is high in patients with $\mathrm{HCM}$ with $\mathrm{AF}$ but is not related to the severity of symptoms. ${ }^{50,172}$ Occurrence of paroxysmal, persistent, or chronic AF is a strong indication for anticoagulation with a vitamin $\mathrm{K}$ antagonist. ${ }^{170}$ Whether there is a threshold for AF that warrants anticoagulation is unresolved; however, given the high risk of thromboembolism in HCM, even patients with short episodes of AF should be strongly considered for anticoagulation. Aspirin should be reserved for those who cannot or will not take warfarin or other oral anticoagulants, but its efficacy in HCM is unestablished.

Symptom control may be attained with adequate rate control, although many patients will require rhythm control. Rate control is best maintained by beta blockers and calcium channel blockers. High doses of these agents may be required. Digoxin may modestly reduce ventricular rate at rest and to a lesser extent with exertion. Because there is a paucity of data on rhythm control in patients with HCM, evidence from other patient populations is

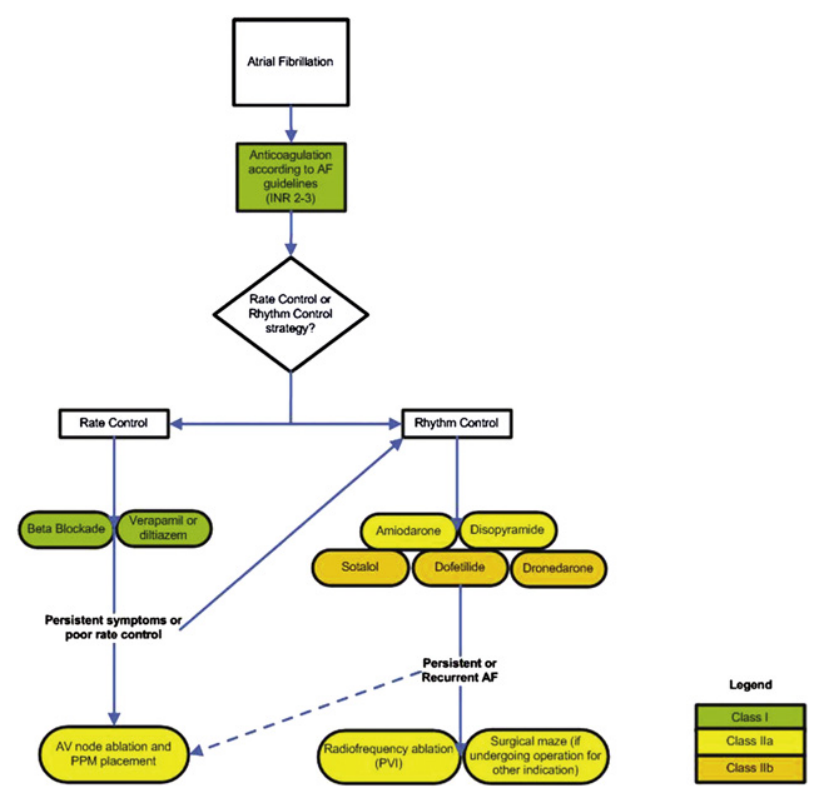

FIGURE 5. Management of AF in HCM. $A F$, Atrial fibrillation; $A V$, atrioventricular; $I N R$, international normalized ratio; $P P M$, permanent pacemaker; $P V I$, pulmonary vein isolation.

extrapolated to HCM. However, whether patients with HCM respond similarly to antiarrhythmic agents is not clear. The "2011 ACCF/AHA/HRS Focused Updates Incorporated Into the ACC/AHA/ESC 2006 Guidelines for the Management of Patients With Atrial Fibrillation" state that disopyramide and amiodarone are potential agents for rhythm control. ${ }^{170}$ The limited published data on amiodarone suggest that it is safe and effective for patients with HCM. ${ }^{358-361}$ Disopyramide has been shown to be safe when prescribed for reduction of LVOT obstruction, but its safety and efficacy in AF are not well established. ${ }^{68,362}$ Dronedarone, an antiarrhythmic agent similar to amiodarone but lacking the iodine moiety and much of the long-term toxicity, has been approved for use in the United States. There are no data regarding the efficacy of dronedarone or the use of flecainide and propafenone in patients with HCM. The management of atrial flutter in HCM is similar to that in other disease states, including the role of radiofrequency ablation.

The long-term benefits of radiofrequency ablation versus antiarrhythmic drugs in patients with HCM remain to be established. It does appear that early success and complication rates are similar between HCM and other forms of heart disease or absence of heart disease. ${ }^{175,178,179,363}$ The surgical maze procedure for AF has shown some limited success ${ }^{364}$; however, whether a prophylactic or therapeutic surgical maze procedure is indicated for patients undergoing other open chest surgical procedures (ie, septal myectomy) is unresolved. 


\section{OCCUPATIONAL CONSIDERATIONS}

In 2002, the US Department of Transportation Federal Motor Carrier Safety Administration published its "Cardiovascular Advisory Panel Guidelines for the Medical Examination of Commercial Motor Vehicle Drivers." The guidelines state that "irrespective of symptoms, a person should not be certified as a [commercial motor vehicle] driver if a firm diagnosis of [HCM] is made ...." ${ }^{365(\mathrm{p} 83) \|}$ Although consideration has subsequently been given to liberalizing this restriction, the guidelines have not yet been revised.

The criteria for the disqualification of aircraft pilots with cardiovascular disease are set by the Federal Aviation Administration. Currently, HCM is regarded as generally incompatible with the highest grade aviation license for commercial pilots, based on the unpredictable risk for impairment in the cockpit attributable to HCM. ${ }^{367}$

\section{STAFF}

\section{American College of Cardiology Foundation}

David R. Holmes, Jr, MD, FACC, President

John C. Lewin, MD, Chief Executive Officer

Janet Wright, MD, FACC, Senior Vice President, Science and Quality

Charlene May, Senior Director, Science and Clinical Policy

\section{American College of Cardiology Foundation/ American Heart Association}

Lisa Bradfield, CAE, Director, Science and Clinical Policy Sue Keller, BSN, MPH, Senior Specialist, Evidence-Based Medicine

Jesse M. Welsh, Specialist, Science and Clinical Policy

\section{American Heart Association}

Ralph L. Sacco, MS, MD, FAAN, FAHA, President

Nancy Brown, Chief Executive Officer

Rose Marie Robertson, MD, FAHA, Chief Science Officer Gayle R. Whitman, PhD, RN, FAHA, FAAN, Senior Vice President, Office of Science Operations

Mark D. Stewart, MPH, Science and Medicine Advisor, Office of Science Operations

Jody Hundley, Production Manager, Scientific Publications, Office of Science Operations

\footnotetext{
"The Federal Motor Carrier Safety Administration defines commercial motor vehicle as a motor vehicle or combination of motor vehicles used in commerce to transport passengers or property if the motor vehicle:

a. has a gross combination weight rating of $\geq 11794 \mathrm{~kg}$ ( $\geq 26001 \mathrm{lb}$ ) inclusive of a towed unit(s) with a gross vehicle weight rating of $\geq 4536 \mathrm{~kg}(10000 \mathrm{lb})$; or

b. has a gross vehicle weight rating of $\geq 11794 \mathrm{~kg}$ ( $\geq 26001 \mathrm{lb}$ ); or

c. is designed to transport $\geq 16$ passengers, including the driver; or

d. is of any size and is used in the transportation of hazardous materials as defined [by the Federal Motor Carrier Safety Administration]. ${ }^{366}$
}

\section{References}

1. ACCF/AHA Task Force on Practice Guidelines. Methodologies and Policies from the ACCF/AHA Task Force on Practice Guidelines. Available at: http:// assets.cardiosource.com/Methodology_Manual_for_ACC_AHA_Writing Committees.pdf and http://circ.ahajournals.org/site/manual/index.xhtml. Accessed July 11, 2011.

1a. Gersh BJ, Maron BJ, Bonow RO, et al. 2011 ACCF/AHA guideline for the diagnosis and treatment of hypertrophic cardiomyopathy: a report of the American College of Cardiology Foundation/American Heart Association Task Force on Practice Guidelines. J Thorac Cardiovasc Surg. 2011;142: e153-203.

2. Teare D. Asymmetrical hypertrophy of the heart in young adults. Br Heart J. 1958;20:1-8

3. Braunwald E, Lambert CT, Rockoff SD, et al. Idiopathic Hypertrophic subaortic stenosis, I: a description of the disease based upon an analysis of 64 patients. Circulation. 1964;30(suppl 4):119.

4. Arad M, Maron BJ, Gorham JM, et al. Glycogen storage diseases presenting as hypertrophic cardiomyopathy. N Engl J Med. 2005;352:362-72.

5. Ho CY, Sweitzer NK, McDonough B, et al. Assessment of diastolic function with Doppler tissue imaging to predict genotype in preclinical hypertrophic cardiomyopathy. Circulation. 2002;105:2992-7.

6. Morita H, Rehm HL, Menesses A, et al. Shared genetic causes of cardiac hypertrophy in children and adults. N Engl J Med. 2008;358:1899-908.

7. Niimura H, Bachinski LL, Sangwatanaroj S, et al. Mutations in the gene for cardiac myosin-binding protein $\mathrm{C}$ and late-onset familial hypertrophic cardiomyopathy. N Engl J Med. 1998;338:1248-57.

8. Van Driest SL, Ackerman MJ, Ommen SR, et al. Prevalence and severity of "benign" mutations in the beta-myosin heavy chain, cardiac troponin $\mathrm{T}$, and alpha-tropomyosin genes in hypertrophic cardiomyopathy. Circulation. 2002; 106:3085-90

9. Van Driest SL, Jaeger MA, Ommen SR, et al. Comprehensive analysis of the beta-myosin heavy chain gene in 389 unrelated patients with hypertrophic cardiomyopathy. J Am Coll Cardiol. 2004;44:602-10.

10. Christiaans I, van Langen IM, Birnie E, et al. Genetic counseling and cardiac care in predictively tested hypertrophic cardiomyopathy mutation carriers: the patients' perspective. Am J Med Genet A. 2009;149A:1444-51.

11. Michie S, French D, Allanson A, et al. Information recall in genetic counselling: a pilot study of its assessment. Patient Educ Couns. 1997;32:93-100.

12. Michie S, Allanson A, Armstrong D, et al. Objectives of genetic counselling: differing views of purchasers, providers and users. $J$ Public Health Med. 1998;20:404-8

13. Offit K, Groeger E, Turner S, et al. The "duty to warn" a patient's family members about hereditary disease risks. JAMA. 2004;292:1469-73.

14. Christiaans I, van Langen IM, Birnie E, et al. Quality of life and psychological distress in hypertrophic cardiomyopathy mutation carriers: a cross-sectional cohort study. Am J Med Genet A. 2009;149A:602-12.

15. Fokstuen S, Lyle R, Munoz A, et al. A DNA resequencing array for pathogenic mutation detection in hypertrophic cardiomyopathy. Hum Mutat. 2008;29: 879-85.

16. Olivotto I, Girolami F, Ackerman MJ, et al. Myofilament protein gene mutation screening and outcome of patients with hypertrophic cardiomyopathy. Mayo Clin Proc. 2008;83:630-8

17. Maron BJ, Niimura H, Casey SA, et al. Development of left ventricular hypertrophy in adults in hypertrophic cardiomyopathy caused by cardiac myosinbinding protein C gene mutations. J Am Coll Cardiol. 2001;38:315-21.

18. Rosenzweig A, Watkins H, Hwang DS, et al. Preclinical diagnosis of familial hypertrophic cardiomyopathy by genetic analysis of blood lymphocytes. $\mathrm{N}$ Engl J Med. 1991;325:1753-60.

19. Spada M, Pagliardini S, Yasuda M, et al. High incidence of later-onset Fabry disease revealed by newborn screening. Am J Hum Genet. 2006;79:31-40.

20. Moolman JC, Corfield VA, Posen B, et al. Sudden death due to troponin T mutations. J Am Coll Cardiol. 1997;29:549-55.

21. Woo A, Rakowski H, Liew JC, et al. Mutations of the beta myosin heavy chain gene in hypertrophic cardiomyopathy: critical functional sites determine prognosis. Heart. 2003;89:1179-85.

22. Ho CY, Lever HM, DeSanctis R, et al. Homozygous mutation in cardiac troponin T: implications for hypertrophic cardiomyopathy. Circulation. 2000;102: 1950-5.

23. Ingles J, Doolan A, Chiu C, et al. Compound and double mutations in patients with hypertrophic cardiomyopathy: implications for genetic testing and counseling. J Med Genet. 2005;42:e59. 
24. Van Driest SL, Vasile VC, Ommen SR, et al. Myosin binding protein C mutations and compound heterozygosity in hypertrophic cardiomyopathy. J Am Coll Cardiol. 2004;44:1903-10.

25. Jeschke B, Uhl K, Weist B, et al. A high risk phenotype of hypertrophic cardiomyopathy associated with a compound genotype of two mutated beta-myosin heavy chain genes. Hum Genet. 1998;102:299-304.

26. Christiaans I, Lekanne dit Deprez RH, van Langen IM, et al. Ventricular fibrillation in MYH7-related hypertrophic cardiomyopathy before onset of ventricular hypertrophy. Heart Rhythm. 2009;6:1366-9.

27. Andersen PS, Havndrup O, Hougs L, et al. Diagnostic yield, interpretation, and clinical utility of mutation screening of sarcomere encoding genes in Danish hypertrophic cardiomyopathy patients and relatives. Hum Mutat. 2009;30:363-70.

28. Christiaans I, Birnie E, van Langen IM, et al. The yield of risk stratification for sudden cardiac death in hypertrophic cardiomyopathy myosin-binding protein C gene mutation carriers: focus on predictive screening. Eur Heart J. 2010;31: $842-8$.

29. Michels M, Soliman OI, Phefferkorn J, et al. Disease penetrance and risk stratification for sudden cardiac death in asymptomatic hypertrophic cardiomyopathy mutation carriers. Eur Heart J. 2009;30:2593-8.

30. Elliott PM, Gimeno JR, Tome MT, et al. Left ventricular outflow tract obstruction and sudden death risk in patients with hypertrophic cardiomyopathy. Eur Heart J. 2006;27:1933-41

31. Maron BJ, Savage DD, Wolfson JK, et al. Prognostic significance of 24 hour ambulatory electrocardiographic monitoring in patients with hypertrophic cardiomyopathy: a prospective study. Am J Cardiol. 1981;48:252-7.

32. Maron BJ, McKenna WJ, Danielson GK, et al. American College of Cardiology/European Society of Cardiology clinical expert consensus document on hypertrophic cardiomyopathy. J Am Coll Cardiol. 2003;42:1687-713.

33. Monserrat L, Elliott PM, Gimeno JR, et al. Non-sustained ventricular tachycardia in hypertrophic cardiomyopathy: an independent marker of sudden death risk in young patients. J Am Coll Cardiol. 2003;42:873-9.

34. Adabag AS, Kuskowski MA, Maron BJ. Determinants for clinical diagnosis of hypertrophic cardiomyopathy. Am J Cardiol. 2006;98:1507-11.

35. Afonso LC, Bernal J, Bax JJ, et al. Echocardiography in hypertrophic cardiomyopathy: the role of conventional and emerging technologies. JACC Cardiovasc Imaging. 2008;1:787-800

36. Fifer MA, Vlahakes GJ. Management of symptoms in hypertrophic cardiomyopathy. Circulation. 2008;117:429-39.

37. Klues HG, Schiffers A, Maron BJ. Phenotypic spectrum and patterns of left ventricular hypertrophy in hypertrophic cardiomyopathy: morphologic observations and significance as assessed by two-dimensional echocardiography in 600 patients. J Am Coll Cardiol. 1995;26:1699-708.

38. Maron BJ. Hypertrophic cardiomyopathy: a systematic review. JAMA. 2002; 287:1308-20.

39. Soor GS, Luk A, Ahn E, et al. Hypertrophic cardiomyopathy: current understanding and treatment objectives. J Clin Pathol. 2009;62:226-35.

40. Wigle ED, Sasson Z, Henderson MA, et al. Hypertrophic cardiomyopathy: the importance of the site and the extent of hypertrophy: a review. Prog Cardiovasc Dis. 1985;28:1-83.

41. Wigle ED, Rakowski H, Kimball BP, et al. Hypertrophic cardiomyopathy: clinical spectrum and treatment. Circulation. 1995;92:1680-92.

42. Binder J, Ommen SR, Gersh BJ, et al. Echocardiography-guided genetic testing in hypertrophic cardiomyopathy: septal morphological features predict the presence of myofilament mutations. Mayo Clin Proc. 2006;81:459-67.

43. Bos JM, Towbin JA, Ackerman MJ. Diagnostic, prognostic, and therapeutic implications of genetic testing for hypertrophic cardiomyopathy. J Am Coll Cardiol. 2009;54:201-11.

44. Hershberger RE, Cowan J, Morales A, et al. Progress with genetic cardiomyopathies: screening, counseling, and testing in dilated, hypertrophic, and arrhythmogenic right ventricular dysplasia/cardiomyopathy. Circ Heart Fail. 2009;2: 253-61.

45. Maron BJ, Seidman JG, Seidman CE. Proposal for contemporary screening strategies in families with hypertrophic cardiomyopathy. J Am Coll Cardiol. 2004;44:2125-32

46. Schwartz ML, Cox GF, Lin AE, et al. Clinical approach to genetic cardiomyopathy in children. Circulation. 1996;94:2021-38.

47. Dimitrow PP, Dubiel JS. Echocardiographic risk factors predisposing to sudden cardiac death in hypertrophic cardiomyopathy. Heart. 2005;91:93-4.

48. Efthimiadis GK, Parcharidou DG, Giannakoulas G, et al. Left ventricular outflow tract obstruction as a risk factor for sudden cardiac death in hypertrophic cardiomyopathy. Am J Cardiol. 2009;104:695-9.
49. Harris KM, Spirito P, Maron MS, et al. Prevalence, clinical profile, and significance of left ventricular remodeling in the end-stage phase of hypertrophic cardiomyopathy. Circulation. 2006;114:216-25.

50. Maron BJ, Olivotto I, Spirito P, et al. Epidemiology of hypertrophic cardiomyopathy-related death: revisited in a large non-referral-based patient population. Circulation. 2000;102:858-64.

51. Maron MS, Olivotto I, Betocchi S, et al. Effect of left ventricular outflow tract obstruction on clinical outcome in hypertrophic cardiomyopathy. $N$ Engl J Med. 2003;348:295-303.

52. Ommen SR, Shah PM, Tajik AJ. Left ventricular outflow tract obstruction in hypertrophic cardiomyopathy: past, present and future. Heart. 2008;94: 1276-81.

53. Sorajja P, Nishimura RA, Gersh BJ, et al. Outcome of mildly symptomatic or asymptomatic obstructive hypertrophic cardiomyopathy: a long-term followup study. J Am Coll Cardiol. 2009;54:234-41.

54. Grigg LE, Wigle ED, Williams WG, et al. Transesophageal Doppler echocardiography in obstructive hypertrophic cardiomyopathy: clarification of pathophysiology and importance in intraoperative decision making. $\mathrm{J} \mathrm{Am} \mathrm{Coll}$ Cardiol. 1992;20:42-52.

55. Marwick TH, Stewart WJ, Lever HM, et al. Benefits of intraoperative echocardiography in the surgical management of hypertrophic cardiomyopathy. $J \mathrm{Am}$ Coll Cardiol. 1992;20:1066-72.

56. Yu EH, Omran AS, Wigle ED, et al. Mitral regurgitation in hypertrophic obstructive cardiomyopathy: relationship to obstruction and relief with myectomy. J Am Coll Cardiol. 2000;36:2219-25.

57. Faber L, Seggewiss H, Welge D, et al. Echo-guided percutaneous septal ablation for symptomatic hypertrophic obstructive cardiomyopathy: 7 years of experience. Eur J Echocardiogr. 2004;5:347-55.

58. Monakier D, Woo A, Puri T, et al. Usefulness of myocardial contrast echocardiographic quantification of risk area for predicting postprocedural complications in patients undergoing septal ethanol ablation for obstructive hypertrophic cardiomyopathy. Am J Cardiol. 2004;94:1515-22.

59. Nagueh SF, Lakkis NM, He ZX, et al. Role of myocardial contrast echocardiography during nonsurgical septal reduction therapy for hypertrophic obstructive cardiomyopathy. J Am Coll Cardiol. 1998;32:225-9.

60. Sorajja P, Valeti U, Nishimura RA, et al. Outcome of alcohol septal ablation for obstructive hypertrophic cardiomyopathy. Circulation. 2008;118:131-9.

61. Carasso S, Woo A, Yang H, et al. Myocardial mechanics explains the time course of benefit for septal ethanol ablation for hypertrophic cardiomyopathy. $J$ Am Soc Echocardiogr. 2008;21:493-9.

62. Fernandes VL, Nielsen C, Nagueh SF, et al. Follow-up of alcohol septal ablation for symptomatic hypertrophic obstructive cardiomyopathy: the Baylor and Medical University of South Carolina experience 1996 to 2007. JACC Cardiovasc Interv. 2008;1:561-70.

63. Jassal DS, Neilan TG, Fifer MA, et al. Sustained improvement in left ventricular diastolic function after alcohol septal ablation for hypertrophic obstructive cardiomyopathy. Eur Heart J. 2006;27:1805-10.

64. Ommen SR, Maron BJ, Olivotto I, et al. Long-term effects of surgical septal myectomy on survival in patients with obstructive hypertrophic cardiomyopathy. J Am Coll Cardiol. 2005;46:470-6.

65. Woo A, Williams WG, Choi R, et al. Clinical and echocardiographic determinants of long-term survival after surgical myectomy in obstructive hypertrophic cardiomyopathy. Circulation. 2005;111:2033-41.

66. Yoerger DM, Picard MH, Palacios IF, et al. Time course of pressure gradient response after first alcohol septal ablation for obstructive hypertrophic cardiomyopathy. Am J Cardiol. 2006;97:1511-4.

67. Maron MS, Olivotto I, Zenovich AG, et al. Hypertrophic cardiomyopathy is predominantly a disease of left ventricular outflow tract obstruction. Circulation. 2006;114:2232-9

68. Sherrid MV, Barac I, McKenna WJ, et al. Multicenter study of the efficacy and safety of disopyramide in obstructive hypertrophic cardiomyopathy. J Am Coll Cardiol. 2005;45:1251-8.

69. Ciampi Q, Betocchi S, Lombardi R, et al. Hemodynamic determinants of exercise-induced abnormal blood pressure response in hypertrophic cardiomyopathy. J Am Coll Cardiol. 2002;40:278-84.

70. Olivotto I, Maron BJ, Montereggi A, et al. Prognostic value of systemic blood pressure response during exercise in a community-based patient population with hypertrophic cardiomyopathy. J Am Coll Cardiol. 1999;33:2044-51.

71. Sadoul N, Prasad K, Elliott PM, et al. Prospective prognostic assessment of blood pressure response during exercise in patients with hypertrophic cardiomyopathy. Circulation. 1997;96:2987-91. 
72. Frenneaux MP, Counihan PJ, Caforio AL, et al. Abnormal blood pressure response during exercise in hypertrophic cardiomyopathy. Circulation. 1990; 82:1995-2002.

73. Moon JC, Fisher NG, McKenna WJ, et al. Detection of apical hypertrophic cardiomyopathy by cardiovascular magnetic resonance in patients with nondiagnostic echocardiography. Heart. 2004;90:645-9.

74. Rickers C, Wilke NM, Jerosch-Herold M, et al. Utility of cardiac magnetic resonance imaging in the diagnosis of hypertrophic cardiomyopathy. Circulation. 2005; 112:855-61

75. Maron MS, Finley JJ, Bos JM, et al. Prevalence, clinical significance, and natural history of left ventricular apical aneurysms in hypertrophic cardiomyopathy. Circulation. 2008;118:1541-9.

76. Maron MS, Maron BJ, Harrigan C, et al. Hypertrophic cardiomyopathy phenotype revisited after 50 years with cardiovascular magnetic resonance. J Am Coll Cardiol. 2009;54:220-8.

77. Maron MS, Lesser JR, Maron BJ. Management implications of massive left ventricular hypertrophy in hypertrophic cardiomyopathy significantly underestimated by echocardiography but identified by cardiovascular magnetic resonance. Am J Cardiol. 2010;105:1842-3.

78. Adabag AS, Maron BJ, Appelbaum E, et al. Occurrence and frequency of arrhythmias in hypertrophic cardiomyopathy in relation to delayed enhancement on cardiovascular magnetic resonance. J Am Coll Cardiol. 2008;51:1369-74.

79. Maron MS, Appelbaum E, Harrigan CJ, et al. Clinical profile and significance of delayed enhancement in hypertrophic cardiomyopathy. Circ Heart Fail. 2008;1:184-91.

80. Rubinshtein R, Glockner JF, Ommen SR, et al. Characteristics and clinical significance of late gadolinium enhancement by contrast-enhanced magnetic resonance imaging in patients with hypertrophic cardiomyopathy. Circ Heart Fail. 2010;3:51-8.

81. O'Hanlon R, Grasso A, Roughton M, et al. Prognostic significance of myocardial fibrosis in hypertrophic cardiomyopathy. J Am Coll Cardiol. 2010;56: 867-74.

82. Moon JC, McKenna WJ, McCrohon JA, et al. Toward clinical risk assessment in hypertrophic cardiomyopathy with gadolinium cardiovascular magnetic resonance. J Am Coll Cardiol. 2003;41:1561-7.

83. Gange CA, Link MS, Maron MS. Utility of cardiovascular magnetic resonance in the diagnosis of Anderson-Fabry disease. Circulation. 2009;120:e96-7.

84. Maceira AM, Joshi J, Prasad SK, et al. Cardiovascular magnetic resonance in cardiac amyloidosis. Circulation. 2005;111:186-93.

85. Moon JC, Sachdev B, Elkington AG, et al. Gadolinium enhanced cardiovascular magnetic resonance in Anderson-Fabry disease: evidence for a disease specific abnormality of the myocardial interstitium. Eur Heart J. 2003;24:2151-5.

86. Redberg RF, Benjamin EJ, Bittner V, et al. ACCF/AHA 2009 performance measures for primary prevention of cardiovascular disease in adults. J Am Coll Cardiol. 2009;54:1364-405.

87. Maron BJ, Chaitman BR, Ackerman MJ, et al. Recommendations for physical activity and recreational sports participation for young patients with genetic cardiovascular diseases. Circulation. 2004;109:2807-16.

88. Spirito P, Seidman CE, McKenna WJ, et al. The management of hypertrophic cardiomyopathy. N Engl J Med. 1997;336:775-85.

89. Adelman AG, Shah PM, Gramiak R, et al. Long-term propranolol therapy in muscular subaortic stenosis. Br Heart J. 1970;32:804-11.

90. Cohen LS, Braunwald E. Amelioration of angina pectoris in idiopathic hypertrophic subaortic stenosis with beta-adrenergic blockade. Circulation. 1967;35: 847-51.

91. Flamm MD, Harrison DC, Hancock EW. Muscular subaortic stenosis: prevention of outflow obstruction with propranolol. Circulation. 1968;38:846-58.

92. Frank MJ, Abdulla AM, Canedo MI, et al. Long-term medical management of hypertrophic obstructive cardiomyopathy. Am J Cardiol. 1978; 42:993-1001

93. Harrison DC, Braunwald E, Glick G, et al. Effects of beta adrenergic blockade on the circulation with particular reference to observations in patients with hypertrophic subaortic stenosis. Circulation. 1964;29:84-98.

94. Stenson RE, Flamm MD Jr, Harrison DC, et al. Hypertrophic subaortic stenosis: clinical and hemodynamic effects of long-term propranolol therapy. Am J Cardiol. 1973;31:763-73.

95. Swanton RH, Brooksby IA, Jenkins BS, et al. Hemodynamic studies of beta blockade in hypertrophic obstructive cardiomyopathy. Eur J Cardiol. 1977;5: 327-41.

96. Wigle ED, Adelman AG, Felderhof $\mathrm{CH}$. Medical and surgical treatment of the cardiomyopathies. Circ Res. 1974;35(suppl II):196-207.
97. Bonow RO, Rosing DR, Bacharach SL, et al. Effects of verapamil on left ventricular systolic function and diastolic filling in patients with hypertrophic cardiomyopathy. Circulation. 1981;64:787-96.

98. Epstein SE, Rosing DR. Verapamil: its potential for causing serious complications in patients with hypertrophic cardiomyopathy. Circulation. 1981;64: 437-41.

99. Rosing DR, Kent KM, Maron BJ, et al. Verapamil therapy: a new approach to the pharmacologic treatment of hypertrophic cardiomyopathy, II: effects on exercise capacity and symptomatic status. Circulation. 1979;60:1208-13.

100. Rosing DR, Kent KM, Borer JS, et al. Verapamil therapy: a new approach to the pharmacologic treatment of hypertrophic cardiomyopathy, I: hemodynamic effects. Circulation. 1979;60:1201-7.

101. Rosing DR, Condit JR, Maron BJ, et al. Verapamil therapy: a new approach to the pharmacologic treatment of hypertrophic cardiomyopathy, III: effects of long-term administration. Am J Cardiol. 1981;48:545-53.

102. Braunwald E, Ebert PA. Hemodynamic alterations in idiopathic hypertrophic subaortic stenosis induced by sympathomimetic drugs. Am J Cardiol. 1962; 10:489-95.

103. Wigle ED, David PR, Labroose CJ, et al. Muscular subaortic stenosis: the interrelation of wall tension, outflow tract "distending pressure" and orifice radius. Am J Cardiol. 1965;15:761-72.

104. Haley JH, Sinak LJ, Tajik AJ, et al. Dynamic left ventricular outflow tract obstruction in acute coronary syndromes: an important cause of new systolic murmur and cardiogenic shock. Mayo Clin Proc. 1999;74:901-6.

105. Kimball BP, Bui S, Wigle ED. Acute dose-response effects of intravenous disopyramide in hypertrophic obstructive cardiomyopathy. Am Heart J. 1993;125: 1691-7.

106. Pollick C, Kimball B, Henderson M, et al. Disopyramide in hypertrophic cardiomyopathy, I: hemodynamic assessment after intravenous administration. Am J Cardiol. 1988;62:1248-51.

107. Pollick C. Disopyramide in hypertrophic cardiomyopathy, II: noninvasive assessment after oral administration. Am J Cardiol. 1988;62:1252-5.

108. Sherrid M, Delia E, Dwyer E. Oral disopyramide therapy for obstructive hypertrophic cardiomyopathy. Am J Cardiol. 1988;62:1085-8.

109. Braunwald E, Bloodwell RD, Goldberg LI, et al. Studies on digitalis, IV: observation in man on the effects of digitalis preparations on the contractility of the non-failing heart and on total vascular resistance. J Clin Invest. 1961; 40:52-9.

110. Braunwald E, Brockenbrough EC, Frye RL. Studies on digitalis, V: comparison of the effects of ouabain on left ventricular dynamics in valvular aortic stenosis and hypertrophic subaortic stenosis. Circulation. 1962;26:166-73.

111. Sonnenblick EH, Williams JF Jr, Glick G, et al. Studies on digitalis, XV: effects of cardiac glycosides on myocardial force-velocity relations in the nonfailing human heart. Circulation. 1966;34:532-9.

112. Bergfeldt L, Schenck-Gustafsson K, Dahlqvist R. Comparative class 1 electrophysiologic and anticholinergic effects of disopyramide and its main metabolite (mono-N-dealkylated disopyramide) in healthy humans. Cardiovasc Drugs Ther. 1992;6:529-37.

113. Birkhead JS, Vaughan Williams EM. Dual effect of disopyramide on atrial and atrioventricular conduction and refractory periods. Br Heart J. 1977;39:657-60.

114. Jensen G, Uhrenholt A. Circulatory effects of intravenous disopyramide in heart failure. J Int Med Res. 1976;4:42-5.

115. Lara M, Oakley GD, Rowbotham D. Potentially dangerous effect of disopyramide on atrioventricular conduction in a patient on digitalis. $\mathrm{Br} \mathrm{Med} \mathrm{J.} \mathrm{1980;}$ 281:198.

116. Morady F, Scheinman MM, Desai J. Disopyramide. Ann Intern Med. 1982;96 337-43.

117. Robertson CE, Miller HC. Extreme tachycardia complicating the use of disopyramide in atrial flutter. Br Heart J. 1980;44:602-3.

118. Elesber A, Nishimura RA, Rihal CS, et al. Utility of isoproterenol to provoke outflow tract gradients in patients with hypertrophic cardiomyopathy. Am J Cardiol. 2008;101:516-20.

119. Krasnow N, Rolett E, Hood WBJ, et al. Reversible obstruction of the ventricular outflow tract. Am J Cardiol. 1963;11:1-7.

120. Pierce GE, Morrow AG, Braunwald E. Idiopathic hypertrophic subaortic stenosis, 3: intraoperative studies of the mechanism of obstruction and its hemodynamic consequences. Circulation. 1964;30(suppl 4):152.

121. Whalen RE, Cohen AI, Sumner RG, et al. Demonstration of the dynamic nature of idiopathic hypertrophic subaortic stenosis. Am J Cardiol. 1963;11:8-17.

122. van der Lee C, Scholzel B, ten Berg JM, et al. Usefulness of clinical, echocardiographic, and procedural characteristics to predict outcome after 
percutaneous transluminal septal myocardial ablation. Am J Cardiol. 2008; 101:1315-20.

123. Firoozi S, Elliott PM, Sharma S, et al. Septal myotomy-myectomy and transcoronary septal alcohol ablation in hypertrophic obstructive cardiomyopathy: a comparison of clinical, haemodynamic and exercise outcomes. Eur Heart J. 2002;23:1617-24.

124. Ralph-Edwards A, Woo A, McCrindle BW, et al. Hypertrophic obstructive cardiomyopathy: comparison of outcomes after myectomy or alcohol ablation adjusted by propensity score. J Thorac Cardiovasc Surg. 2005;129:351-8.

125. Smedira NG, Lytle BW, Lever HM, et al. Current effectiveness and risks of isolated septal myectomy for hypertrophic obstructive cardiomyopathy. Ann Thorac Surg. 2008;85:127-33.

126. Theodoro DA, Danielson GK, Feldt RH, et al. Hypertrophic obstructive cardiomyopathy in pediatric patients: results of surgical treatment. J Thorac Cardiovasc Surg. 1996;112:1589-97.

127. Gietzen FH, Leuner CJ, Obergassel L, et al. Transcoronary ablation of septal hypertrophy for hypertrophic obstructive cardiomyopathy: feasibility, clinical benefit, and short term results in elderly patients. Heart. 2004;90:638-44.

128. Kuhn H, Lawrenz T, Lieder F, et al. Survival after transcoronary ablation of septal hypertrophy in hypertrophic obstructive cardiomyopathy (TASH): a 10 year experience. Clin Res Cardiol. 2008;97:234-43.

129. Kwon DH, Kapadia SR, Tuzcu EM, et al. Long-term outcomes in high-risk symptomatic patients with hypertrophic cardiomyopathy undergoing alcohol septal ablation. JACC Cardiovasc Interv. 2008;1:432-8.

130. Nagueh SF, Ommen SR, Lakkis NM, et al. Comparison of ethanol septal reduction therapy with surgical myectomy for the treatment of hypertrophic obstructive cardiomyopathy. J Am Coll Cardiol. 2001;38:1701-6.

131. Qin JX, Shiota T, Lever HM, et al. Outcome of patients with hypertrophic obstructive cardiomyopathy after percutaneous transluminal septal myocardial ablation and septal myectomy surgery. J Am Coll Cardiol. 2001;38:1994-2000.

132. Erwin JP III, Nishimura RA, Lloyd MA, et al. Dual chamber pacing for patients with hypertrophic obstructive cardiomyopathy: a clinical perspective in 2000 . Mayo Clin Proc. 2000;75:173-80.

133. Gadler F, Linde C, Daubert C, et al. Significant improvement of quality of life following atrioventricular synchronous pacing in patients with hypertrophic obstructive cardiomyopathy. Data from 1 year of follow-up PIC study group Pacing In Cardiomyopathy. Eur Heart J. 1999;20:1044-50.

134. Slade AK, Sadoul N, Shapiro L, et al. DDD pacing in hypertrophic cardiomyopathy: a multicentre clinical experience. Heart. 1996;75:44-9.

135. Ommen SR, Nishimura RA, Squires RW, et al. Comparison of dual-chamber pacing versus septal myectomy for the treatment of patients with hypertrophic obstructive cardiomyopathy: a comparison of objective hemodynamic and exercise end points. J Am Coll Cardiol. 1999;34:191-6.

136. Maron BJ, Nishimura RA, McKenna WJ, et al. Assessment of permanent dualchamber pacing as a treatment for drug-refractory symptomatic patients with obstructive hypertrophic cardiomyopathy: a randomized, double-blind, crossover study (M-PATHY). Circulation. 1999;99:2927-33.

137. Nishimura RA, Trusty JM, Hayes DL, et al. Dual-chamber pacing for hypertrophic cardiomyopathy: a randomized, double-blind, crossover trial. J Am Coll Cardiol. 1997;29:435-41.

138. Kappenberger L, Linde C, Daubert C, et al. Pacing in hypertrophic obstructive cardiomyopathy: a randomized crossover study: PIC Study Group. Eur Heart J. 1997; 18:1249-56.

139. Maron BJ, Spirito P. Implications of left ventricular remodeling in hypertrophic cardiomyopathy. Am J Cardiol. 1998;81:1339-44.

140. Biagini E, Spirito P, Leone O, et al. Heart transplantation in hypertrophic cardiomyopathy. Am J Cardiol. 2008;101:387-92.

141. Gajarski R, Naftel DC, Pahl E, et al. Outcomes of pediatric patients with hypertrophic cardiomyopathy listed for transplant. J Heart Lung Transplant. 2009;28: 1329-34.

142. Towbin JA. Cardiomyopathy and heart transplantation in children. Curr Opin Cardiol. 2002;17:274-9.

143. Maron BJ. Risk stratification and role of implantable defibrillators for prevention of sudden death in patients with hypertrophic cardiomyopathy. Circ J. 2010;74:2271-82

144. Maron BJ. Contemporary insights and strategies for risk stratification and prevention of sudden death in hypertrophic cardiomyopathy. Circulation. 2010; 121:445-56.

145. Cecchi F, Maron BJ, Epstein SE. Long-term outcome of patients with hypertrophic cardiomyopathy successfully resuscitated after cardiac arrest. J Am Coll Cardiol. 1989;13:1283-8.
146. Elliott PM, Sharma S, Varnava A, et al. Survival after cardiac arrest or sustained ventricular tachycardia in patients with hypertrophic cardiomyopathy. $\mathrm{J} \mathrm{Am}$ Coll Cardiol. 1999;33:1596-601.

147. Elliott PM, Poloniecki J, Dickie S, et al. Sudden death in hypertrophic cardiomyopathy: identification of high risk patients. J Am Coll Cardiol. 2000;36: 2212-8.

148. Fananapazir L, Chang AC, Epstein SE, et al. Prognostic determinants in hypertrophic cardiomyopathy: prospective evaluation of a therapeutic strategy based on clinical, Holter, hemodynamic, and electrophysiological findings. Circulation. 1992;86:730-40.

149. Maki S, Ikeda H, Muro A, et al. Predictors of sudden cardiac death in hypertrophic cardiomyopathy. Am J Cardiol. 1998;82:774-8.

150. Maron BJ, Spirito P, Shen WK, et al. Implantable cardioverter-defibrillators and prevention of sudden cardiac death in hypertrophic cardiomyopathy. JAMA. 2007;298:405-12.

151. McKenna W, Deanfield J, Faruqui A, et al. Prognosis in hypertrophic cardiomyopathy: role of age and clinical, electrocardiographic and hemodynamic features. Am J Cardiol. 1981;47:532-8.

152. Spirito P, Autore C, Rapezzi C, et al. Syncope and risk of sudden death in hypertrophic cardiomyopathy. Circulation. 2009;119:1703-10.

153. Maron BJ, Shen WK, Link MS, et al. Efficacy of implantable cardioverterdefibrillators for the prevention of sudden death in patients with hypertrophic cardiomyopathy. N Engl J Med. 2000;342:365-73.

154. Maron BJ, Spirito P. Implantable defibrillators and prevention of sudden death in hypertrophic cardiomyopathy. J Cardiovasc Electrophysiol. 2008;19: 1118-26.

155. Bos JM, Maron BJ, Ackerman MJ, et al. Role of family history of sudden death in risk stratification and prevention of sudden death with implantable defibrillators in hypertrophic cardiomyopathy. Am J Cardiol. 2010;106:1481-6.

156. Elliott PM, Gimeno Blanes JR, Mahon NG, et al. Relation between severity of left-ventricular hypertrophy and prognosis in patients with hypertrophic cardiomyopathy. Lancet. 2001;357:420-4.

157. Sorajja P, Nishimura RA, Ommen SR, et al. Use of echocardiography in patients with hypertrophic cardiomyopathy: clinical implications of massive hypertrophy. J Am Soc Echocardiogr. 2006;19:788-95.

158. Spirito P, Bellone P, Harris KM, et al. Magnitude of left ventricular hypertrophy and risk of sudden death in hypertrophic cardiomyopathy. N Engl J Med. 2000; 342:1778-85.

159. Boriani G, Maron BJ, Shen WK, et al. Prevention of sudden death in hypertrophic cardiomyopathy: but which defibrillator for which patient? Circulation. 2004; 110:e438-42

160. Hauser RG, Maron BJ, Marine JE, et al. Safety and efficacy of transvenous highvoltage implantable cardioverter-defibrillator leads in high-risk hypertrophic cardiomyopathy patients. Heart Rhythm. 2008;5:1517-22

161. Kleemann T, Becker T, Doenges K, et al. Annual rate of transvenous defibrillation lead defects in implantable cardioverter-defibrillators over a period of $>10$ years. Circulation. 2007;115:2474-80.

162. Maisel WH, Sweeney MO, Stevenson WG, et al. Recalls and safety alerts involving pacemakers and implantable cardioverter-defibrillator generators. JAMA. 2001;286:793-9.

163. Maron BJ, Ackerman MJ, Nishimura RA, et al. Task Force 4: HCM and other cardiomyopathies, mitral valve prolapse, myocarditis, and Marfan syndrome. $J$ Am Coll Cardiol. 2005;45:1340-5.

164. Pelliccia A, Fagard R, Bjornstad HH, et al. Recommendations for competitive sports participation in athletes with cardiovascular disease: a consensus document from the Study Group of Sports Cardiology of the Working Group of Cardiac Rehabilitation and Exercise Physiology and the Working Group of Myocardial and Pericardial Diseases of the European Society of Cardiology. Eur Heart J. 2005;26:1422-45.

165. Maron BJ, Epstein SE, Roberts WC. Causes of sudden death in competitive athletes. J Am Coll Cardiol. 1986;7:204-14.

166. Maron BJ. Sudden death in young athletes. N Engl J Med. 2003;349:1064-75

167. Maron BJ, Carney KP, Lever HM, et al. Relationship of race to sudden cardiac death in competitive athletes with hypertrophic cardiomyopathy. J Am Coll Cardiol. 2003;41:974-80.

168. Maron BJ, Doerer JJ, Haas TS, et al. Sudden deaths in young competitive athletes: analysis of 1866 deaths in the United States, 1980-2006. Circulation. 2009; 119:1085-92.

169. Corrado D, Basso C, Rizzoli G, et al. Does sports activity enhance the risk of sudden death in adolescents and young adults? J Am Coll Cardiol. 2003;42: 1959-63. 
170. Fuster V, Ryden LE, Cannom DS, et al. 2011 ACCF/AHA/HRS Focused Updates Incorporated Into the ACC/AHA/ESC 2006 Guidelines for the Management of Patients With Atrial Fibrillation. Circulation. 2011;123:e269-367.

171. Maron BJ, Olivotto I, Bellone P, et al. Clinical profile of stroke in 900 patients with hypertrophic cardiomyopathy. J Am Coll Cardiol. 2002;39:301-7.

172. Olivotto I, Cecchi F, Casey SA, et al. Impact of atrial fibrillation on the clinical course of hypertrophic cardiomyopathy. Circulation. 2001;104:2517-24.

173. Connolly SJ, Ezekowitz MD, Yusuf S, et al. Dabigatran versus warfarin in patients with atrial fibrillation. N Engl J Med. 2009;361:1139-51.

174. Tendera M, Wycisk A, Schneeweiss A, et al. Effect of sotalol on arrhythmias and exercise tolerance in patients with hypertrophic cardiomyopathy. Cardiology. 1993;82:335-42

175. Bunch TJ, Munger TM, Friedman PA, et al. Substrate and procedural predictors of outcomes after catheter ablation for atrial fibrillation in patients with hypertrophic cardiomyopathy. J Cardiovasc Electrophysiol. 2008;19:1009-14.

176. Callans DJ. Ablation of atrial fibrillation in the setting of hypertrophic cardiomyopathy. J Cardiovasc Electrophysiol. 2008;19:1015-6.

177. Di Donna P, Olivotto I, Delcre SD, et al. Efficacy of catheter ablation for atrial fibrillation in hypertrophic cardiomyopathy: impact of age, atrial remodelling, and disease progression. Europace. 2010;12:347-55.

178. Gaita F, Di Donna P, Olivotto I, et al. Usefulness and safety of transcatheter ablation of atrial fibrillation in patients with hypertrophic cardiomyopathy. Am J Cardiol. 2007;99:1575-81.

179. Kilicaslan F, Verma A, Saad E, et al. Efficacy of catheter ablation of atrial fibrillation in patients with hypertrophic obstructive cardiomyopathy. Heart Rhythm. 2006;3:275-80.

180. Bascou V, Ferrandis J, Bauer V, et al. Obstructive myocardiopathy and pregnancy. J Gynecol Obstet Biol Reprod (Paris). 1993;22:309-11.

181. Fitzgerald-Butt SM, Byrne L, Gerhardt CA, et al. Parental knowledge and attitudes toward hypertrophic cardiomyopathy genetic testing. Pediatr Cardiol. 2010;31:195-202.

182. Maron BJ. Hypertrophic cardiomyopathy: an important global disease. Am J Med. 2004;116:63-5

183. Zou Y, Song L, Wang Z, et al. Prevalence of idiopathic hypertrophic cardiomyopathy in China: a population-based echocardiographic analysis of 8080 adults. Am J Med. 2004;116:14-8.

184. Maron BJ, Gardin JM, Flack JM, et al. Prevalence of hypertrophic cardiomyopathy in a general population of young adults: echocardiographic analysis of 4111 subjects in the CARDIA Study Coronary Artery Risk Development in (Young) Adults. Circulation. 1995;92:785-9.

185. Maron BJ, Epstein SE. Hypertrophic cardiomyopathy: a discussion of nomenclature. Am J Cardiol. 1979;43:1242-4.

186. Maron BJ, Towbin JA, Thiene G, et al. Contemporary definitions and classification of the cardiomyopathies: an American Heart Association scientific statement from the Council on Clinical Cardiology, Heart Failure and Transplantation Committee; Quality of Care and Outcomes Research and Functional Genomics and Translational Biology Interdisciplinary Working Groups; and Council on Epidemiology and Prevention. Circulation. 2006;113:1807-16.

187. Maron BJ, Seidman CE, Ackerman MJ, et al. How should hypertrophic cardiomyopathy be classified? What's in a name? Dilemmas in nomenclature characterizing hypertrophic cardiomyopathy and left ventricular hypertrophy. Circ Cardiovasc Genet. 2009;2:81-5.

188. Maron BJ, Yeates L, Semsarian C. Clinical challenges of genotype positive $(+)$-phenotype negative $(-)$ family members in hypertrophic cardiomyopathy. Am J Cardiol. 2011;107:604-8

189. Maron BJ, Semsarian C. Emergence of gene mutation carriers and the expanding disease spectrum of hypertrophic cardiomyopathy. Eur Heart J. 2010;31:1551-3.

190. Maron BJ, Gottdiener JS, Epstein SE. Patterns and significance of distribution of left ventricular hypertrophy in hypertrophic cardiomyopathy: a wide angle, two dimensional echocardiographic study of 125 patients. Am J Cardiol. 1981;48:418-28

191. Maron BJ, Pelliccia A, Spirito P. Cardiac disease in young trained athletes: insights into methods for distinguishing athlete's heart from structural heart disease, with particular emphasis on hypertrophic cardiomyopathy. Circulation. 1995;91:1596-601.

192. Maron BJ, Pelliccia A. The heart of trained athletes: cardiac remodeling and the risks of sports, including sudden death. Circulation. 2006;114:1633-44.

193. Maron BJ. Distinguishing hypertrophic cardiomyopathy from athlete's heart physiological remodelling: clinical significance, diagnostic strategies and implications for preparticipation screening. Br J Sports Med. 2009;43: 649-56.
194. Pelliccia A, Kinoshita N, Pisicchio C, et al. Long-term clinical consequences of intense, uninterrupted endurance training in Olympic athletes. J Am Coll Cardiol. 2010;55:1619-25.

195. Pelliccia A, Di Paolo FM, De Blasiis E, et al. Prevalence and clinical significance of aortic root dilation in highly trained competitive athletes. Circulation. 2010;122:698-706. 3.

196. Cox GF, Sleeper LA, Lowe AM, et al. Factors associated with establishing a causal diagnosis for children with cardiomyopathy. Pediatrics. 2006;118: 1519-31.

197. Scaglia F, Towbin JA, Craigen WJ, et al. Clinical spectrum, morbidity, and mortality in 113 pediatric patients with mitochondrial disease. Pediatrics. 2004;114: 925-31.

198. Monserrat L, Gimeno-Blanes JR, Marin F, et al. Prevalence of Fabry disease in a cohort of 508 unrelated patients with hypertrophic cardiomyopathy. J Am Coll Cardiol. 2007;50:2399-403.

199. Alcalai R, Seidman JG, Seidman CE. Genetic basis of hypertrophic cardiomyopathy: from bench to the clinics. J Cardiovasc Electrophysiol. 2008;19: 104-10.

200. Maron BJ, Roberts WC, Arad M, et al. Clinical outcome and phenotypic expression in LAMP2 cardiomyopathy. JAMA. 2009;301:1253-9.

201. Yang Z, McMahon CJ, Smith LR, et al. Danon disease as an underrecognized cause of hypertrophic cardiomyopathy in children. Circulation. 2005;112: 1612-7.

202. Colan SD, Lipshultz SE, Lowe AM, et al. Epidemiology and cause-specific outcome of hypertrophic cardiomyopathy in children: findings from the Pediatric Cardiomyopathy Registry. Circulation. 2007;115:773-81.

203. Gelb BD, Tartaglia M. Noonan syndrome and related disorders: dysregulated RAS-mitogen activated protein kinase signal transduction. Hum Mol Genet. 2006;15(Spec No 2):R220-6.

204. Montalvo AL, Bembi B, Donnarumma M, et al. Mutation profile of the GAA gene in 40 Italian patients with late onset glycogen storage disease type II. Hum Mutat. 2006;27:999-1006.

205. Pandit B, Sarkozy A, Pennacchio LA, et al. Gain-of-function RAF1 mutations cause Noonan and LEOPARD syndromes with hypertrophic cardiomyopathy. Nat Genet. 2007;39:1007-12.

206. van den Hout HM, Hop W, van Diggelen OP, et al. The natural course of infantile Pompe's disease: 20 original cases compared with 133 cases from the literature. Pediatrics. 2003;112:332-40.

207. Ahmad F, Seidman JG, Seidman CE. The genetic basis for cardiac remodeling Annu Rev Genomics Hum Genet. 2005;6:185-216.

208. Seidman JG, Seidman C. The genetic basis for cardiomyopathy: from mutation identification to mechanistic paradigms. Cell. 2001;104:557-67.

209. Maron BJ. Hypertrophic cardiomyopathy centers. Am J Cardiol. 2009;104 1158-9.

210. Ingles J, Lind JM, Phongsavan P, et al. Psychosocial impact of specialized cardiac genetic clinics for hypertrophic cardiomyopathy. Genet Med. 2008;10: 117-20.

211. Cannan CR, Reeder GS, Bailey KR, et al. Natural history of hypertrophic cardiomyopathy: a population-based study, 1976 through 1990. Circulation. 1995; 92:2488-95.

212. Cecchi F, Olivotto I, Montereggi A, et al. Hypertrophic cardiomyopathy in Tuscany: clinical course and outcome in an unselected regional population. $\mathrm{J} \mathrm{Am}$ Coll Cardiol. 1995;26:1529-36.

213. Maron BJ, Casey SA, Poliac LC, et al. Clinical course of hypertrophic cardiomyopathy in a regional United States cohort. JAMA. 1999;281:650-5.

214. Spirito P, Chiarella F, Carratino L, et al. Clinical course and prognosis of hypertrophic cardiomyopathy in an outpatient population. N Engl J Med. 1989;320: 749-55.

215. Maron BJ, Semsarian C, Shen WK, et al. Circadian patterns in the occurrence of malignant ventricular tachyarrhythmias triggering defibrillator interventions in patients with hypertrophic cardiomyopathy. Heart Rhythm. 2009;6: 599-602.

216. Brock R. Functional obstruction of the left ventricle; acquired aortic subvalvar stenosis. Guys Hosp Rep. 1957;106:221-38.

217. Criley JM, Siegel RJ. Has “obstruction” hindered our understanding of hypertrophic cardiomyopathy? Circulation. 1985;72:1148-54.

218. Criley JM, Siegel RJ. Obstruction is unimportant in the pathophysiology of hypertrophic cardiomyopathy. Postgrad Med J. 1986;62:515-29.

219. Criley JM. Unobstructed thinking (and terminology) is called for in the understanding and management of hypertrophic cardiomyopathy. J Am Coll Cardiol. 1997;29:741-3. 
220. Maron BJ, Maron MS, Wigle ED, et al. The 50-year history, controversy, and clinical implications of left ventricular outflow tract obstruction in hypertrophic cardiomyopathy: from idiopathic hypertrophic subaortic stenosis to hypertrophic cardiomyopathy. J Am Coll Cardiol. 2009;54:191-200.

221. Panza JA, Petrone RK, Fananapazir L, et al. Utility of continuous wave Doppler echocardiography in the noninvasive assessment of left ventricular outflow tract pressure gradient in patients with hypertrophic cardiomyopathy. J Am Coll Cardiol. 1992;19:91-9.

222. Sasson Z, Yock PG, Hatle LK, et al. Doppler echocardiographic determination of the pressure gradient in hypertrophic cardiomyopathy. J Am Coll Cardiol. 1988;11:752-6.

223. Falicov RE, Resnekov L, Bharati S, et al. Mid-ventricular obstruction: a variant of obstructive cardiomyopathy. Am J Cardiol. 1976;37:432-7.

224. Maron BJ, Nishimura RA, Danielson GK. Pitfalls in clinical recognition and a novel operative approach for hypertrophic cardiomyopathy with severe outflow obstruction due to anomalous papillary muscle. Circulation. 1998;98:2505-8.

225. Geske JB, Sorajja P, Ommen SR, et al. Left ventricular outflow tract gradient variability in hypertrophic cardiomyopathy. Clin Cardiol. 2009;32:397-402.

226. Watkins H, McKenna WJ, Thierfelder L, et al. Mutations in the genes for cardiac troponin $\mathrm{T}$ and alpha-tropomyosin in hypertrophic cardiomyopathy. $\mathrm{N}$ Engl J Med. 1995;332:1058-64.

227. Watkins H, Rosenzweig A, Hwang DS, et al. Characteristics and prognostic implications of myosin missense mutations in familial hypertrophic cardiomyopathy. $N$ Engl J Med. 1992;326:1108-14.

228. Watkins H, Thierfelder L, Hwang DS, et al. Sporadic hypertrophic cardiomyopathy due to de novo myosin mutations. J Clin Invest. 1992;90:1666-71.

229. Girolami F, Ho CY, Semsarian C, et al. Clinical features and outcome of hypertrophic cardiomyopathy associated with triple sarcomere protein gene mutations. J Am Coll Cardiol. 2010;55:1444-53.

230. Saltzman AJ, Mancini-DiNardo D, Li C, et al. The cardiac myosin binding protein C Arg502Trp mutation: a common cause of hypertrophic cardiomyopathy. Circ Res. 2010;106:1549-52.

231. Kelly M, Semsarian C. Multiple mutations in genetic cardiovascular disease: a marker of disease severity? Circ Cardiovasc Genet. 2009;2:182-90.

232. Chimenti C, Pieroni M, Morgante E, et al. Prevalence of Fabry disease in female patients with late-onset hypertrophic cardiomyopathy. Circulation. 2004;110: 1047-53.

233. Rigon F, Bianchin L, Bernasconi S, et al. Update on age at menarche in Italy: toward the leveling off of the secular trend. J Adolesc Health. 2010;46:238-44.

234. Maron BJ, Sherrid MV, Haas TS, et al. Novel hypertrophic cardiomyopathy phenotype: segmental hypertrophy isolated to the posterobasal left ventricular free wall. Am J Cardiol. 2010;106:750-2.

235. Harrigan CJ, Appelbaum E, Maron BJ, et al. Significance of papillary muscle abnormalities identified by cardiovascular magnetic resonance in hypertrophic cardiomyopathy. Am J Cardiol. 2008;101:668-73.

236. Kwon DH, Setser RM, Thamilarasan M, et al. Abnormal papillary muscle morphology is independently associated with increased left ventricular outflow tract obstruction in hypertrophic cardiomyopathy. Heart. 2008;94:1295-301.

237. Choudhury L, Mahrholdt H, Wagner A, et al. Myocardial scarring in asymptomatic or mildly symptomatic patients with hypertrophic cardiomyopathy. $J \mathrm{Am}$ Coll Cardiol. 2002;40:2156-64.

238. Al-Mallah M, Kwong RY. Clinical application of cardiac CMR. Rev Cardiovasc Med. 2009; 10:134-41.

239. Bruder O, Wagner A, Jensen CJ, et al. Myocardial scar visualized by cardiovascular magnetic resonance imaging predicts major adverse events in patients with hypertrophic cardiomyopathy. J Am Coll Cardiol. 2010;56:875-87.

240. Sorajja P, Ommen SR, Nishimura RA, et al. Adverse prognosis of patients with hypertrophic cardiomyopathy who have epicardial coronary artery disease. Circulation. 2003;108:2342-8.

241. Smith SC Jr, Feldman TE, Hirshfeld JW Jr, et al. ACC/AHA/SCAI 2005 guideline update for percutaneous coronary intervention. Circulation. 2006;113: e166-286.

242. Yetman AT, McCrindle BW, MacDonald C, et al. Myocardial bridging in children with hypertrophic cardiomyopathy: a risk factor for sudden death. $N$ Engl J Med. 1998;339:1201-9.

243. Mohiddin SA, Begley D, Shih J, et al. Myocardial bridging does not predict sudden death in children with hypertrophic cardiomyopathy but is associated with more severe cardiac disease. J Am Coll Cardiol. 2000;36:2270-8.

244. Sorajja P, Ommen SR, Nishimura RA, et al. Myocardial bridging in adult patients with hypertrophic cardiomyopathy. J Am Coll Cardiol. 2003;42: 889-94.
245. O'Gara PT, Bonow RO, Maron BJ, et al. Myocardial perfusion abnormalities in patients with hypertrophic cardiomyopathy: assessment with thallium-201 emission computed tomography. Circulation. 1987;76:1214-23.

246. Dilsizian V, Bonow RO, Epstein SE, et al. Myocardial ischemia detected by thallium scintigraphy is frequently related to cardiac arrest and syncope in young patients with hypertrophic cardiomyopathy. J Am Coll Cardiol. 1993; 22:796-804

247. Maron BJ, Wolfson JK, Epstein SE, et al. Intramural ("small vessel") coronary artery disease in hypertrophic cardiomyopathy. J Am Coll Cardiol. 1986;8: 545-57.

248. Camici P, Chiriatti G, Lorenzoni R, et al. Coronary vasodilation is impaired in both hypertrophied and nonhypertrophied myocardium of patients with hypertrophic cardiomyopathy: a study with nitrogen-13 ammonia and positron emission tomography. J Am Coll Cardiol. 1991;17:879-86.

249. Cannon RO III, McIntosh CL, Schenke WH, et al. Effect of surgical reduction of left ventricular outflow obstruction on hemodynamics, coronary flow, and myocardial metabolism in hypertrophic cardiomyopathy. Circulation. 1989;79: 766-75

250. Cecchi F, Olivotto I, Gistri R, et al. Coronary microvascular dysfunction and prognosis in hypertrophic cardiomyopathy. N Engl J Med. 2003;349:1027-35.

251. Olivotto I, Cecchi F, Gistri R, et al. Relevance of coronary microvascular flow impairment to long-term remodeling and systolic dysfunction in hypertrophic cardiomyopathy. J Am Coll Cardiol. 2006;47:1043-8.

252. Maron BJ, Casey SA, Hauser RG, et al. Clinical course of hypertrophic cardiomyopathy with survival to advanced age. J Am Coll Cardiol. 2003;42:882-8.

253. Maron BJ, Mathenge R, Casey SA, et al. Clinical profile of hypertrophic cardiomyopathy identified de novo in rural communities. J Am Coll Cardiol. 1999;33: 1590-5.

254. Sherrid MV, Pearle G, Gunsburg DZ. Mechanism of benefit of negative inotropes in obstructive hypertrophic cardiomyopathy. Circulation. 1998;97:41-7.

255. Alvares RF, Goodwin JF. Non-invasive assessment of diastolic function in hypertrophic cardiomyopathy on and off beta adrenergic blocking drugs. Br Heart J. 1982;48:204-12

256. Bourmayan C, Razavi A, Fournier C, et al. Effect of propranolol on left ventricular relaxation in hypertrophic cardiomyopathy: an echographic study. Am Heart J. 1985;109:1311-6.

257. Gilligan DM, Chan WL, Joshi J, et al. A double-blind, placebo-controlled crossover trial of nadolol and verapamil in mild and moderately symptomatic hypertrophic cardiomyopathy. J Am Coll Cardiol. 1993;21:1672-9.

258. Bonow RO, Frederick TM, Bacharach SL, et al. Atrial systole and left ventricular filling in hypertrophic cardiomyopathy: effect of verapamil. Am J Cardiol. 1983;51:1386-91.

259. Bonow RO, Ostrow HG, Rosing DR, et al. Effects of verapamil on left ventricular systolic and diastolic function in patients with hypertrophic cardiomyopathy: pressure-volume analysis with a nonimaging scintillation probe. Circulation. 1983;68:1062-73.

260. Bonow RO, Dilsizian V, Rosing DR, et al. Verapamil-induced improvement in left ventricular diastolic filling and increased exercise tolerance in patients with hypertrophic cardiomyopathy: short- and long-term effects. Circulation. 1985; 72:853-64.

261. Bonow RO, Vitale DF, Maron BJ, et al. Regional left ventricular asynchrony and impaired global left ventricular filling in hypertrophic cardiomyopathy: effect of verapamil. J Am Coll Cardiol. 1987;9:1108-16.

262. Kass DA, Wolff MR, Ting CT, et al. Diastolic compliance of hypertrophied ventricle is not acutely altered by pharmacologic agents influencing active processes. Ann Intern Med. 1993;119:466-73.

263. Betocchi S, Piscione F, Losi MA, et al. Effects of diltiazem on left ventricular systolic and diastolic function in hypertrophic cardiomyopathy. Am J Cardiol. 1996;78:451-7

264. Sugihara H, Taniguchi Y, Ito K, et al. Effects of diltiazem on myocardial perfusion abnormalities during exercise in patients with hypertrophic cardiomyopathy. Ann Nucl Med. 1998;12:349-54

265. Pollick C. Muscular subaortic stenosis: hemodynamic and clinical improvement after disopyramide. $N$ Engl J Med. 1982;307:997-9.

266. Sigwart U. Non-surgical myocardial reduction for hypertrophic obstructive cardiomyopathy. Lancet. 1995;346:211-4.

267. Balaram SK, Tyrie L, Sherrid MV, et al. Resection-plication-release for hypertrophic cardiomyopathy: clinical and echocardiographic follow-up. Ann Thorac Surg. 2008;86:1539-44.

268. Austin BA, Kwon DH, Smedira NG, et al. Abnormally thickened papillary muscle resulting in dynamic left ventricular outflow tract obstruction: an unusual 
presentation of hypertrophic cardiomyopathy. JAm Soc Echocardiogr. 2009;22: 105-6.

269. Klues HG, Proschan MA, Dollar AL, et al. Echocardiographic assessment of mitral valve size in obstructive hypertrophic cardiomyopathy: anatomic validation from mitral valve specimen. Circulation. 1993;88:548-55.

270. Minakata K, Dearani JA, Nishimura RA, et al. Extended septal myectomy for hypertrophic obstructive cardiomyopathy with anomalous mitral papillary muscles or chordae. J Thorac Cardiovasc Surg. 2004;127:481-9.

271. Schoendube FA, Klues HG, Reith S, et al. Surgical correction of hypertrophic obstructive cardiomyopathy with combined myectomy, mobilisation and partial excision of the papillary muscles. Eur $J$ Cardiothorac Surg. 1994;8:603-8.

272. Klues HG, Maron BJ, Dollar AL, et al. Diversity of structural mitral valve alterations in hypertrophic cardiomyopathy. Circulation. 1992;85:1651-60.

273. McCully RB, Nishimura RA, Tajik AJ, et al. Extent of clinical improvement after surgical treatment of hypertrophic obstructive cardiomyopathy. Circulation. 1996;94:467-71

274. Gadler F, Linde C, Juhlin-Dannfelt A, et al. Long-term effects of dual chamber pacing in patients with hypertrophic cardiomyopathy without outflow tract obstruction at rest. Eur Heart J. 1997;18:636-42.

275. Valeti US, Nishimura RA, Holmes DR, et al. Comparison of surgical septal myectomy and alcohol septal ablation with cardiac magnetic resonance imaging in patients with hypertrophic obstructive cardiomyopathy. J Am Coll Cardiol. 2007;49:350-7.

276. Maron BJ, Ommen SR, Nishimura RA, et al. Myths about surgical myectomy: rumors of its death have been greatly exaggerated. Am J Cardiol. 2008;101: 887-9.

277. Faber L, Seggewiss H, Gietzen FH, et al. Catheter-based septal ablation for symptomatic hypertrophic obstructive cardiomyopathy: follow-up results of the TASH-registry of the German Cardiac Society. Z Kardiol. 2005;94:516-23.

278. Fernandes VL, Nagueh SF, Wang W, et al. A prospective follow-up of alcohol septal ablation for symptomatic hypertrophic obstructive cardiomyopathy: the Baylor experience (1996-2002). Clin Cardiol. 2005;28:124-30.

279. Lakkis NM, Nagueh SF, Dunn JK, et al. Nonsurgical septal reduction therapy for hypertrophic obstructive cardiomyopathy: one-year follow-up. J Am Coll Cardiol. 2000;36:852-5.

279a. Chang SM, Nagueh SF, Spencer WH III, et al. Complete heart block: determinants and clinical impact in patients with hypertrophic obstructive cardiomyopathy undergoing nonsurgical septal reduction therapy. J Am Coll Cardiol. 2003;42:296-300

279b. Qin JX, Shiota T, Lever HM, et al. Conduction system abnormalities in patients with obstructive hypertrophic cardiomyopathy following septal reduction interventions. Am J Cardiol. 2004;93:171-5.

279c. Talreja DR, Nishimura RA, Edwards WD, et al. Alcohol septal ablation versus surgical septal myectomy: comparison of effects on atrioventricular conduction tissue. J Am Coll Cardiol. 2004;44:2329-32.

280. Cohn LH, Trehan H, Collins JJ Jr. Long-term follow-up of patients undergoing myotomy/myectomy for obstructive hypertrophic cardiomyopathy. Am J Cardiol. 1992;70:657-60.

281. Kirklin JW, Ellis FH Jr. Surgical relief of diffuse subvalvular aortic stenosis. Circulation. 1961;24:739-42.

282. McIntosh CL, Maron BJ. Current operative treatment of obstructive hypertrophic cardiomyopathy. Circulation. 1988;78:487-95.

283. Mohr R, Schaff HV, Puga FJ, et al. Results of operation for hypertrophic obstructive cardiomyopathy in children and adults less than 40 years of age. Circulation. 1989;80:I191-6.

284. Morrow AG, Brockenbrough EC. Surgical treatment of idiopathic hypertrophic subaortic stenosis: technic and hemodynamic results of subaortic ventriculomyotomy. Ann Surg. 1961;154:181-9.

285. Robbins RC, Stinson EB. Long-term results of left ventricular myotomy and myectomy for obstructive hypertrophic cardiomyopathy. J Thorac Cardiovasc Surg. 1996;111:586-94.

286. Schulte HD, Borisov K, Gams E, et al. Management of symptomatic hypertrophic obstructive cardiomyopathy: long-term results after surgical therapy. Thorac Cardiovasc Surg. 1999;47:213-8.

287. Williams WG, Wigle ED, Rakowski H, et al. Results of surgery for hypertrophic obstructive cardiomyopathy. Circulation. 1987;76:V104-8.

288. Williams WG, Rebeyka IM. Surgical intervention and support for cardiomyopathies of childhood. Prog Pediatr Cardiol. 1992;1:61-71.

289. Schoendube FA, Klues HG, Reith S, et al. Long-term clinical and echocardiographic follow-up after surgical correction of hypertrophic obstructive cardio- myopathy with extended myectomy and reconstruction of the subvalvular mitral apparatus. Circulation. 1995;92(suppl 9):II122-7.

290. Maron BJ. Controversies in cardiovascular medicine: surgical myectomy remains the primary treatment option for severely symptomatic patients with obstructive hypertrophic cardiomyopathy. Circulation. 2007;116:196-206.

291. Sherrid MV, Chaudhry FA, Swistel DG. Obstructive hypertrophic cardiomyopathy: echocardiography, pathophysiology, and the continuing evolution of surgery for obstruction. Ann Thorac Surg. 2003;75:620-32.

292. Maron BJ, Harding AM, Spirito P, et al. Systolic anterior motion of the posterior mitral leaflet: a previously unrecognized cause of dynamic subaortic obstruction in patients with hypertrophic cardiomyopathy. Circulation. 1983;68:282-93.

293. Spirito P, Maron BJ, Rosing DR. Morphologic determinants of hemodynamic state after ventricular septal myotomy-myectomy in patients with obstructive hypertrophic cardiomyopathy: M mode and two-dimensional echocardiographic assessment. Circulation. 1984;70:984-95.

294. Nishimura RA, Holmes DR Jr. Clinical practice: hypertrophic obstructive cardiomyopathy. $N$ Engl J Med. 2004;350:1320-7.

295. McLeod CJ, Ommen SR, Ackerman MJ, et al. Surgical septal myectomy decreases the risk for appropriate implantable cardioverter defibrillator discharge in obstructive hypertrophic cardiomyopathy. Eur Heart J. 2007;28:2583-8.

296. Ten Cate FJ, Soliman OI, Michels M, et al. Long-term outcome of alcohol septal ablation in patients with obstructive hypertrophic cardiomyopathy: a word of caution. Circ Heart Fail. 2010;3:362-9.

297. Maron BJ, Dearani JA, Ommen SR, et al. The case for surgery in obstructive hypertrophic cardiomyopathy. J Am Coll Cardiol. 2004;44:2044-53.

298. ElBardissi AW, Dearani JA, Nishimura RA, et al. Septal myectomy after previous septal artery ablation in hypertrophic cardiomyopathy. Mayo Clin Proc. 2007;82:1516-22

299. Klues HG, Roberts WC, Maron BJ. Anomalous insertion of papillary muscle directly into anterior mitral leaflet in hypertrophic cardiomyopathy: significance in producing left ventricular outflow obstruction. Circulation. 1991;84: 1188-97.

300. Faber L, Seggewiss H, Gleichmann U. Percutaneous transluminal septal myocardial ablation in hypertrophic obstructive cardiomyopathy: results with respect to intraprocedural myocardial contrast echocardiography. Circulation. 1998;98:2415-21

301. Lakkis NM, Nagueh SF, Kleiman NS, et al. Echocardiography-guided ethanol septal reduction for hypertrophic obstructive cardiomyopathy. Circulation. 1998;98:1750-5.

302. Faber L, Seggewiss H, Ziemssen P, et al. Intraprocedural myocardial contrast echocardiography as a routine procedure in percutaneous transluminal septal myocardial ablation: detection of threatening myocardial necrosis distant from the septal target area. Catheter Cardiovasc Interv. 1999;47:462-6.

303. Holmes DR Jr, Valeti US, Nishimura RA. Alcohol septal ablation for hypertrophic cardiomyopathy: indications and technique. Catheter Cardiovasc Interv. 2005;66:375-89.

304. Veselka J, Zemanek D, Tomasov P, et al. Alcohol septal ablation for obstructive hypertrophic cardiomyopathy: ultra-low dose of alcohol $(1 \mathrm{ml})$ is still effective. Heart Vessels. 2009;24:27-31.

305. Veselka J, Duchonova R, Palenickova J, et al. Age-related hemodynamic and morphologic differences in patients undergoing alcohol septal ablation for hypertrophic obstructive cardiomyopathy. Circ J. 2006;70:880-4.

306. Baggish AL, Smith RN, Palacios I, et al. Pathological effects of alcohol septal ablation for hypertrophic obstructive cardiomyopathy. Heart. 2006;92:1773-8.

307. Flores-Ramirez R, Lakkis NM, Middleton KJ, et al. Echocardiographic insights into the mechanisms of relief of left ventricular outflow tract obstruction after nonsurgical septal reduction therapy in patients with hypertrophic obstructive cardiomyopathy. J Am Coll Cardiol. 2001;37:208-14.

308. Kuhn H, Gietzen FH, Schafers M, et al. Changes in the left ventricular outflow tract after transcoronary ablation of septal hypertrophy (TASH) for hypertrophic obstructive cardiomyopathy as assessed by transoesophageal echocardiography and by measuring myocardial glucose utilization and perfusion. Eur Heart J. 1999;20:1808-17.

309. Park TH, Lakkis NM, Middleton KJ, et al. Acute effect of nonsurgical septal reduction therapy on regional left ventricular asynchrony in patients with hypertrophic obstructive cardiomyopathy. Circulation. 2002;106:412-5.

310. Lakkis N. New treatment methods for patients with hypertrophic obstructive cardiomyopathy. Curr Opin Cardiol. 2000;15:172-7.

311. Mazur W, Nagueh SF, Lakkis NM, et al. Regression of left ventricular hypertrophy after nonsurgical septal reduction therapy for hypertrophic obstructive cardiomyopathy. Circulation. 2001;103:1492-6. 
312. van Dockum WG, Beek AM, Ten Cate FJ, et al. Early onset and progression of left ventricular remodeling after alcohol septal ablation in hypertrophic obstructive cardiomyopathy. Circulation. 2005;111:2503-8.

313. Faber L, Meissner A, Ziemssen P, et al. Percutaneous transluminal septal myocardial ablation for hypertrophic obstructive cardiomyopathy: long term follow up of the first series of 25 patients. Heart. 2000;83:326-31.

314. Gietzen FH, Leuner CJ, Raute-Kreinsen U, et al. Acute and long-term results after transcoronary ablation of septal hypertrophy (TASH): catheter interventional treatment for hypertrophic obstructive cardiomyopathy. Eur Heart J. 1999;20:1342-54.

315. Kim JJ, Lee CW, Park SW, et al. Improvement in exercise capacity and exercise blood pressure response after transcoronary alcohol ablation therapy of septal hypertrophy in hypertrophic cardiomyopathy. Am J Cardiol. 1999;83:1220-3.

316. Serber ER, Sears SF, Nielsen CD, et al. Depression, anxiety, and quality of life in patients with obstructive hypertrophic cardiomyopathy three months after alcohol septal ablation. Am J Cardiol. 2007;100:1592-7.

317. Leonardi RA, Kransdorf EP, Simel DL, et al. Meta-analyses of septal reduction therapies for obstructive hypertrophic cardiomyopathy: comparative rates of overall mortality and sudden cardiac death after treatment. Circ Cardiovasc Interv. 2010;3:97-104.

318. Alam M, Dokainish H, Lakkis NM. Hypertrophic obstructive cardiomyopathyalcohol septal ablation vs. myectomy: a meta-analysis. Eur Heart J. 2009;30: 1080-7.

319. Olivotto I, Ommen SR, Maron MS, et al. Surgical myectomy versus alcohol septal ablation for obstructive hypertrophic cardiomyopathy: will there ever be a randomized trial? J Am Coll Cardiol. 2007;50:831-4.

320. Nishimura RA, Ommen SR. Septal reduction therapy for obstructive hypertrophic cardiomyopathy and sudden death: what statistics cannot tell you. Circ Cardiovasc Interv. 2010;3:91-3.

321. Chen AA, Palacios IF, Mela T, et al. Acute predictors of subacute complete heart block after alcohol septal ablation for obstructive hypertrophic cardiomyopathy. Am J Cardiol. 2006;97:264-9.

322. Faber L, Welge D, Fassbender D, et al. Percutaneous septal ablation for symptomatic hypertrophic obstructive cardiomyopathy: managing the risk of procedure-related AV conduction disturbances. Int J Cardiol. 2007;119:163-7.

323. Reinhard W, Ten Cate FJ, Scholten M, et al. Permanent pacing for complete atrioventricular block after nonsurgical (alcohol) septal reduction in patients with obstructive hypertrophic cardiomyopathy. Am J Cardiol. 2004;93:1064-6.

324. van Dockum WG, Ten Cate FJ, ten Berg JM, et al. Myocardial infarction after percutaneous transluminal septal myocardial ablation in hypertrophic obstructive cardiomyopathy: evaluation by contrast-enhanced magnetic resonance imaging. J Am Coll Cardiol. 2004;43:27-34.

325. Boltwood CM Jr, Chien W, Ports T. Ventricular tachycardia complicating alcohol septal ablation. $N$ Engl J Med. 2004;351:1914-5.

326. Hori Y, Ueda M, Nakayama T, et al. Occurrence of de novo sustained monomorphic ventricular tachycardia induced after percutaneous transluminal alcohol septal myocardial ablation for hypertrophic obstructive cardiomyopathy. Int J Cardiol. 2007;119:403-7.

327. Kazmierczak J, Kornacewicz-Jach Z, Kisly M, et al. Electrocardiographic changes after alcohol septal ablation in hypertrophic obstructive cardiomyopathy. Heart. 1998;80:257-62.

328. Lawrenz T, Obergassel L, Lieder F, et al. Transcoronary ablation of septal hypertrophy does not alter ICD intervention rates in high risk patients with hypertrophic obstructive cardiomyopathy. Pacing Clin Electrophysiol. 2005;28: 295-300.

329. McGregor JB, Rahman A, Rosanio S, et al. Monomorphic ventricular tachycardia: a late complication of percutaneous alcohol septal ablation for hypertrophic cardiomyopathy. Am J Med Sci. 2004;328:185-8.

330. Noseworthy PA, Rosenberg MA, Fifer MA, et al. Ventricular arrhythmia following alcohol septal ablation for obstructive hypertrophic cardiomyopathy. Am J Cardiol. 2009; 104:128-32.

331. Simon RD, Crawford FA III, Spencer WH III, et al. Sustained ventricular tachycardia following alcohol septal ablation for hypertrophic obstructive cardiomyopathy. Pacing Clin Electrophysiol. 2005;28:1354-6.

332. Cuoco FA, Spencer WH III, Fernandes VL, et al. Implantable cardioverterdefibrillator therapy for primary prevention of sudden death after alcohol septal ablation of hypertrophic cardiomyopathy. J Am Coll Cardiol. 2008;52:1718-23.

333. Agarwal S, Tuzcu EM, Desai MY, et al. Updated meta-analysis of septal alcohol ablation versus myectomy for hypertrophic cardiomyopathy. J Am Coll Cardiol. 2010;55:823-34.

334. Deleted in proof.
335. Fananapazir L, Epstein ND, Curiel RV, et al. Long-term results of dual-chamber (DDD) pacing in obstructive hypertrophic cardiomyopathy: evidence for progressive symptomatic and hemodynamic improvement and reduction of left ventricular hypertrophy. Circulation. 1994;90:2731-42.

336. Jeanrenaud X, Goy JJ, Kappenberger L. Effects of dual-chamber pacing in hypertrophic obstructive cardiomyopathy. Lancet. 1992;339:1318-23.

337. McDonald K, McWilliams E, O'Keeffe B, et al. Functional assessment of patients treated with permanent dual chamber pacing as a primary treatment for hypertrophic cardiomyopathy. Eur Heart J. 1988;9:893-8.

338. Linde C, Gadler F, Kappenberger L, et al. Placebo effect of pacemaker implantation in obstructive hypertrophic cardiomyopathy: PIC Study Group Pacing In Cardiomyopathy. Am J Cardiol. 1999;83:903-7.

339. Cannon RO III, Tripodi D, Dilsizian V, et al. Results of permanent dual-chamber pacing in symptomatic nonobstructive hypertrophic cardiomyopathy. Am J Cardiol. 1994;73:571-6.

340. Maron BJ, Haas TS, Shannon KM, et al. Long-term survival after cardiac arrest in hypertrophic cardiomyopathy. Heart Rhythm. 2009;6:993-7.

341. Gimeno JR, Tome-Esteban M, Lofiego C, et al. Exercise-induced ventricular arrhythmias and risk of sudden cardiac death in patients with hypertrophic cardiomyopathy. Eur Heart J. 2009;30:2599-605.

342. Olivotto I, Gistri R, Petrone P, et al. Maximum left ventricular thickness and risk of sudden death in patients with hypertrophic cardiomyopathy. J Am Coll Cardiol. 2003;41:315-21.

343. Cecchi F, Olivotto I, Montereggi A, et al. Prognostic value of non-sustained ventricular tachycardia and the potential role of amiodarone treatment in hypertrophic cardiomyopathy: assessment in an unselected non-referral based patient population. Heart. 1998;79:331-6.

344. Kizilbash AM, Heinle SK, Grayburn PA. Spontaneous variability of left ventricular outflow tract gradient in hypertrophic obstructive cardiomyopathy. Circulation. 1998;97:461-6.

345. Anan R, Greve G, Thierfelder L, et al. Prognostic implications of novel beta cardiac myosin heavy chain gene mutations that cause familial hypertrophic cardiomyopathy. J Clin Invest. 1994;93:280-5.

346. Marian AJ, Roberts R. Molecular genetic basis of hypertrophic cardiomyopathy: genetic markers for sudden cardiac death. J Cardiovasc Electrophysiol. 1998;9:88-99.

347. Semsarian C, Yu B, Ryce C, et al. Sudden cardiac death in familial hypertrophic cardiomyopathy: are "benign" mutations really benign? Pathology. 1997;29: 305-8.

348. Ackerman MJ, VanDriest SL, Ommen SR, et al. Prevalence and agedependence of malignant mutations in the beta-myosin heavy chain and tropo$\operatorname{nin} \mathrm{T}$ genes in hypertrophic cardiomyopathy: a comprehensive outpatient perspective. J Am Coll Cardiol. 2002;39:2042-8.

349. Van Driest SL, Maron BJ, Ackerman MJ. From malignant mutations to malignant domains: the continuing search for prognostic significance in the mutant genes causing hypertrophic cardiomyopathy. Heart. 2004;90:7-8.

350. McKenna WJ, Behr ER. Hypertrophic cardiomyopathy: management, risk stratification, and prevention of sudden death. Heart. 2002;87:169-76.

351. Lin G, Nishimura RA, Gersh BJ, et al. Device complications and inappropriate implantable cardioverter defibrillator shocks in patients with hypertrophic cardiomyopathy. Heart. 2009;95:709-14.

352. Hauser RG, Maron BJ. Lessons from the failure and recall of an implantable cardioverter-defibrillator. Circulation. 2005;112:2040-2.

353. Hauser RG, Maisel WH, Friedman PA, et al. Longevity of Sprint Fidelis implantable cardioverter-defibrillator leads and risk factors for failure: implications for patient management. Circulation. 2011;123:358-63.

354. Almquist AK, Montgomery JV, Haas TS, et al. Cardioverter-defibrillator implantation in high-risk patients with hypertrophic cardiomyopathy. Heart Rhythm. 2005;2:814-9.

355. Maron BJ, Shirani J, Poliac LC, et al. Sudden death in young competitive athletes: clinical, demographic, and pathological profiles. JAMA. 1996;276: 199-204.

356. Pelliccia A, Zipes DP, Maron BJ. Bethesda Conference \#36 and the European Society of Cardiology Consensus Recommendations revisited: a comparison of U.S. and European criteria for eligibility and disqualification of competitive athletes with cardiovascular abnormalities. J Am Coll Cardiol. 2008;52: 1990-6.

357. Doi Y, Kitaoka H. Hypertrophic cardiomyopathy in the elderly: significance of atrial fibrillation. J Cardiol. 2001;37(suppl 1):133-8.

358. Harris L, McKenna WJ, Rowland E, et al. Side effects of long-term amiodarone therapy. Circulation. 1983;67:45-51. 
359. McKenna WJ, Harris L, Rowland E, et al. Amiodarone for long-term management of patients with hypertrophic cardiomyopathy. Am J Cardiol. 1984;54:802-10.

360. McKenna WJ, Harris L, Mulrow JP, et al. Amiodarone dose titration: a method to minimise side effects during long term therapy. Br J Clin Pract Suppl. 1986; 44:121-31.

361. Robinson K, Frenneaux MP, Stockins B, et al. Atrial fibrillation in hypertrophic cardiomyopathy: a longitudinal study. J Am Coll Cardiol. 1990;15:1279-85.

362. Matsubara H, Nakatani S, Nagata S, et al. Salutary effect of disopyramide on left ventricular diastolic function in hypertrophic obstructive cardiomyopathy. J Am Coll Cardiol. 1995;26:768-75.

363. Liu X, Ouyang F, Mavrakis H, et al. Complete pulmonary vein isolation guided by three-dimensional electroanatomical mapping for the treatment of paroxysmal atrial fibrillation in patients with hypertrophic obstructive cardiomyopathy. Europace. 2005;7:421-7.
364. Chen MS, McCarthy PM, Lever HM, et al. Effectiveness of atrial fibrillation surgery in patients with hypertrophic cardiomyopathy. Am J Cardiol. 2004; 93:373-5.

365. US Department of Transportation Motor Carrier Safety Administration. Cardiovascular Advisory Panel Guidelines for the Medical Examination of Commercial Motor Vehicle Drivers. Available at: http://www.fmcsa.dot.gov/documents/ cardio.pdf. Accessed May 6, 2011.

366. US Department of Transportation Motor Carrier Safety Administration Commercial Driver's License Standards; Requirements and Penalties, Section $\S$ 383.5. Definitions. Available at: http://www.fmcsa.dot.gov/rulesregulations/administration/fmcsr/fmcsrruletext.aspx?reg=383.5. Accessed May 6, 2011.

367. Maron BJ, Barry JA, Poole RS. Pilots, hypertrophic cardiomyopathy, and issues of aviation and public safety. Am J Cardiol. 2004;93:441-4.

APPENDIX 1. Author relationships with industry and other entities (relevant)—2011 ACCF/AHA guideline for the diagnosis and treatment of hypertrophic cardiomyopathy

\begin{tabular}{|c|c|c|c|c|c|c|c|c|}
\hline $\begin{array}{l}\text { Committee } \\
\text { member }\end{array}$ & Employer/title & Consultant & $\begin{array}{l}\text { Speaker's } \\
\text { bureau }\end{array}$ & $\begin{array}{l}\text { Ownership/ } \\
\text { partnership/ } \\
\text { principal }\end{array}$ & $\begin{array}{l}\text { Personal } \\
\text { research }\end{array}$ & $\begin{array}{l}\text { Institutional, } \\
\text { organizational, } \\
\text { or other } \\
\text { financial benefit }\end{array}$ & Expert witness & $\begin{array}{l}\text { Voting } \\
\text { recusals by } \\
\text { section } \\
\text { number* }\end{array}$ \\
\hline $\begin{array}{l}\text { Bernard J. } \\
\text { Gersh, } \\
\text { Co-Chair }\end{array}$ & $\begin{array}{l}\text { Mayo Clinic_-Professor } \\
\text { of Medicine }\end{array}$ & $\begin{array}{l}\text { - Abbott } \\
\text { Laboratories } \dagger \\
\text { - AstraZeneca } \\
\text { - Boston Scientific } \\
\text { - Bristol-Myers } \\
\quad \text { Squibb }\end{array}$ & None & None & $\begin{array}{l}\text { - Amorcyte } \\
\text { (DSMB) }\end{array}$ & $\begin{array}{l}\bullet \mathrm{CV} \\
\text { Therapeutics }\end{array}$ & None & $\begin{array}{c}6.2 .2 .6 \\
6.2 .3 \\
6.3 .2 \\
6.3 .2 .4\end{array}$ \\
\hline $\begin{array}{l}\text { Barry J. } \\
\text { Maron, } \\
\text { Co-Chair }\end{array}$ & $\begin{array}{l}\text { Minneapolis Heart Institute } \\
\text { Foundation-Director, } \\
\text { Hypertrophic Cardiomyopathy } \\
\text { Center }\end{array}$ & - GeneDx $\ddagger$ & None & None & - Medtronic & None & None & $\begin{array}{c}5.1 \\
6.3 .2 \\
6.3 .2 .4\end{array}$ \\
\hline $\begin{array}{r}\text { Robert O. } \\
\text { Bonow }\end{array}$ & $\begin{array}{l}\text { Northwestern University Feinberg } \\
\text { School of Medicine-Goldberg } \\
\text { Distinguished Professor of } \\
\text { Medicine; Chief, Division } \\
\text { of Cardiology }\end{array}$ & None & None & None & None & None & None & None \\
\hline $\begin{array}{l}\text { Joseph A. } \\
\text { Dearani }\end{array}$ & $\begin{array}{l}\text { Mayo Clinic_-Professor of } \\
\text { Surgery }\end{array}$ & None & None & None & None & None & None & None \\
\hline $\begin{array}{l}\text { Michael A. } \\
\text { Fifer }\end{array}$ & $\begin{array}{l}\text { Massachusetts General Hospital- } \\
\text { Director, Hypertrophic } \\
\text { Cardiomyopathy Program }\end{array}$ & None & None & None & - Merck $^{\ddagger}$ & None & None & 6.2 .1 \\
\hline Mark S. Link & $\begin{array}{l}\text { Tufts Medical Center-Professor } \\
\text { of Medicine }\end{array}$ & None & $\begin{array}{l}\text { - Medtronic } \\
\text { - Guidant }\end{array}$ & None & - Guidant & None & $\begin{array}{l}\text { - Plaintiff, wrongful } \\
\text { death secondary } \\
\text { electrocution, } \\
\text { 2007-2009 } \\
\text { - Defendant, } \\
\text { postoperative valve } \\
\text { replacement } \\
\text { management, } \\
\text { 2007-2010 }\end{array}$ & $\begin{array}{c}6.2 .2 .6 \\
6.3 .2 \\
6.3 .2 .4\end{array}$ \\
\hline $\begin{array}{l}\text { Srihari S. } \\
\text { Naidu }\end{array}$ & $\begin{array}{l}\text { Winthrop University Hospital- } \\
\text { Director, Cardiac Catheterization } \\
\text { Laboratory; Director, Hypertrophic } \\
\text { Cardiomyopathy Center }\end{array}$ & None & $\begin{array}{l}\text { - Abbott } \\
\text { Vascular } \\
\text { - Cordis } \\
\text { - Medtronic }\end{array}$ & None & None & None & None & $\begin{array}{c}6.2 .2 .6 \\
6.3 .2 \\
6.3 .2 .4\end{array}$ \\
\hline $\begin{array}{l}\text { Rick A. } \\
\text { Nishimura }\end{array}$ & $\begin{array}{l}\text { Mayo Clinic_-Consultant in } \\
\text { Cardiology }\end{array}$ & None & None & None & None & None & None & None \\
\hline $\begin{array}{l}\text { Steve R. } \\
\text { Ommen }\end{array}$ & $\begin{array}{l}\text { Mayo Clinic_-Professor of } \\
\text { Medicine }\end{array}$ & None & None & None & None & None & None & None \\
\hline $\begin{array}{l}\text { Harry } \\
\text { Rakowski }\end{array}$ & $\begin{array}{l}\text { Toronto General Hospital, } \\
\text { University Health Network- } \\
\text { Director, Hypertrophic } \\
\text { Cardiomyopathy Center; } \\
\text { Wigle Chair for HCM Research; } \\
\text { Professor of Medicine, University } \\
\text { of Toronto }\end{array}$ & None & None & None & $\begin{array}{l}\text { - Medtronic Valve } \\
\text { Device (DSMB) }\end{array}$ & None & None & None \\
\hline
\end{tabular}




\begin{tabular}{|c|c|c|c|c|c|c|c|c|}
\hline $\begin{array}{c}\text { Committee } \\
\text { member }\end{array}$ & Employer/title & Consultant & $\begin{array}{c}\text { Speaker's } \\
\text { bureau }\end{array}$ & $\begin{array}{c}\text { Ownership/ } \\
\text { partnership/ } \\
\text { principal }\end{array}$ & $\begin{array}{l}\text { Personal } \\
\text { research }\end{array}$ & $\begin{array}{c}\text { Institutional, } \\
\text { organizational, } \\
\text { or other } \\
\text { financial benefit }\end{array}$ & Expert witness & $\begin{array}{c}\text { Voting } \\
\text { recusals by } \\
\text { section } \\
\text { number* } \\
\end{array}$ \\
\hline $\begin{array}{r}\text { Christine E. } \\
\text { Seidman }\end{array}$ & $\begin{array}{l}\text { Howard Hughes Medical Institute; } \\
\text { Harvard Medical School/ } \\
\text { Brigham and Women's Hospital- } \\
\text { Investigator; T.W. Smith Professor } \\
\text { of Medicine and Genetics }\end{array}$ & None & None & None & None & None & None & None \\
\hline $\begin{array}{l}\text { Jeffrey A. } \\
\text { Towbin }\end{array}$ & $\begin{array}{l}\text { Cincinnati Children's Hospital- } \\
\text { Executive Co-Director, The } \\
\text { Heart Institute; Professor } \\
\text { and Chief, Pediatric } \\
\text { Cardiology }\end{array}$ & None & None & None & None & None & None & None \\
\hline $\begin{array}{l}\text { James E. } \\
\text { Udelson }\end{array}$ & $\begin{array}{l}\text { Tufts Medical Center-Chief, } \\
\text { Division of Cardiology }\end{array}$ & None & None & None & None & None & None & None \\
\hline $\begin{array}{r}\text { Clyde W. } \\
\text { Yancy } \\
\end{array}$ & $\begin{array}{l}\text { Baylor University Medical } \\
\text { Center-Medical Director }\end{array}$ & None & None & None & None & None & None & None \\
\hline
\end{tabular}

APPENDIX 2. Reviewer relationships with industry and other entities (Relevant)—2011 ACCF/AHA guideline for the diagnosis and treatment of hypertrophic cardiomyopathy

\begin{tabular}{|c|c|c|c|c|c|c|c|}
\hline $\begin{array}{l}\text { Peer } \\
\text { reviewer }\end{array}$ & Representation & Consultant & $\begin{array}{c}\text { Speaker's } \\
\text { bureau }\end{array}$ & $\begin{array}{l}\text { Ownership/ } \\
\text { partnership/ } \\
\text { principal }\end{array}$ & Personal research & $\begin{array}{c}\text { Institutional, } \\
\text { organizational, } \\
\text { or other financial } \\
\text { benefit } \\
\end{array}$ & $\begin{array}{r}\text { Expert } \\
\text { witness } \\
\end{array}$ \\
\hline $\begin{array}{l}\text { David R. } \\
\text { Holmes, Jr }\end{array}$ & $\begin{array}{l}\text { Official Reviewer-ACCF Board } \\
\text { of Governors/ACCF } \\
\text { Interventional Scientific Council }\end{array}$ & None & None & None & None & None & None \\
\hline $\begin{array}{l}\text { William J. } \\
\text { McKenna }\end{array}$ & Official Reviewer-AHA & None & None & None & None & None & None \\
\hline $\begin{array}{l}\text { William G. } \\
\text { Stevenson }\end{array}$ & $\begin{array}{l}\text { Official Reviewer-ACCF/AHA } \\
\text { Task Force on Practice } \\
\text { Guidelines }\end{array}$ & None & None & None & None & None & None \\
\hline $\begin{array}{l}\text { Carole A. } \\
\text { Warnes }\end{array}$ & $\begin{array}{l}\text { Official Reviewer-ACCF Board } \\
\text { of Trustees }\end{array}$ & None & None & None & None & None & None \\
\hline $\begin{array}{l}\text { Michael } \\
\text { Argenziano }\end{array}$ & Organizational Reviewer-AATS & None & None & None & None & None & None \\
\hline $\begin{array}{l}\text { Drew E. } \\
\text { Baldwin }\end{array}$ & Organizational Reviewer-SCAI & None & None & None & $\begin{array}{l}\text { - Atrium } \dagger \\
\text { - GlaxoSmithWellcome } \dagger \\
\text { - Harvard Clinical } \\
\text { Research Institute } \dagger\end{array}$ & $\begin{array}{l}\text { - Greater New } \\
\text { Orleans Health } \\
\text { Services Corps* }\end{array}$ & None \\
\hline Hugh Calkins & Organizational Reviewer-HRS & - Medtronic & $\begin{array}{l}\text { - Boston } \\
\text { Scientific }\end{array}$ & None & $\begin{array}{l}\text { - Boston Scientific* } \\
\text { - Medtronic* } \\
\text { - St. Jude Medical* }\end{array}$ & None & None \\
\hline Milind Y. Desai & Organizational Reviewer-ASNC & None & None & None & None & None & None \\
\hline $\begin{array}{l}\text { Vasken } \\
\text { Dilsizian }\end{array}$ & Organizational Reviewer-ASNC & None & None & None & None & None & None \\
\hline $\begin{array}{l}\text { N.A. Mark } \\
\text { Estes III }\end{array}$ & Organizational Reviewer-HRS & $\begin{array}{l}\text { - Boston } \\
\text { Scientific }\end{array}$ & None & None & None & None & None \\
\hline $\begin{array}{l}\text { Michael } \\
\text { Givertz }\end{array}$ & Organizational Reviewer-HFSA & None & None & None & None & None & None \\
\hline Stuart Katz & Organizational Reviewer-HFSA & $\begin{array}{l}\text { - Amgen } \\
\text { - Bristol-Myers } \\
\text { Squibb } \\
\text { - Paracor } \\
\text { - Terumo }\end{array}$ & - Otsuka & None & None & None & None \\
\hline
\end{tabular}




\begin{tabular}{|c|c|c|c|c|c|c|c|}
\hline $\begin{array}{c}\text { Peer } \\
\text { reviewer }\end{array}$ & Representation & Consultant & $\begin{array}{l}\text { Speaker's } \\
\text { bureau }\end{array}$ & $\begin{array}{c}\text { Ownership/ } \\
\text { partnership/ } \\
\text { principal }\end{array}$ & Personal research & $\begin{array}{c}\text { Institutional, } \\
\text { organizational, } \\
\text { or other financial } \\
\text { benefit }\end{array}$ & $\begin{array}{l}\text { Expert } \\
\text { witness }\end{array}$ \\
\hline John A. Kern & Organizational Reviewer-AATS & None & None & None & None & None & None \\
\hline Sherif Nagueh & Organizational Reviewer-ASE & None & None & None & None & None & None \\
\hline Paul Sorajja & Organizational Reviewer-SCAI & None & None & None & None & None & None \\
\hline $\begin{array}{l}\text { Kirk T. } \\
\text { Spencer }\end{array}$ & Organizational Reviewer-ASE & None & None & None & None & None & None \\
\hline Gus J. Vlahakes & Organizational Reviewer-STS & None & None & None & None & None & None \\
\hline Herbert B. Ward & Organizational Reviewer-STS & None & None & None & None & None & None \\
\hline Nancy M. Albert & $\begin{array}{l}\text { Content Reviewer-ACCF/AHA Task } \\
\text { Force on Practice Guidelines }\end{array}$ & None & None & None & None & None & None \\
\hline Jeffrey L. Anderson & $\begin{array}{l}\text { Content Reviewer-ACCF/AHA Task } \\
\text { Force on Practice Guidelines }\end{array}$ & None & None & None & $\begin{array}{l}\text { - AstraZeneca (DSMB) } \\
\text { - Toshiba }\end{array}$ & None & None \\
\hline Richard G. Bach & Content Reviewer & None & None & None & None & None & None \\
\hline Jorge A. Belardi & $\begin{array}{l}\text { Content Reviewer- ACCF } \\
\text { Interventional Scientific Council }\end{array}$ & $\begin{array}{l}\text { - Boston Scientific } \\
\text { - Medtronic CardioVascular } \\
\text { - Medtronic Vascular }\end{array}$ & $\begin{array}{l}\text { - Abbott } \\
\text { - Boston Scientific }\end{array}$ & None & None & None & None \\
\hline Eugene Braunwald & Content Reviewer & None & None & None & None & None & None \\
\hline John E. Brush, Jr & Content Reviewer & $\begin{array}{l}\text { - Prometheus Payment }{ }^{\dagger} \\
\text { - United Healthcare }\end{array}$ & None & None & None & None & None \\
\hline James A. Burke & $\begin{array}{l}\text { Content Reviewer-ACCF } \\
\text { Interventional Scientific } \\
\text { Council }\end{array}$ & None & None & None & None & None & None \\
\hline Jose G. Diez & $\begin{array}{l}\text { Content Reviewer-ACCF } \\
\text { Interventional Scientific } \\
\text { Council }\end{array}$ & - Sanofi-aventis & Sanofi-aventis & None & None & None & None \\
\hline Jon C. George & $\begin{array}{l}\text { Content Reviewer-ACCF } \\
\text { Interventional Scientific } \\
\text { Council }\end{array}$ & None & None & None & None & None & None \\
\hline Robert A. Guyton & $\begin{array}{l}\text { Content Reviewer—ACCF/AHA } \\
\text { Task Force on Practice } \\
\text { Guidelines }\end{array}$ & None & None & None & None & None & None \\
\hline Judith S. Hochman & $\begin{array}{l}\text { Content Reviewer—ACCF/AHA } \\
\text { Task Force on Practice } \\
\text { Guidelines }\end{array}$ & - GlaxoSmithKline & None & None & None & None & None \\
\hline Frederick G. Kushner & $\begin{array}{l}\text { Content Reviewer_ACCF/AHA } \\
\text { Task Force on Practice } \\
\text { Guidelines }\end{array}$ & None & None & None & None & None & None \\
\hline Gilead I. Lancaster & $\begin{array}{l}\text { Content Reviewer-ACCF Board } \\
\text { of Governors }\end{array}$ & None & None & - Cardiogal & None & None & None \\
\hline Bruce W. Lytle & Content Reviewer & None & None & None & None & None & None \\
\hline Abeel A. Mangi & Content Reviewer & None & None & None & None & None & None \\
\hline Gerard R. Martin & $\begin{array}{l}\text { Content Reviewer-ACCF Adult } \\
\text { Congenital and Pediatric } \\
\text { Cardiology Council }\end{array}$ & None & None & None & None & None & None \\
\hline Debabrata Mukherjee & $\begin{array}{l}\text { Content Reviewer-ACCF } \\
\text { Interventional Scientific } \\
\text { Council }\end{array}$ & None & None & None & None & None & None \\
\hline Joseph P. Murgo & Content Reviewer & None & None & None & None & None & None \\
\hline Patrick T. O'Gara & Content Reviewer & None & None & None & None & None & None \\
\hline E. Magnus Ohman & $\begin{array}{l}\text { Content Reviewer_ACCF/AHA } \\
\text { Task Force on Practice } \\
\text { Guidelines }\end{array}$ & None & None & None & None & None & None \\
\hline John F. Robb & $\begin{array}{l}\text { Content Reviewer-ACCF Board } \\
\text { of Governors }\end{array}$ & None & None & None & None & None & None \\
\hline George P. Rodgers & $\begin{array}{l}\text { Content Reviewer-ACCF Board } \\
\text { of Governors }\end{array}$ & None & None & None & None & None & None \\
\hline Chris Semsarian & Content Reviewer & None & None & None & None & None & None \\
\hline Richard J. Shemin & $\begin{array}{l}\text { Content Reviewer-ACCF } \\
\text { Surgeons' Scientific Council }\end{array}$ & $\begin{array}{l}\text { - Edwards } \\
\text { Lifesciences }\end{array}$ & None & None & None & None & None \\
\hline
\end{tabular}




\begin{tabular}{|c|c|c|c|c|c|c|c|}
\hline $\begin{array}{c}\text { Peer } \\
\text { reviewer }\end{array}$ & Representation & Consultant & $\begin{array}{l}\text { Speaker's } \\
\text { bureau }\end{array}$ & $\begin{array}{l}\text { Ownership/ } \\
\text { partnership/ } \\
\text { principal }\end{array}$ & Personal research & $\begin{array}{c}\text { Institutional, } \\
\text { organizational, } \\
\text { or other financial } \\
\text { benefit }\end{array}$ & $\begin{array}{l}\text { Expert } \\
\text { witness }\end{array}$ \\
\hline Mark V. Sherrid & Content Reviewer & None & $\begin{array}{l}\text { - Boston } \\
\text { Scientific } \\
\text { - GeneDx } \\
\text { - Medtronic } \\
\text { - St. Jude Medical }\end{array}$ & None & - CardioNet & None & None \\
\hline William H. Spencer & Content Reviewer & None & None & Medtronic* & None & None & None \\
\hline Paolo Spirito & Content Reviewer & None & None & None & None & None & None \\
\hline Edward F. Terrien & $\begin{array}{l}\text { Content Reviewer-ACCF Board } \\
\text { of Governors }\end{array}$ & None & None & None & None & None & None \\
\hline Juan Villafane & $\begin{array}{l}\text { Content Reviewer-ACCF Board } \\
\text { of Governors }\end{array}$ & None & None & None & None & None & None \\
\hline Gary D. Webb & $\begin{array}{l}\text { Content Reviewer- ACCF Adult } \\
\text { Congenital and Pediatric } \\
\text { Cardiology Council }\end{array}$ & None & None & None & None & None & None \\
\hline Walter R. Wilson & Content Reviewer & None & None & None & None & None & None \\
\hline
\end{tabular}

This table represents the relationships of reviewers with industry and other entities that were disclosed at the time of peer review and determined to be relevant. It does not necessarily reflect relationships with industry at the time of publication. A person is deemed to have a significant interest in a business if the interest represents ownership of $\geq 5 \%$ of the voting stock or share of the business entity, or ownership of $\geq \$ 10000$ of the fair market value of the business entity; or if funds received by the person from the business entity exceed 5\% of the person's gross income for the previous year. A relationship is considered to be modest if it is less than significant under the preceding definition. Relationships that exist with no financial benefit are also included for the purpose of transparency. Relationships in this table are modest unless otherwise noted. Names are listed in alphabetical order within each category of review. AATS, American Association for Thoracic Surgery; ACCF, American College of Cardiology Foundation; AHA, American Heart Association; ASE, American Society of Echocardiography; ASNC, American Society of Nuclear Cardiology; DSMB, data safety monitoring board; HFSA, Heart Failure Society of America; HRS, Heart Rhythm Society; SCAI, Society for Cardiovascular Angiography and Interventions; and STS, Society of Thoracic Surgeons. *Significant relationship. $\dagger$ No financial benefit. 